PNEUMATIC NON-CONTACT ROUGHNESS ASSESSMENT OF MOVING SURFACES 


\title{
PNEUMATIC Non-CONTACT ROUGHNESS ASSESSMENT OF MOVING SURFACES
}

\author{
By \\ DREW A. GRANDY, B. ENG
}

\begin{abstract}
A Thesis
Submitted to the School of Graduate Studies

in Partial Fulfillment of the Requirements

for the Degree

Master of Applied Science
\end{abstract}

McMaster University

(C) Copyright by Drew A. Grandy, September 2008 
MASTER OF APP]_IED SCIENCE (2008)

(Department of Merhanical Engineering)
McMaster University

Hamilton, Ontario

TITLE:

Pneumatic Non-Contact Roughness Assessment of Moving Surfaces

AUTHOR: $\quad$ Drew A. Grandy, B. Eng (McMaster University)

SUPERVISOR: $\quad$ Dr. Philip Koshy

NUMBER OF PAGES: $\quad$ xiii, 133 


\section{Abstract}

All machined surfaces inherently have roughness. The level of control of this surface is dependent on the specifications outlined for its intended use. In strictly controlled situations, the monitoring and characterization of these surfaces becomes increasingly important to ensure that each component conforms to specifications. For this reason, the need for in-situ monitoring systems has increased in order to optimize manufacturing time and minimize generated scrap for companies to remain competitive in industry. Current in-situ roughness monitoring systems, such as optical methods, are limited by the harst environments in which these systems are required to operate and the requirement for highly reflective materials. Accordingly, the need to develop a more robust system is required. The objective of this work was to develop and test a noncontact surface roughness characterization system which can be implemented into a machining center in order to provide in-situ measurements where currently available methods are rendered inappropriate.

Through the: use of a pneumatic technique, a non-contact surface assessment tool has been developed and tested for use in a machining center. The development began offline for characte ization of surfaces created by different machining operations and was then introduced into a turning center for in-situ evaluation. The developed system is capable of distinguishing surfaces created from different machining operations with the same $R_{a}$ values, characterize milled and turned surfaces down to $R_{a}$ values of $0.8 \mu \mathrm{m}$ that are comparable with stylus measurements, impervious to external influences on the measurement prociss such as cutting fluid, capable of characterizing moving surfaces 
with surface speeds up to $100 \mathrm{~m} / \mathrm{min}$, provides surface characterization around the entire workpiece instead of along a single line, and can be operated in-process to monitor the entire workpiece or be used to make spot checks for important surface features.

The develop 2 d system is capable of providing a method for in-situ monitoring of machined surfaces where currently available techniques fall short. The limitations caused by the harsh environment in which these in-situ monitoring devices operate and the limitations of work jiece materials have been eliminated and the developed system has been proven to provide results comparable to stylus measurements that are the industrial standard.

This work : $s$ the basis for the development of a non-contact, in-situ surface roughness assessment tool. Limitations of the current device are also presented. Further research and development avenues are identified to expand the operating envelope of the developed pneumatic system. 


\section{Acknowledgements}

The author wrould like to acknowledge all of the people who have supported me in one form or another over the course of my education. Much of their support has provided me with endless opportunities in my life.

Firstly, I would like to thank my supervisor, Dr. Philip Koshy, who has provided continuous support and direction during my post-secondary education. Beginning as a professor for a second year undergraduate mechanics course, followed by an introductory course into machining processes, Dr. Koshy has helped me discover my interest in manufacturing technologies.

Second, I would like to acknowledge all of my friends and family who have been there during all of the highs and lows encountered during research, both providing encouragement and support in times of need. I would also like to thank the GSA softball league for providing an excellent escape during the summer months and allowing me to participate in the sport I love.

Lastly, I went to extend special thanks to Ron Lodewyks, Jim McLaren, Mark MacKenzie, and Warren Reynolds for all of their help in the machine shop and MMRI facilities. Without hese knowledgeable and talented individuals, much of this research could not have beerı completed. 
Dedicated to my family who have endlessly supported me in all of my academic adventures 


\section{Table of Contents}

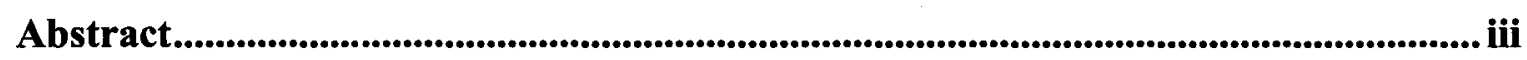

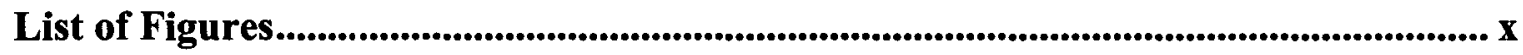

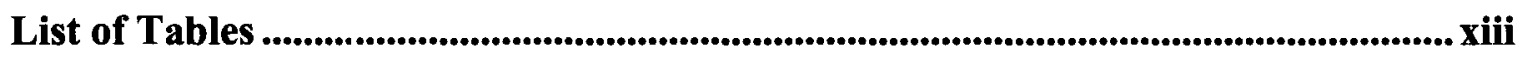

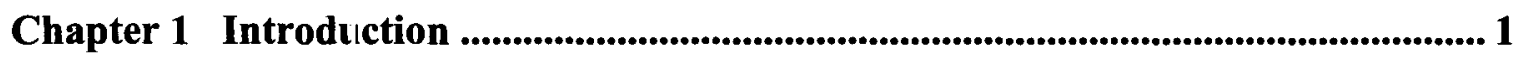

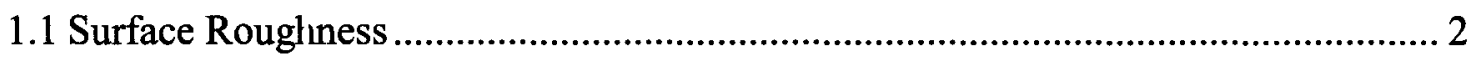

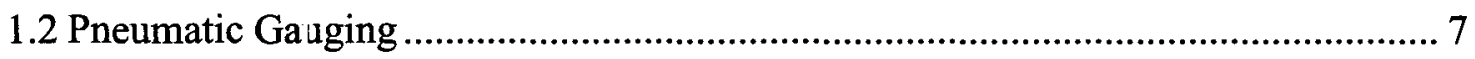

1.3 Scope and Organization of Present Work ……................................................... 12

Chapter 2 Literature Review ............................................................................................. 14

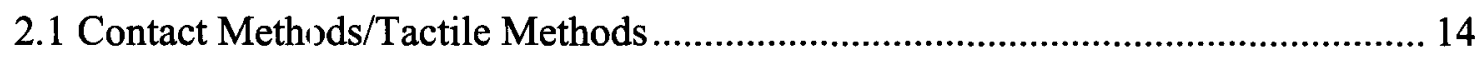

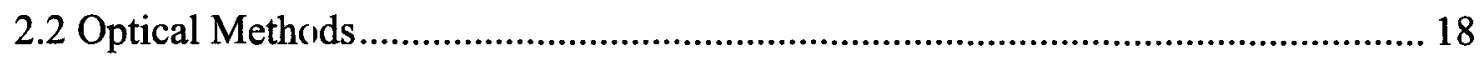

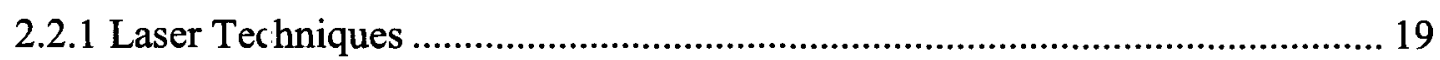

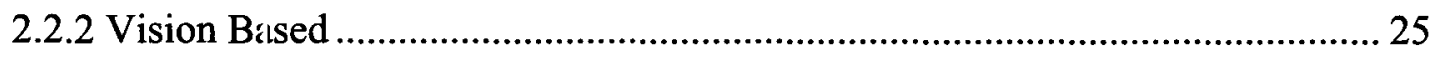

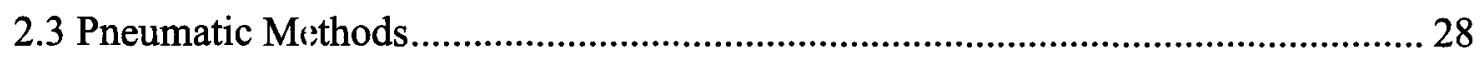

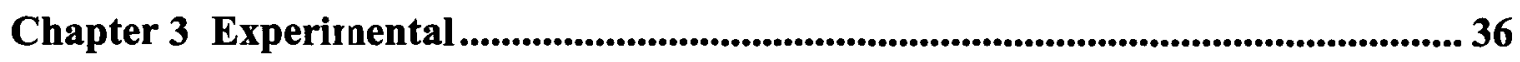

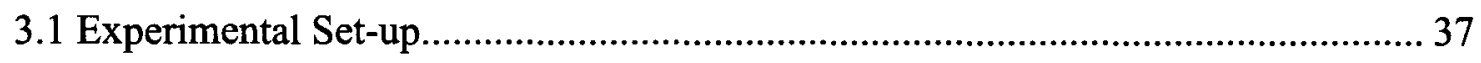

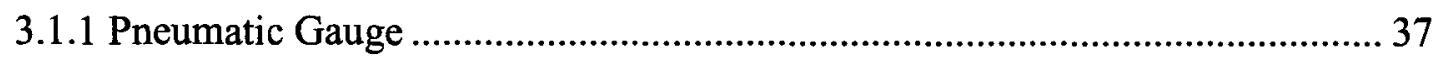

3.1.2 Machines Used for Testing ......................................................................... 38

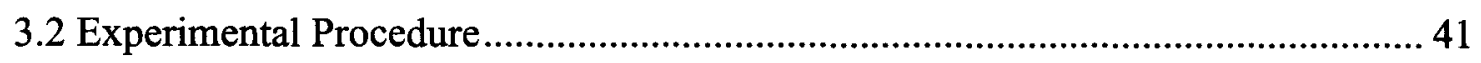

3.2.1 Pneumatic Gauge Development.................................................................... 42 
3.2.2 In-process Simulation

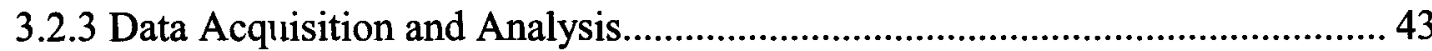

Chapter 4 Results and Discussion ............................................................................................. 46

4.1 Analysis of Stırface Standards Using Tactile Measurement ................................. 47

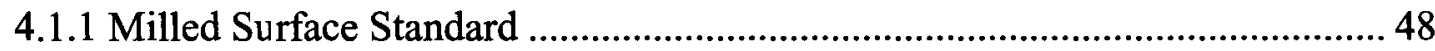

4.1.2 Turned Surface Standards ........................................................................... 51

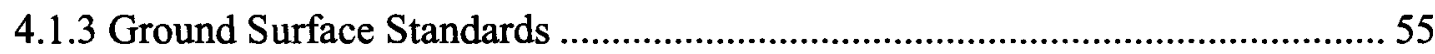

4.2 Development of Pneumatic Gauge for Surface Roughness Assessment ................ 57

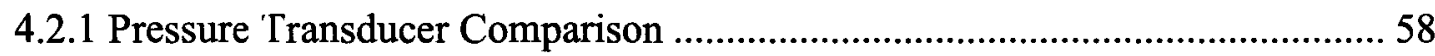

4.2.2 Effects o: Nozzle and Control Orifice Dimensions .......................................... 64

4.2.3 Effects of Supply Pressure on Sensor Sensitivity ........................................... 70

4.3 Pneumatic Characterization of Surface Standards ................................................ 72

4.3.1 Pneumat c Assessment of Milled Surface ...................................................... 73

4.3.2 Pneumatic Assessment of Turned Surfaces .................................................... 79

4.3.3 Pneumatic Assessment of Ground Surfaces .................................................. 84

4.4 Pneumatic C.aracterization of a Jominy Sample in a Turning Environment......... 87

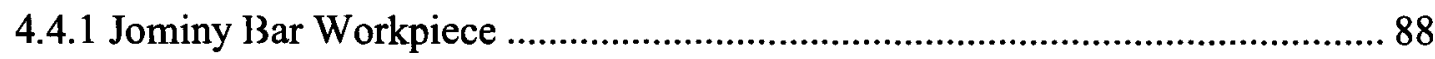

4.4.2 Pneumatic Surface Assessment of a Stationary Jominy Sample ..................... 94

4.4.3 Pneumalic Surface Assessment of a Rotating Jominy Sample ..................... 100 
Chapter 5 Conclusions and Future Work ...................................................................... 122

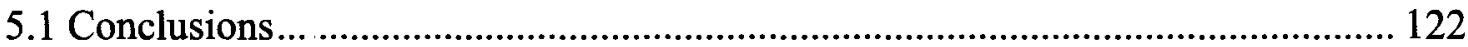

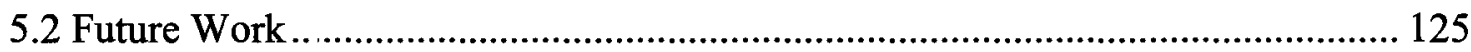

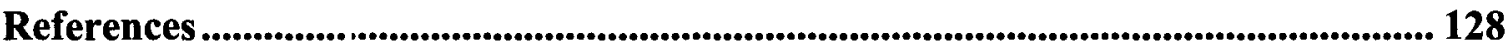

Appendix A - Press ure Transducer Specifications.............................................................. 131 


\section{List of Figures}

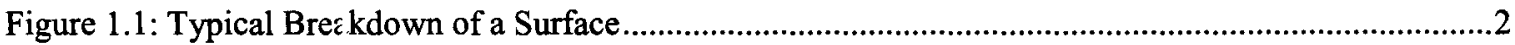

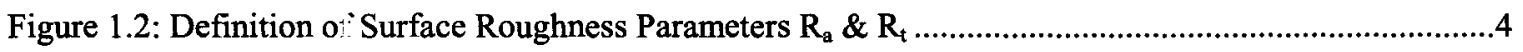

Figure 1.3: Surface Measurements in Manufacture and Performance Sequence ..........................................5

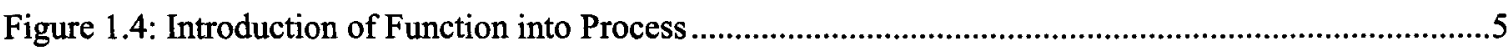

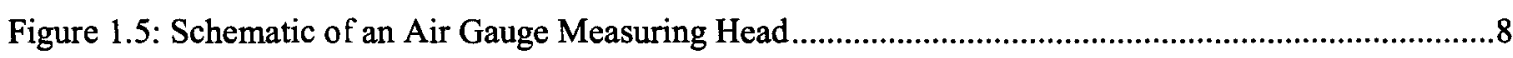

Figure 1.6: Pneumatic Characteristic Curves for Varying Supply Pressures ............................................10

Figure 1.7: Pneumatic C'haracteristic Curves for Varying Control Orifice Diameters ................................10

Figure 1.8: Effect of Rcughness on Pneumatic Gauging ....................................................................11

Figure 2.1: Stylus Probs of a Mechanical Profilometer ..........................................................................15

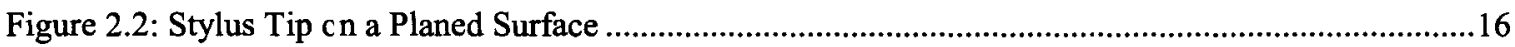

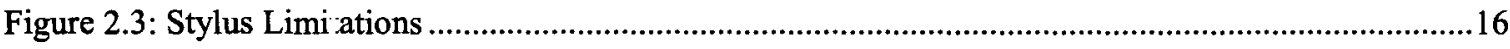

Figure 2.4: Deutschke Method for In-Process Roughness Measurement ..................................................17

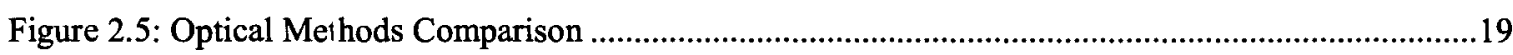

Figure 2.6: Laser Bear. Light Distribution from a Rough Surface …....................................................20

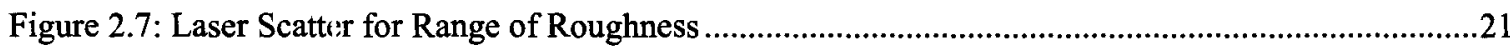

Figure 2.8: Correlation between Spectral Intensity and Surface Roughness...............................................21

Figure 2.9: Typical Scetter Patterns From Various Turned Surface Standards ............................................23

Figure 2.10: Schematic of Acrylic Nozzle to Assist Laser Measurement .....................................................25

Figure 2.11: Sample O Itputs of Acquired Data from Vision Based Measurements ....................................27

Figure 2.12: Typical Pneumatic Gauge Design.................................................................................28

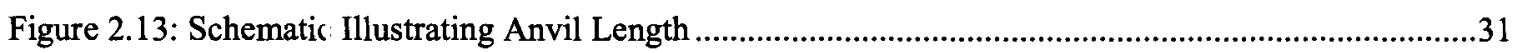

Figure 2.14: Comparis on between Pneumatic and Stylus Measurements ................................................32

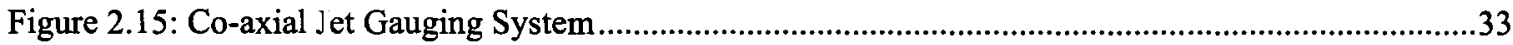

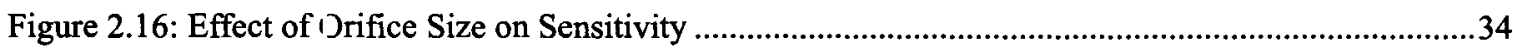

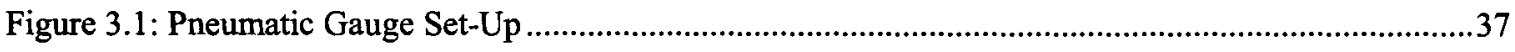

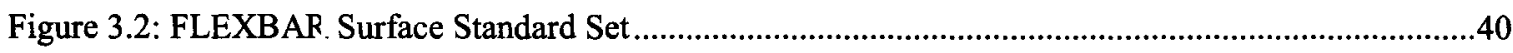

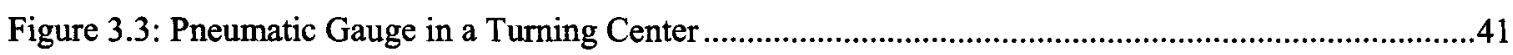

Figure 4.1: Schematic of Surface Characterization using Pneumatic Techniques ......................................46

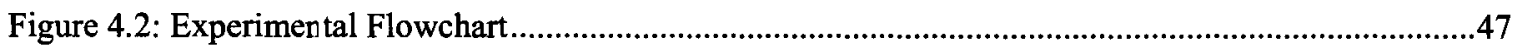

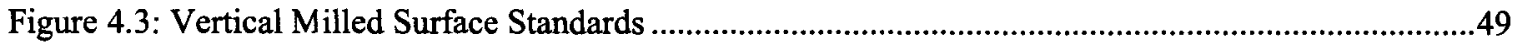

Figure 4.4: Stylus Measurements from Milled Standards (12.5-3.2 $\left.\mu \mathrm{m} \mathrm{R}_{\mathrm{a}}\right)$............................................49

Figure 4.5: Stylus Me:isurements from Milled Standards (1.6-0.4 $\mu \mathrm{m} \mathrm{R}_{\mathrm{a}}$ ) ...............................................50

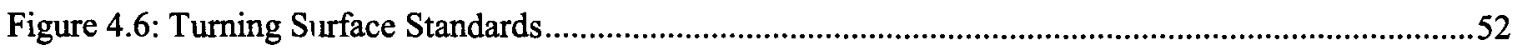


Figure 4.7: Stylus Measurements from Turned Standards (12.5-3.2 $\mu \mathrm{m} \mathrm{R}_{\mathrm{a}}$ ) .........................................55

Figure 4.8: Stylus Measu'ements from Turned Standards (1.6-0.4 $\left.\mu \mathrm{m} \mathrm{R}_{\mathrm{a}}\right)$.............................................53

Figure 4.9: Highlighted Frequency Domain from Turned Standards $\left(1.6-0.4 \mu \mathrm{m} \mathrm{R}_{\mathrm{a}}\right)$..............................54

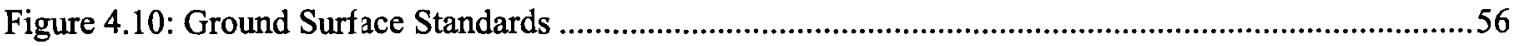

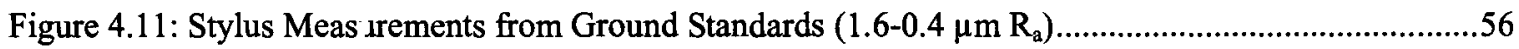

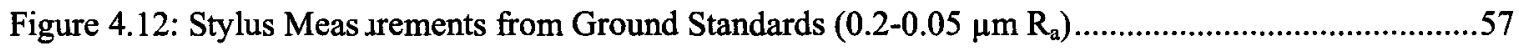

Figure 4.13: Microphone Signal for Milled Standards (12.5-3.2 $\mu \mathrm{m} \mathrm{R}_{\mathrm{a}}$ ) ...............................................60

Figure 4.14: Microphone Signal for Milled Standards (1.6-0.4 $\mu \mathrm{m} \mathbf{R}_{\mathrm{a}}$ ) ................................................60

Figure 4.15: Transducer :Signal for Milled Standards (12.5-3.2 $\mu \mathrm{m} \mathrm{R}_{\mathrm{a}}$ ) .............................................61

Figure 4.16: Transducer ijignal for Milled Standards (1.6-0.4 $\left.\mu \mathrm{m} \mathrm{R}_{\mathrm{a}}\right)$...............................................61

Figure 4.17: Microphone vs. Pressure Transducer Raw Signal Comparison ...........................................63

Figure 4.18: Milled Standard Signals (12.5-3.2 $\mu \mathrm{m} \mathrm{R} \mathrm{R}_{\mathrm{a}}$ ), $\mathrm{Ps}=138 \mathrm{kPa}, \mathrm{Dn}=1.5 \mathrm{~mm}, \mathrm{Dc}=0.825 \mathrm{~mm} \ldots \ldots \ldots . .66$

Figure 4.19: Milled Stanilard Signals (1.6-0.4 $\left.\mu \mathrm{m} \mathrm{R}_{\mathrm{a}}\right), \mathrm{Ps}=138 \mathrm{kPa}, \mathrm{Dn}=1.5 \mathrm{~mm}, \mathrm{Dc}=0.825 \mathrm{~mm}$...........66

Figure 4.20: FFT Waterf all Plot from Milled Surface Standards (12.5-0.4 $\mu \mathrm{m} \mathrm{R}_{\mathrm{a}}$ ) ..................................67

Figure 4.21: FFT Waterfall Plot from Milled Surface Standards (3.2-0.4 $\mu \mathrm{m} \mathbf{R}_{\mathrm{a}}$ ) .................................67

Figure 4.22: Milled Stan tard Signals (1.6-0.4 $\mu \mathrm{m} \mathrm{R}$ ), $\mathrm{Ps}=138 \mathrm{kPa}, \mathrm{Dn}=0.58 \mathrm{~mm}, \mathrm{Dc}=0.51 \mathrm{~mm} \ldots \ldots \ldots \ldots . .68$

Figure 4.23: Frequency 1)omain Comparison of the Two Nozzles Used on Lower $\mathrm{R}_{\mathrm{a}}$ Values ....................69

Figure 4.24: Effect of Supply Pressure on Signal Strength .....................................................................70

Figure 4.25: Backpressu*e Signals from Milled Standards (12.5-3.2 $\mu \mathrm{m} \mathbf{R}_{\mathbf{a}}$ ) …..................................74

Figure 4.26: Backpressu:e Signals from Milled Standards (1.6-0.4 $\mu \mathrm{m} \mathrm{R}_{\mathrm{a}}$ ) .........................................74

Figure 4.27: Amplitude at Dominant Frequencies Comparison for Milled Surface Standards ....................76

Figure 4.28: Stylus and J'ressure Signal Comparison of Milled Surfaces $\left(3.2 \mu \mathrm{m}\right.$ and $\left.1.6 \mu \mathrm{m} \mathrm{R}_{\mathrm{a}}\right) \ldots \ldots \ldots \ldots . . .76$

Figure 4.29: FFT Waterjall Plot from Milled Surface Standards ............................................................78

Figure 4.30: FFT Waterjall Plot of Milled Standards for Lower $\mathrm{R}_{\mathrm{a}}$ Values............................................78

Figure 4.31: Backpressure Signals from Turned Standards (12.5-3.2 $\left.\mu \mathrm{m} \mathrm{R}_{\mathrm{a}}\right)$........................................80

Figure 4.32: Stylus and ?ressure Signal Comparison of Turned Surfaces $\left(12.5 \mu \mathrm{m}\right.$ and $\left.3.2 \mu \mathrm{m} \mathrm{R}_{\mathrm{a}}\right) \ldots \ldots \ldots . . .81$

Figure 4.33: Amplitudes at Dominant Frequencies Comparison for Turned Surface Standards...................82

Figure 4.34: Backpressure Signals from Turned Standards $\left(1.6-0.4 \mu \mathrm{m} \mathbf{R}_{\mathrm{a}}\right)$............................................82

Figure 4.35: Topograph $\mathrm{c}$ view of FFT Waterfall Plot from Turned Surface Standards ............................83

Figure 4.36: Backpressure Signals from Ground Standards (1.6-0.4 $\left.\mu \mathrm{m} \mathrm{R}_{\mathrm{a}}\right)$.........................................85

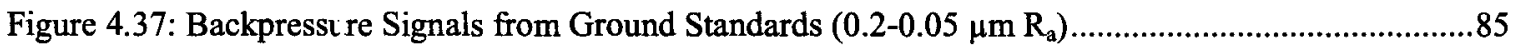

Figure 4.38: Ground Su face Waterfall Topography of the Frequency Domain ........................................87

Figure 4.39: Hardness : $n$ d Roughness along the Jominy Sample ......................................................89

Figure 4.40: Jominy Sainple and Pneumatic Nozzle Setup ...................................................................90

Figure 4.41: Stylus Measurements along Jominy Bar, FFT Corresponding to F=100 $\mathrm{mm} / \mathrm{min}(0-30 \mathrm{~mm}) \ldots 91$ 
Figure 4.42: Stylus Measırements along Jominy Bar, FFT Corresponding to $F=100 \mathrm{~mm} / \mathrm{min}(30-50 \mathrm{~mm}) .92$

Figure 4.43: Stylus Meası urements along Jominy Bar, FFT Corresponding to $F=100 \mathrm{~mm} / \mathrm{min}(50-70 \mathrm{~mm}) .92$

Figure 4.44: Images of $\mathrm{S} \epsilon$ lect Locations on Jominy Sample .............................................................94

Figure 4.45: Stylus Meas Irements and FFT at Select Locations of Jominy Bar ( $F=100 \mathrm{~mm} / \mathrm{min})$............95

Figure 4.46: Backpressure Signal and FFT at Select Locations of Jominy Bar (F=100 mm/min) ............96

Figure 4.47: Backpressur s Signal and FFT at Select Locations of Jominy Bar (F=200 $\mathrm{mm} / \mathrm{min})$.............98

Figure 4.48: Backpressure Signal and FFT at Select Locations of Jominy Bar $(\mathrm{F}=300 \mathrm{~mm} / \mathrm{min}) \ldots \ldots \ldots \ldots \ldots . . .98$

Figure 4.49: Backpressure Signal and FFT at Select Locations of Jominy Bar (F=400 mm/min) .............99

Figure 4.50: Backpressure Signal and FFT for Select Locations of Rotating Jominy Sample...................102

Figure 4.51: Backpressure Signal and FFT Without SOD Compensation ..............................................105

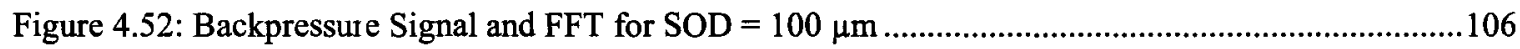

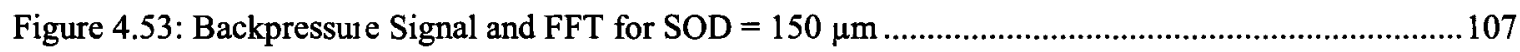

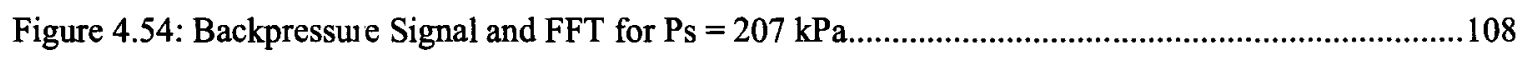

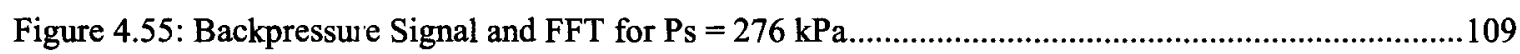

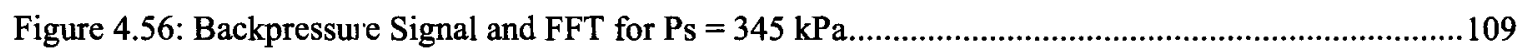

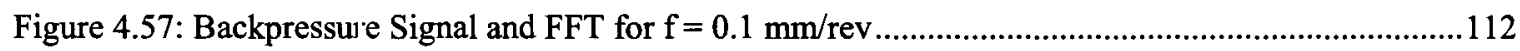

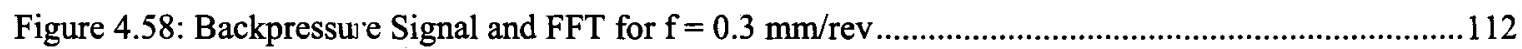

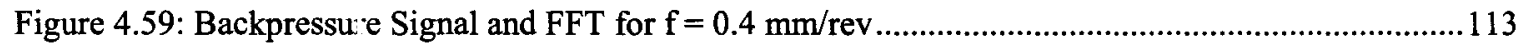

Figure 4.60: Backpressu:e Signal and FFT with the use of Cutting Fluid ..............................................114

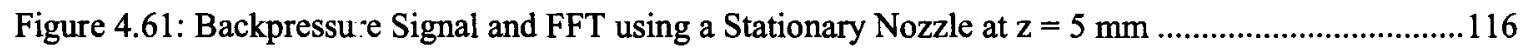

Figure 4.62: Backpressure Signal and FFT using a Stationary Nozzle at $\mathrm{z}=35 \mathrm{~mm}$.........................117

Figure 4.63: Backpressure Signal and FFT using a Stationary Nozzle at $\mathrm{z}=55 \mathrm{~mm}$...........................117

Figure 4.64: Backpressure Signal and FFT using a Stationary Nozzle at $\mathbf{z}=70 \mathrm{~mm}$..........................118

Figure 4.65: Backpressure Signal and FFT at $z=5 \mathrm{~mm}, \mathrm{~V}=60 \mathrm{~m} / \mathrm{min}$.............................................120

Figure 4.66: Backpressure Signal and FFT at $z=5 \mathrm{~mm}, \mathrm{~V}=100 \mathrm{~m} / \mathrm{min}$..............................................120

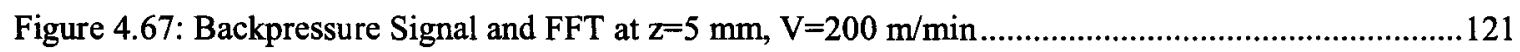




\section{List of Tables}

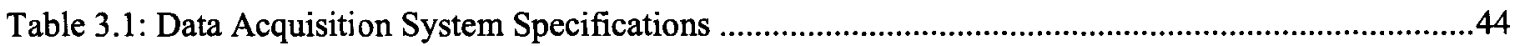

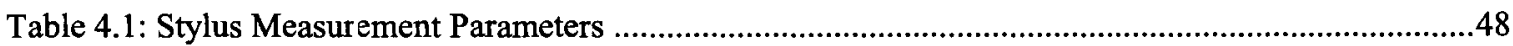

Table 4.2: Calculated $R_{\mathrm{a}}$ values and Dominant Frequencies for Milled Standards ....................................51

Table 4.3: Calculated $R_{a}$ values and Dominant Frequencies for Turned Standards ...................................55

Table 4.4: Pressure Sensior Comparison Experiment Parameters..................................................................59

Table 4.5: Dimensions $0:$ the Nozzles used for Comparison ...................................................................65

Table 4.6: Effects of Supply Pressure on Peak to Valley Distance and Dominant Frequency Amplitude....71

Table 4.7: Dominant Frequency Comparison from Milled Surface Standards...........................................75

Table 4.8: Dominant Frequency Comparison from Turned Surface Standards.........................................81

Table 4.9: Cutting Paranieters used for Jominy Sample........................................................................

Table 4.10: Calculated $\mathrm{R}_{\mathrm{a}}$ Values Along the Jominy Sample.....................................................................91

Table 4.11: Gauging Parameters for Rotating Workpiece with Nozzle Feed..........................................102

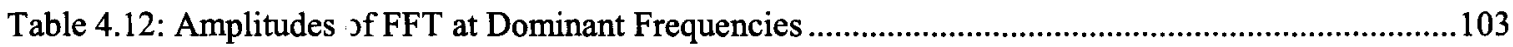

Table 4.13: Amplitudes Jf FFT at Dominant Frequencies without SOD Compensation ..........................105

Table 4.14: Comparison of Amplitudes of FFT at Dominant Frequencies for Larger Supply Pressure .....111

Table 4.15: Select Locations and $R_{a}$ Values Used for Stationary Nozzle Tests .........................................116 


\section{A. Sc. Thesis McMaster University - Mechanical Engineering Drew A. Grandy}

\section{Chapter 1}

\section{Introduction}

The importance of monitoring surface roughness in manufacturing environments is dependent on the intended use of the manufactured part. Surface roughness is often times neglected in favour of faster machining times to reduce the overall cost per machined component, unless the surface quality has been specified for the part. Typically, a reduction of surface roughness corresponds to an exponential increase in the overall machining tine, thus increasing the cost of each machined component. Not only will the careful cortrol of the relevant machining parameters used to generate each component increase the machining time, the measurement of the surface of each component to ensure conformation to specifications will further add to the cycle time. For this reason, a careful balance must be met between product manufacture and the importance of its performance.

In situations where components require strict surface specifications, a monitoring process must be imjlemented that is capable of determining if the machined component is up to specifications in a quick and accurate manner. Accordingly, in-situ surface characterization has become very important to aid in minimizing any additional time required to monitor the roughness of machined components. Before these in-situ methods can be discussed, it is important to understand how surfaces are characterized and understand what the roughness parameters assigned to these surfaces represent. 


\section{A. Sc. Thesis McMaster University - Mechanical Engineering Drew A. Grandy}

\subsection{Surface Roughness}

Surface roughness is a universal characteristic of all surfaces which takes many forms. Typically, machined surfaces can be broken down into three different characteristics as the surface cannot be separated from its manufacture. Figure 1.1 illustrates how a typical machined surface can be separated to display the roughness, waviness, and form, all of which play an important role in characterizing a machined surface. Roughness is an inevitable effect caused by the removal of material by the cutting tool whereas waviness is typically the result of a problem with the machine tool, usually a vibration caused by lack of stiffness or a balance issue [1]. Similarly, the longest wavelengths of the form error are typically a result of weight deflections or long-term thermal effects and should be minimized by carefully designing the machining center and through proper control of machining parameters.

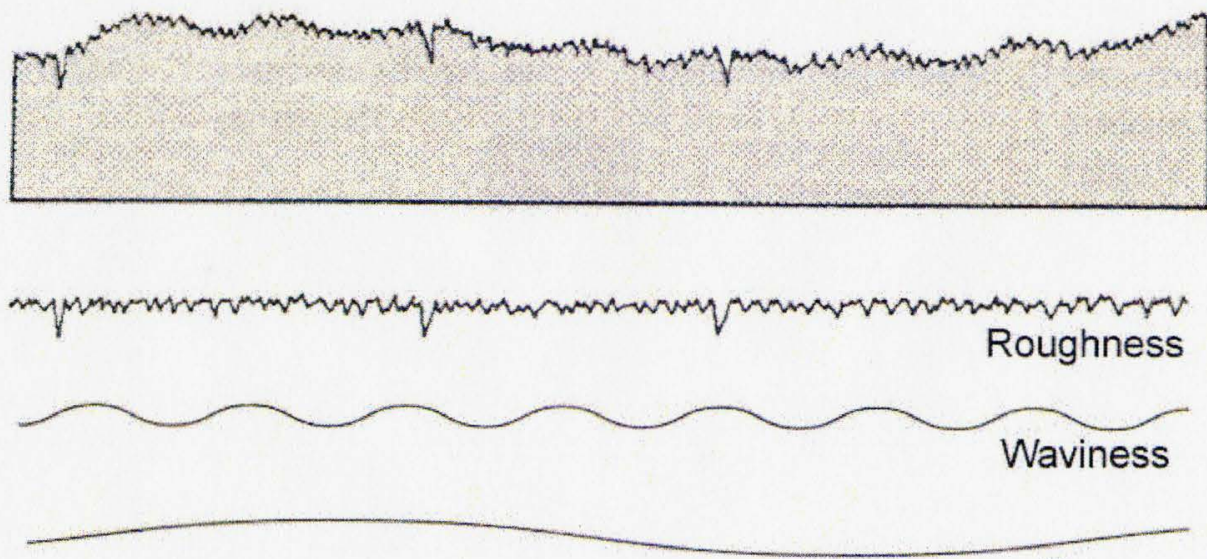

Form

Figure 1.1: Typical Breakdown of a Surface [1] 
M. A. Sc. Thesis McMaster University - Mechanical Engineering Drew A. Grandy

Since waviness and form errors can typically be avoided through careful control, the focus of this work will be on roughness and its measurement. To characterize the roughness of a sulface, quantitative parameters have been developed. The most commonly used parameters to describe surface roughness are the average height departure parameter denoted as $R_{a}$ and the maximum peak to valley depth denoted by $R_{t}$, however $\mathrm{R}_{\mathrm{a}}$ is more commonly adopted. Figure 1.2 is provided to illustrate these parameters in refere ace to a surface. $R_{a}$ is calculated using equation (1.1) where $y(x)$ is the departure from the reference mean of the evaluation length $(\mathrm{L})$ of the profile data. Typically, the evaluation length is broken up into smaller sections referred to as the sampling length or cut-off length. By breaking the evaluation length up into the smaller sampling lengths provides two benefits when calculating the $R_{a}$ value of a surface. The first is to ensure hat the effects of waviness occurring at longer wavelengths is minimized, and the second is to average the calculated $R_{a}$ value determined in each sampling length over the entire evaluation length. This helps minimize the effects of location dependence: when taking a roughness measurement from a surface, and provides a more accurate representation of the surface roughness across a machined component.

$$
R_{a}=\frac{1}{L} \int_{0}^{L}|y(x)| d x
$$




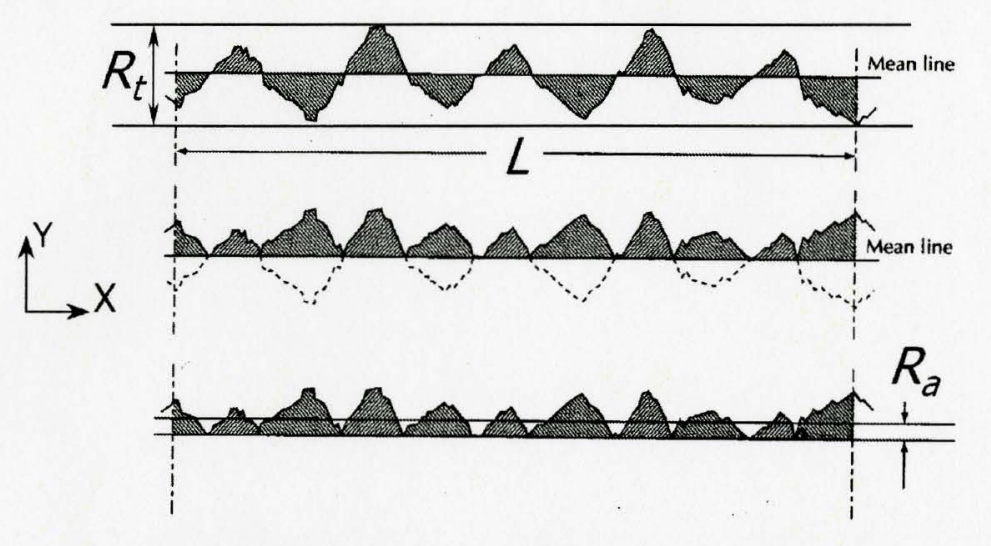

Figure 1.2: Definition of Surface Roughness Parameters $R_{a} \& R_{t}$ (adapted from [1])

As mentioned previously, surfaces generated in a machining process often provide valuable information on the process. Different applications typically view surface roughness as either a benefit or a nuisance depending on the function intended for the machined component. For this reason, the importance of surface roughness is often regarded as being on the fringe of general engineering since it is frequently regarded as an irritant that has to be dealt with, as opposed to a window into the process physics. Surface measurement can often be viewed as the link between the manufacture of a part and its function. Figure 1.3 is provided to assist in demonstrating such a statement where surface measurement lies between the manufacture of the workpiece, which is dependent on the machine tool and process control, as well as the function of the surface. 


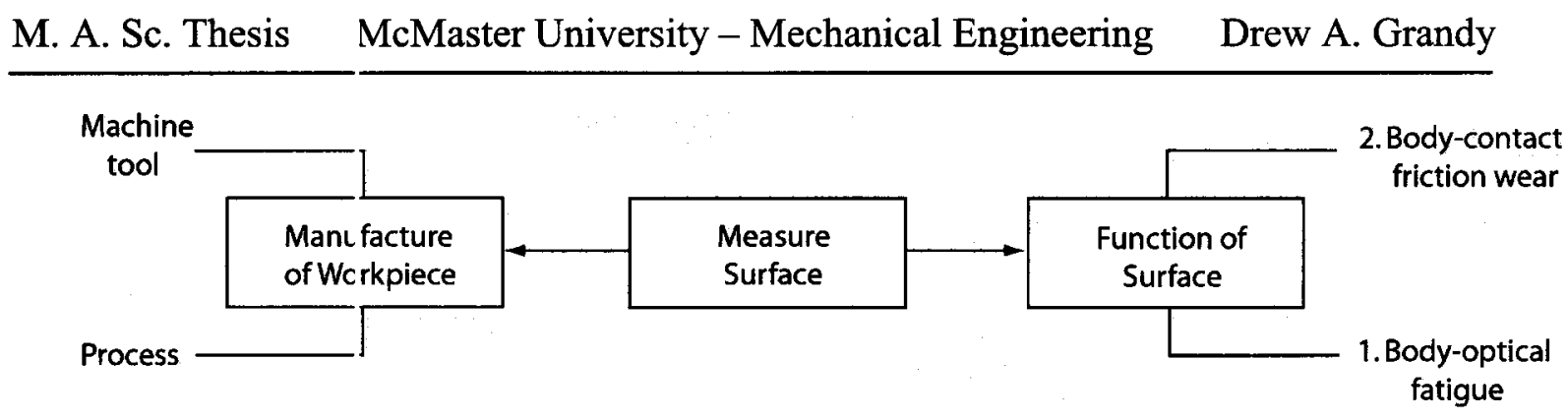

Figure 1.3: , Jurface Measurements in Manufacture and Performance Sequence [1]

From Figure 1.3 it can be established that surface metrology has two major roles; to help control the manufacture through the process and machine tool, and to help optimize the function of the surface. Through control of manufacture, repeatability and quality of conformance can be raised while functional optimization helps enhance the quality of design [1]. Thus by monitoring the surfaces being produced, valuable information can be obtained into the quality of the part as well as the manufacturing process. An implementation of such a system is displayed in Figure 1.4.

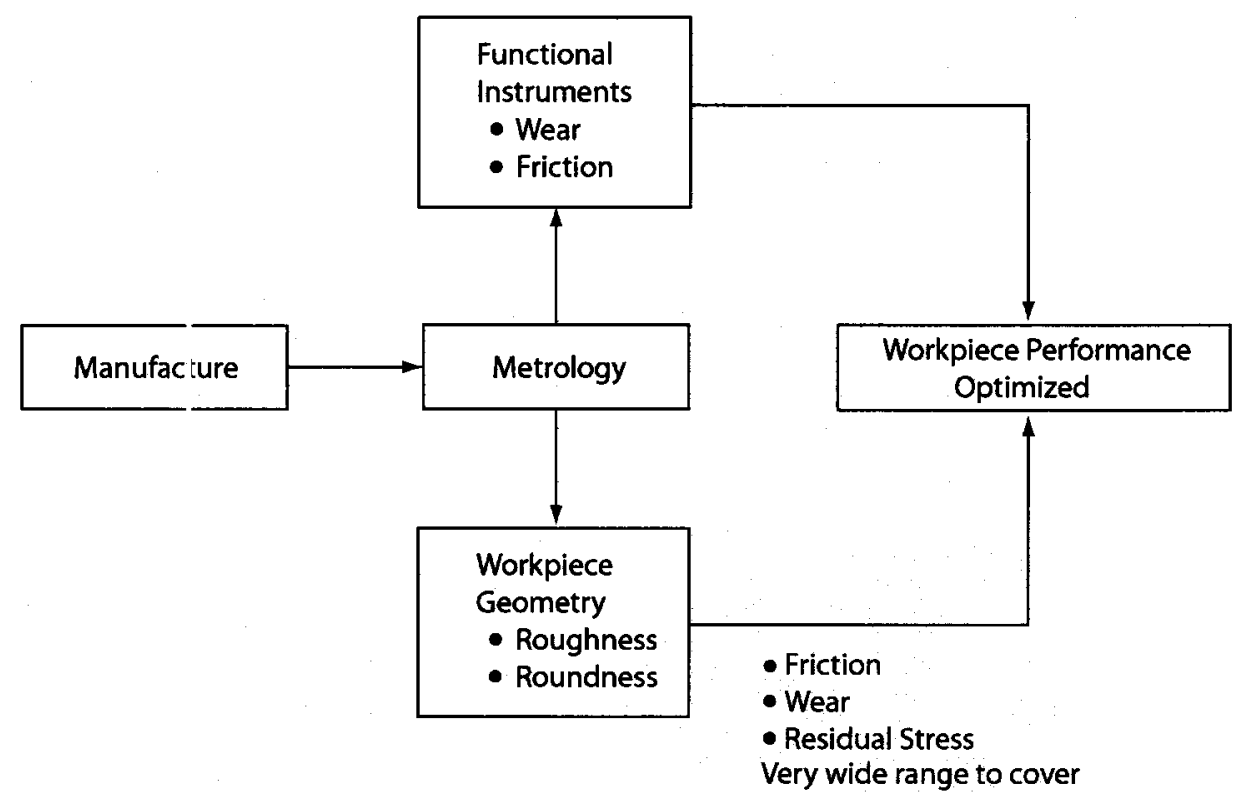

Figure 1.4: Introduction of Function into Process [1] 
M. A. Sc. Thesis McMaster University - Mechanical Engineering Drew A. Grandy

Many different techniques have been developed over the years to measure surfaces, the most mportant of these being the profilometer. Currently, the surface profilometer is the only operation that is anchored in national and international standards, particularly the para neters and measurement conditions to ensure comparability of the measurement results [2]. For this reason, tactile methods have become the most widely accepted method in industry to characterize surfaces. In terms of monitoring applications however, tactile methods are generally set-up off-line in measuring rooms away from the areas where component manufacturing occurs due to the delicate nature of these systems. Due to the relatively slow surface characterization and the need for careful environmental controls required for tactile methods, process monitoring occurs periodically, taking component samples at set intervals for surface specification verification. Once a component is found to be out of specification, all of the components machined after the last successful verification up to the component that was found to be out of specification must be scrapped.

In order to minimize waste, new methods of surface characterization have been developed to monitor surface specifications in-situ. One of these in-situ monitoring methods that has been developed and accepted in industry is optical measuring methods. Optical 3D measurirg methods provide fast, wide area sampling point acquisition to determine the form and surface characteristics of the workpiece. Some of the benefits of optical methods are that the measuring process is non-contact, the process can be automated to a great extent, it has a high measuring rate, and the surface of the measured object is acquired as a whole [2]. Although optical methods are capable of in-situ 
M. A. Sc. Thesis McMaster University - Mechanical Engineering Drew A. Grandy monitoring of surface characteristics, they are still limited by a number of factors such as the optical properties of the workpiece such as reflectivity, the requirement of a obstruction free surface for monitoring, and the dependence on light intensity control within the measurerent environment. Due to these limitations, the applications where optical methods can kie employed for in-situ monitoring are still limited. For this reason, a novel method which is impervious to the issues limiting optical methods must be developed. We turn to a method of measuring displacement and monitoring form errors of manufactured components that has already been accepted in industry which utilizes compressed air as the working medium in order to solve many of the problems associated with optical methods. The work presented in this thesis is on the development of a novel non-contact method for in-situ assessment of the roughness of a moving surface through the adaptation of pneumatic gauging techniques.

\subsection{Pneumatic Gauging}

The pneumatis gauge is a simple device that is widely used in precision gauging and monitoring applications. With proper design and calibration, a pneumatic gauge is capable of providing quick, accurate, non-contact displacement measurements through the use of compressed air as the working medium. A schematic of a typical air gauge is provided in Figure 1.5 to illustrate the important design features that will be used in the development of the theory of pneumatic gauging. 
M. A. Sc. Thesis McMaster University - Mechanical Engineering Drew A. Grandy

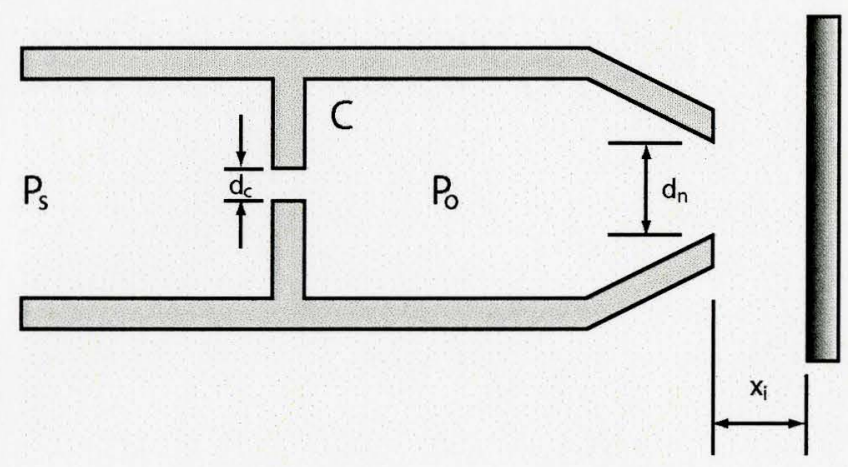

Figure 1.5: Schematic of an Air Gauge Measuring Head

Fluid at a regulated pressure $\left(\mathrm{P}_{\mathrm{s}}\right)$ is supplied through a control orifice of diameter $\left(d_{c}\right)$ to the atmosphere via a nozzle of diameter $\left(d_{n}\right)$ while passing through a variable pressure chamber $(\mathrm{C})$. As the fluid escapes the nozzle and impinges on the work surface in close proximity, a variable flow restriction is created which directly reflects the distance $\left(\mathrm{x}_{\mathrm{i}}\right)$ to the surface to changes in back pressure $\left(\mathrm{P}_{\mathrm{o}}\right)$ within $\mathrm{C}$. For a limited range of motion, the change in distance $\mathrm{x}_{\mathrm{i}}$ is nearly proportional to the change in back pressure $P_{0}$. Ideally (rigid pressure chambers and incompressible fluid) a sudden change in $x_{i}$ would result in an instantaneous change in $\mathrm{P}_{\mathrm{o}}$, however the system dynamics are more closely approximated by a linear first-order system for small changes in $\mathrm{x}_{\mathrm{i}}$. Through conservation of mass and the assumption of incompressible flow, Doebelin [3] developed the following formulae for the mass flow through the system where $G_{s}$ is the mass flow through the supply orifice, $G_{n}$ is the mass flow through the nozzle, $C_{d}$ is the discharge coefficient, $\rho$ is the fluid mass density, and $P_{s}$ is the supply pressure.

$$
G_{s}=\frac{C_{d} \pi d_{c}^{2}}{4} \sqrt{2 \rho\left(P_{s}-P_{o}\right)}
$$


The escape area of the flow through the nozzle is taken as the surface area of a cylinder of height $x_{i}$ and diameter $d_{n}$ which gives the following formula for the mass through the nozzle.

$$
G_{n}=C_{d} \pi d_{n} x_{i} \sqrt{2 \rho\left(P_{o}-P_{a m b i e n t}\right)}
$$

For steady state, $G_{n}=G_{s}$ giving the back-pressure in $C$ as:

$$
P_{o}=\frac{P_{s}}{1+16\left(\frac{d_{n}^{2}}{d_{c}^{4}}\right) x_{i}^{2}}
$$

Since $\mathrm{x}_{\mathrm{i}}$ is a second order term, the sensitivity $\mathrm{dP}_{\mathrm{o}} / \mathrm{dx}_{\mathrm{i}}$ will change with the displacement of the surface from the nozzle tip. The distance $x_{\max }$ where the sensitivity is maximum can be determined as:

$$
x_{\max }=0.145 d_{c}^{2} / d_{n}
$$

The maximum sensitivity is obtained as:

$$
K_{\max }=\frac{2.6 d_{n} P_{s}}{d_{c}^{2}}
$$

Thus by controlling the parameters, $P_{s}, d_{n}$, and $d_{c}$ we are capable of adjusting the optimum standoff distance and the sensitivity of the pneumatic gauge. To aid in the visualization of the effects of these parameters on the performance and sensitivity of the gauge, characteristic surves have been presented for changes in supply pressure in Figure 1.6 and changes to the control orifice in Figure 1.7. 


\section{A. Sc. Thesis McMaster University - Mechanical Engineering Drew A. Grandy}

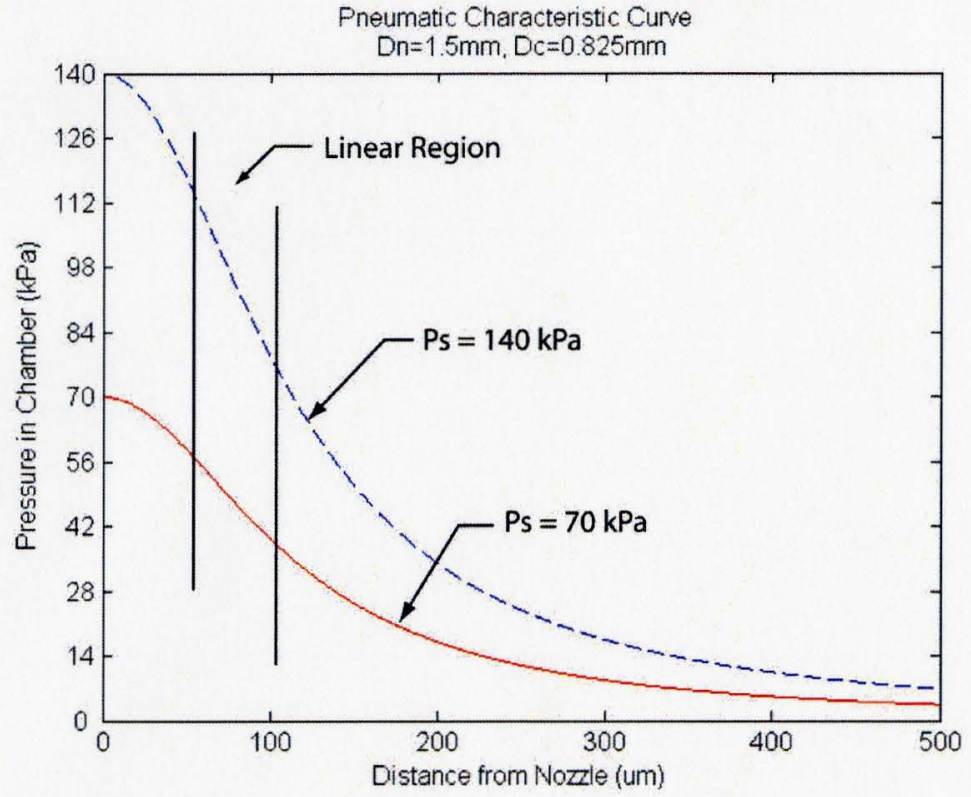

Figure 1.6: Pneumatic Characteristic Curves for Varying Supply Pressures

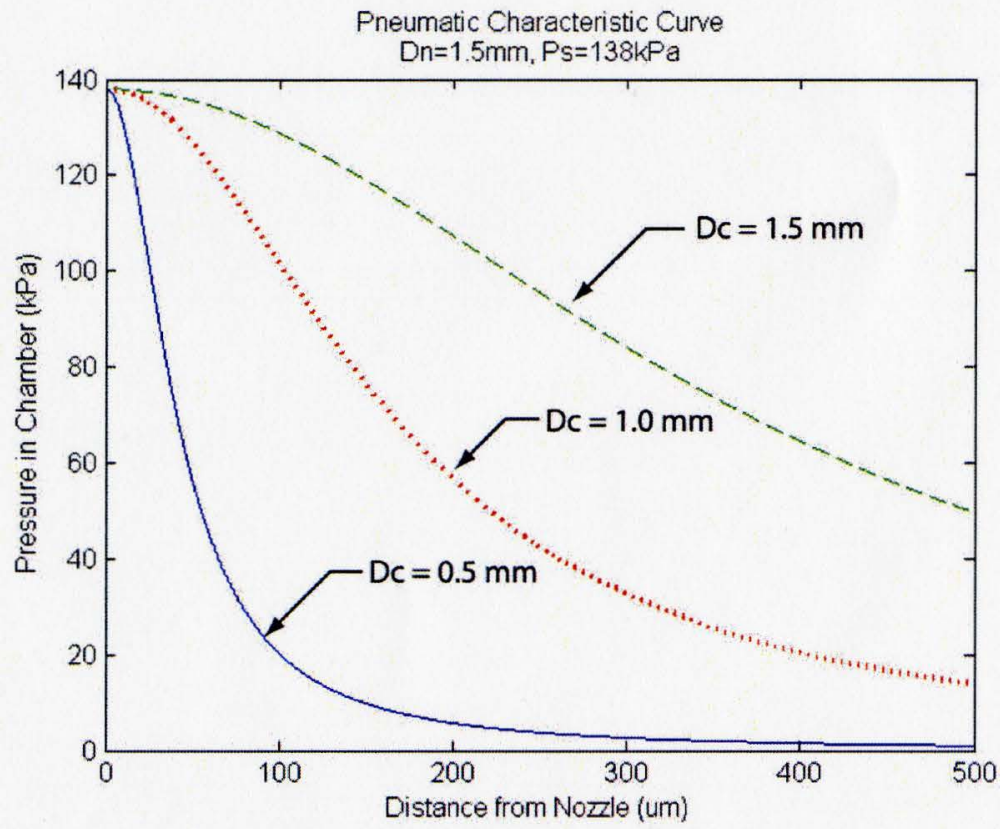

Figure 1.7: Pneumatic Characteristic Curves for Varying Control Orifice Diameters 


\section{A. Sc. Thesis McMaster University - Mechanical Engineering Drew A. Grandy}

As can be seen in Figure 1.6, doubling the supply pressure doubles the sensitivity of the gauge while still maintaining the same optimum stand-off distance. Figure 1.6 also helps display the fact that the linear range for which the gauge can operate remains constant when increasing the supply pressure. Figure 1.7 illustrates how these parameters change as the control orifice diameter is increased for a constant supply pressure and nozzle diameter. As the control orifice diameter is increased the sensitivity decreases drastically, while the optimum stand-off distance increases.

The equations presented previously have been developed for $\mathrm{x}_{\mathrm{i}}$ being the distance between the nozzle tip and an ideal smooth plane surface, for which the escape area of the nozzle $A_{m}$ is given by $\pi d_{n} x_{i}$. As shown in Figure 1.8, if a machined surface with peak points touching line $\mathrm{S}$ is placed under the nozzle, the roughness creates an increase in the escape area $\left(\Delta \mathrm{A}_{\mathrm{m}}\right)$, as represented by equation (1.7) [4].

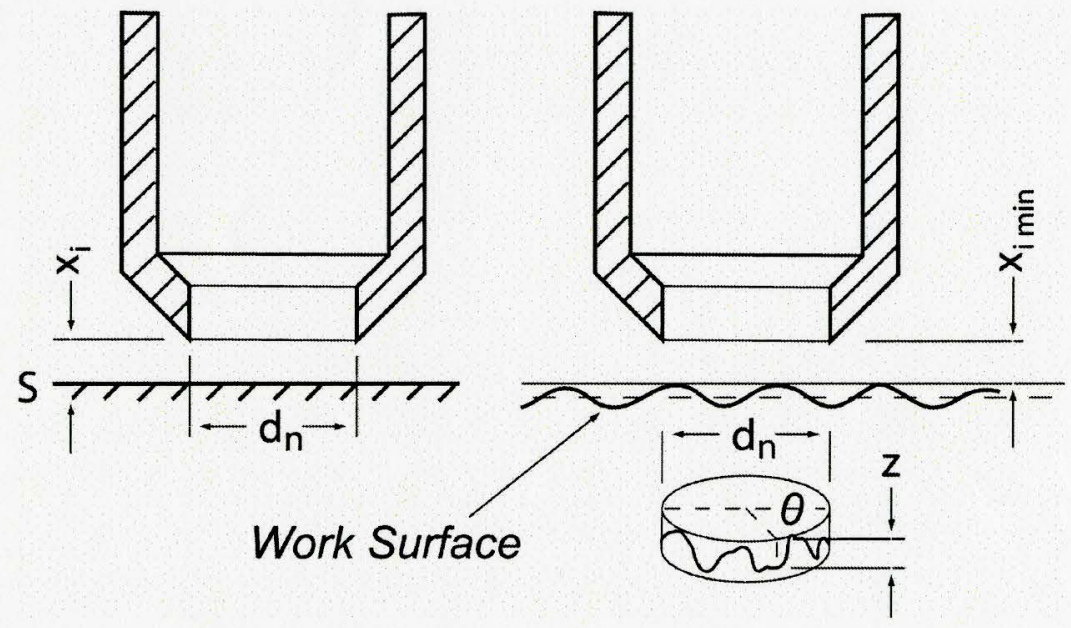

Figure 1.8: Effect of Roughness on Pneumatic Gauging (adapted from [4]) 
M. A. Sc. Thesis McMaster University - Mechanical Engineering Drew A. Grandy

$$
\Delta A_{m}=\int_{0}^{2 \pi} Z\left(d_{n} / 2\right) d \theta=\left(d_{n} / 2\right)\left(Z_{1} \Delta \theta+Z_{2} \Delta \theta+\cdots+Z_{n} \Delta \theta=\pi d_{n} Z_{m e a n}\right.
$$

Relating to $\Delta \mathrm{A}_{\mathrm{m}}$ ther 2 is a pressure change of $\Delta \mathrm{P}_{\mathrm{o}}$ thus the average height $\mathrm{Z}_{\text {mean }}$ can be measured through the: back-pressure change within $C$. In fact $Z_{\text {mean }}$ corresponds directly to the mean roughness of the surface $R_{a}$ over the nominal escape area of the nozzle. Through the developments presented in pneumatic gauging, it has been proposed that the roughness of a surface can be detected using these non-contact measurement systems. The focus of this thesis is on the development and testing of a pneumatic system that can be implemented online for in-situ monitoring of surface roughness.

\subsection{Scope and Organization of Present Work}

This thesis focuses on the development and testing of an in-situ non-contact surface measuring device which utilizes pneumatic techniques. Relevant background information and review of current roughness measurement techniques is presented in Chapter 2, with specific attention directed to in-situ non-contact methods. Current research into improving pneumatic gauging and initial stages of surface roughness assessment through the use of air-gauging systems and analysis methods are also presented. In Chapter 3, experimental methods and data analysis techniques used for the current study are disisussed. The design and function of the experimental apparatus and measuring equipment are also provided. Experimental results are then presented in Chapter 4. The results are analyzed and discussed towards the feasibility of implementing a pneumatic device for in-process monitoring. Finally, the major findings from the work 
M. A. Sc. Thesis McMaster University - Mechanical Engineering Drew A. Grandy

outlined in this report are summarized in Chapter 5, where conclusions are drawn and recommendations are made for the direction of future research. 
M. A. Sc. Thesis McMaster University - Mechanical Engineering Drew A. Grandy

\section{Chapter 2}

\section{Literature Review}

Surface roughness in machining is a balance between cost and performance. If a part contacts a surface (ie. bearings) then its roughness will have to be minimized to reduce friction and 'wear, however carefully controlling and measuring the roughness requires more machining time. Many different techniques are available to profile a surface through off-line methods, however when these are implemented within a machining center for online measurement, several factors severely limit their performance. In order to develop a robust and accurate roughness measurement system for in-situ monitoring, the current technology must be reviewed to fully utilize their benefits and offset the problems associated with them. This section provides a review of said technologies to sutline the progression of surface roughness measurement methods from their inception to the present day.

\subsection{Contact Method:/Tactile Methods}

Contact methods have become the industrial standard by which all other measurement techniques are evaluated. The stylus profilometer utilizes a diamond tipped stylus that is traversed over the surface to be measured. Typical stylus transducers consist of a beam pivoted about two knife edges which has a stylus at one end and a ferrite block on the other. The ferrite block is located between two coils, and as the stylus deflects due to the surface irregulcrities, the ferrite block moves within the coils causing a variation in the inductance bridge circuit. When the stylus is neutral, the inductance bridge is 
M. A. Sc. Thesis McMaster University - Mechanical Engineering Drew A. Grandy balanced and as the stylus changes position, a change in the inductance of the coils causes a modulating high-frequency carrier signal that is now proportional to the displacement of the stylus [5]. The direction of displacement of the stylus is indicated by the relative change in the phase of the carrier signal, allowing the signal to be amplified and demodulated to give a signal representing a surface profile [6]. Figure 2.1 illustrates the construction of a typical stylus probe.

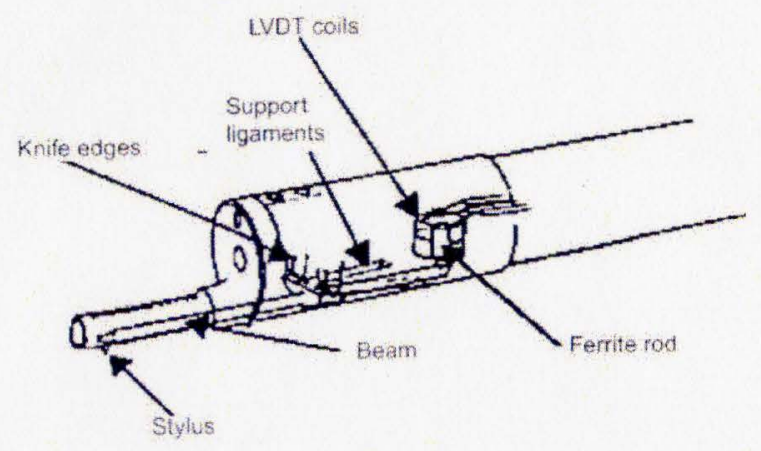

Figure 2.1: Stylus Probe of a Mechanical Profilometer [6]

Some of the benefits of a mechanical profiler are that they have good lateral resolution, a large height measurement range up to several micrometers, and are not affected by the material properties of the surface being measured as long as the material is not too soft. Since the diamond stylus contacts the surface, it is possible to leave trace marks unless the loading of the stylus is carefully controlled. Another disadvantage of the stylus profiler is that typically a single stylus tip is traversed along the surface resulting in a single 2-D profile. To gain an understanding of an entire surface, multiple passes must be taken in order to obtain a 3-D profile of the entire surface. This can be very time consuming and does not allow for quick assessment of a machined surface. Nowicki [7] 


\section{A. Sc. Thesis McMaster University - Mechanical Engineering Drew A. Grandy}

developed a stylus probe that incorporates multiple stylus tips into a single device to aid in the 3-D profile generation and to speed up the surface profiling process; however this device is still only capable of providing discrete paths across a surface and was never widely accepted.

One of the limitations of the stylus type profilometers is the resolution of the diamond tip. As the magnitude of the geometric features on the surface approach the radius of the tip of the stylus, erroneous profiles will be created. Figure 2.2 is a micrograph of a machined surface and a $5 \mu \mathrm{m}$ stylus tip to illustrate how the radius of the stylus tip cannot reach the bottom of deep grooves, or reentrant grooves shown in Figure 2.3.

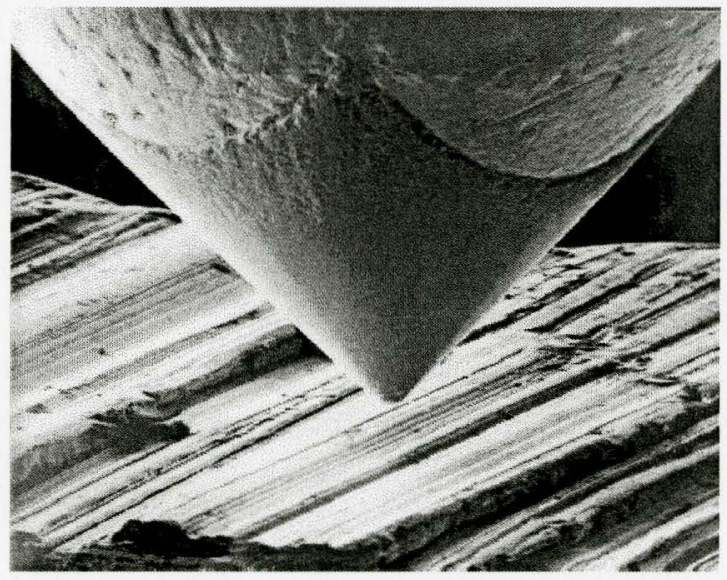

Figure 2.2: Stylus Tip on a Planed Surface, 5 um Radius [8]

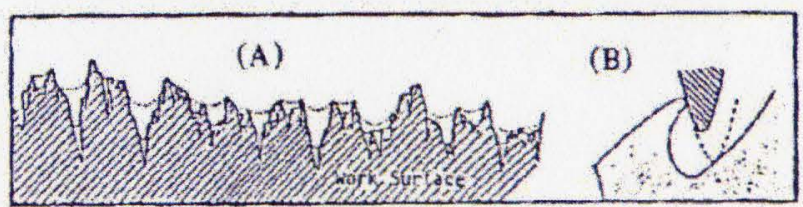

Figure 2.3: Stylus Limitations (A) Cannot Reach Deep Grooves and

(B) Cannot Touch Recess of Reentrant Grooves [4] 
Due to the delicate nature of the mechanism used to measure the surface roughness in stylus type surface profilers, these devices are best used in a laboratory environment and are not suitable for incorporation into a machining center for online surface characterization. The only known attempt to employ a stylus technique in an inprocess grinding environment was by Deutschke [9], however the instrument was only used to take sampled outputs as opposed to a continuous signal. This device consisted of a cylinder with a hole in the side for the transducer to protrude from, while the centrifugal force pushed the transducer against the workpiece. Every revolution of the workpiece turned the drum while the transducer produced a set of point heights for each revolution. It was found howeve: that the system tended to indent the surface instead of just making point contact, and so the device was never successful [1]. A schematic of such a device is provided in Figure 2.4.

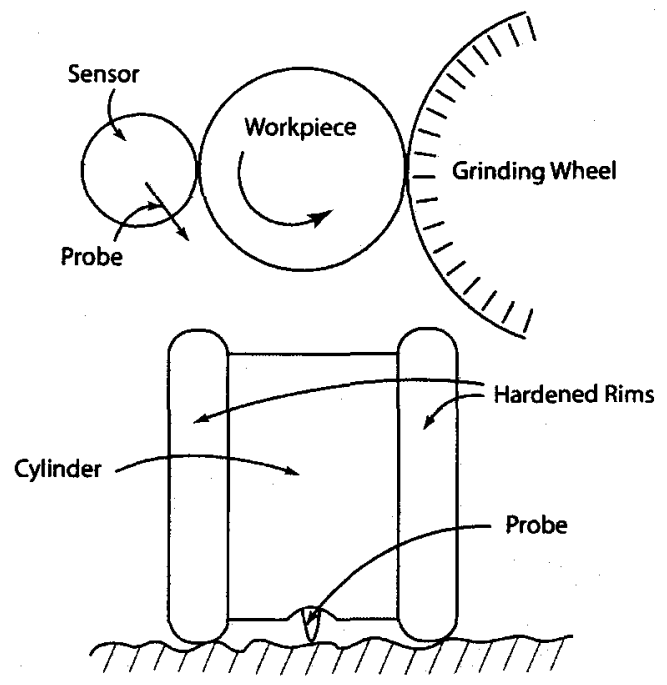

Figure 2.4: Deut:chke Method for In-Process Roughness Measurement (adapted from [1]) 
M. A. Sc. Thesis McMaster University - Mechanical Engineering Drew A. Grandy

Continuous roughness measurements acquired in-process are not feasible due to many factors relating to the physical nature of a stylus device. For a stylus incorporated into a live machining operation such as turning, the stylus tip would wear extremely fast requiring the diamond tip to be replaced frequently. This is quite costly and not practical in an industrial setting. Also, the stylus instruments are limited to slow surface speeds to minimize the dynamic effects introduced to the stylus from the passing surface. At high speeds, the stylus tip can begin to float across the surface producing spurious surface outputs. Therefore, the use of contact methods to measure surface roughness is limited to off-line measurement stations where the machined component must be removed from the machine and transfer:ed to another station where the stylus measurement can take place, or alternatively through the use of a less accurate hand held unit.

\subsection{Optical Methods}

Many different measurement techniques are available that employ optics to characterize a surface as outlined in a review paper by Hocken [10]. The majority of these techniques employ the use of a laser with different methods of analyzing the reflected beam; however there are also newly developed methods which incorporate vision based analysis to gauge surface roughness for in-process measurement. With optical methods nearly approaching results comparable to those achieved from a stylus, a balance must be reached between the speed, cost and fidelity of the devices. It is not economically feasible to get high speed with high fidelity as demonstrated in Figure 2.5 

comparing different optical techniques [1]. A review of different optical methods is provided in this section.

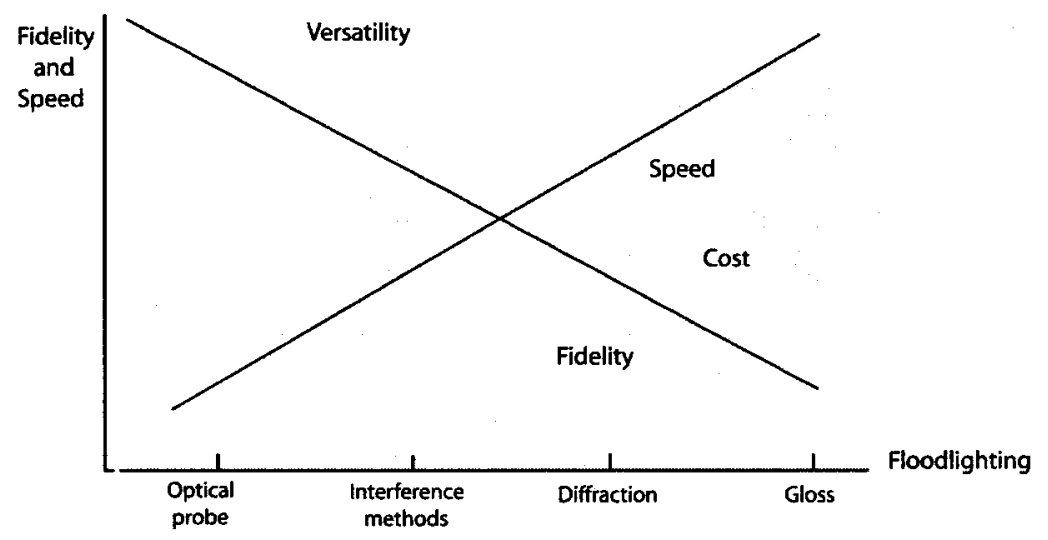

Figure 2.5: Optical Methods Comparison (adapted from [1])

\subsubsection{Laser Techniques}

The most common laser measurement technique is the laser scatter or laser speckle method. This section will focus on these methods as they have been proposed as a non-contact, in-sit $\perp$ measurement device for surface roughness by researchers such as Tay and Tian $[11,12]$. The theory behind laser scattering is that a laser incident on a rough surface will te scattered by the microscopic surface irregularities. A surface can then be characterized by a mirror-like reflection for a smooth surface and a diffuse reflection as the roughness increases. The smooth surface scatters light in a specular direction and as the surface roughness increases the specular component decreases while the scattering of the beam increases [11]. Figure 2.6 illustrates a beam scatter from a rough surface. 
M. A. Sc. Thesis McMaster University - Mechanical Engineering Drew A. Grandy

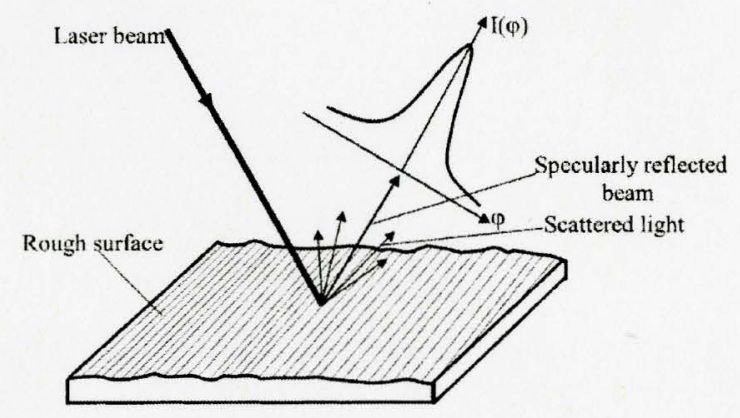

Figure 2.6: Laser Beam Light Distribution from a Rough Surface [11]

The correlation between surface height and the scattered light pattern presented in [12] can be used to provide useful information for surface roughness on the order of a wavelength of the incident beam. For surface irregularities smaller than the wavelength of the scattered light, methods such as vector diffraction and Beckmann scalar theory [13] can be employed to relate the scattered light to surface roughness.

Two examples of the effectiveness of laser scattering techniques are presented by Rao [6]. The first example is capable of characterizing ground surfaces with a roughness range between $0.025 \mu \mathrm{m}-3.2 \mu \mathrm{m} \mathrm{R}_{\mathrm{a}}$. From Figure 2.7 it is clear that there is a distinct qualitative difference of the laser scatter over the range of roughness and Figure 2.8 demonstrates a fair linear relationship between specular reflection and surface roughness up to a roughness of about $0.8 \mu \mathrm{m}$. Above this value, specular reflection is no longer reliable. 


\section{A. Sc. Thesis McMaster University - Mechanical Engineering Drew A. Grandy}

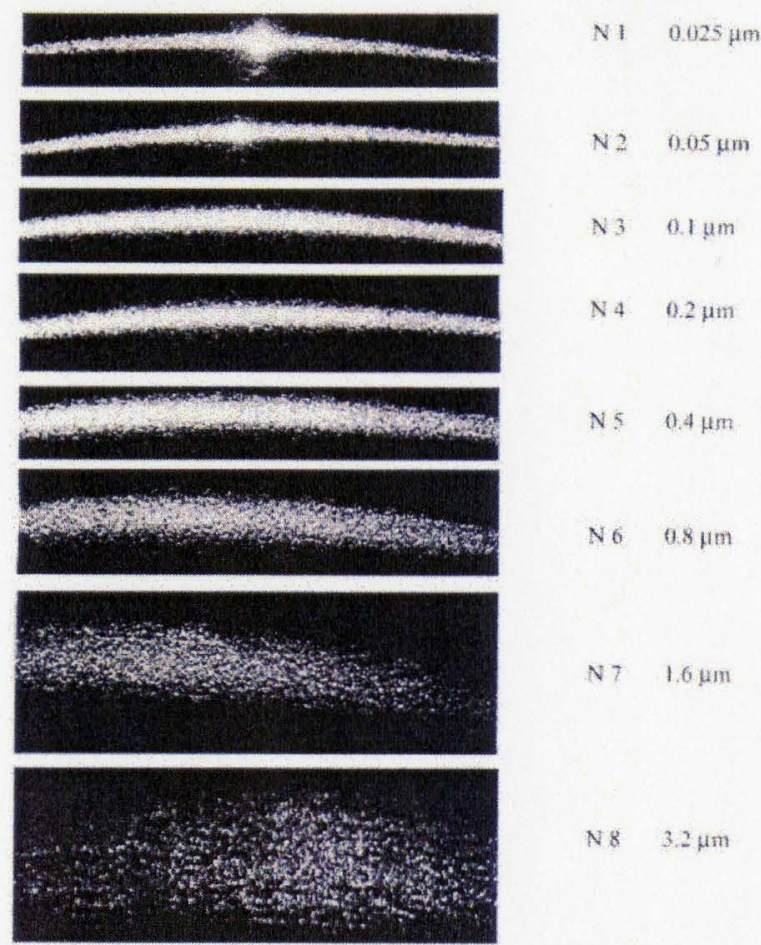

Figure 2.7: Laser Scatter for Range of Roughness [6]

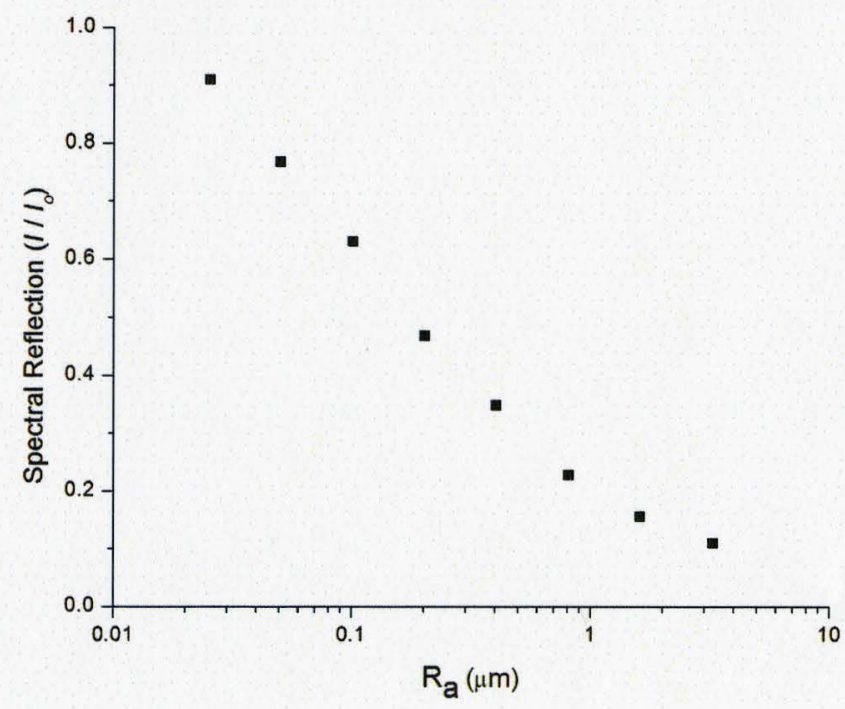

Figure 2.8: Correlation between Spectral Intensity and Surface Roughness (adapted from [6]) 
M. A. Sc. Thesis McMaster University - Mechanical Engineering Drew A. Grandy

The second example using laser scattering is the measurement of surface roughness from turned surfaces. Most of the work done on laser-scattering has understandably been : $\mathrm{n}$ this area in order to provide alternatives to stylus profilometers to be used in-situ. Typically the results obtained from research in this area are mainly directed at rendering measurements that agree with the profilometer results since these are accepted as the industrial standard. Since light scattering from random surfaces is well understood, further investigation into the information carried by the beam scatter needs to be completed. This information could provide information about the surface finish as well as poss ble feedback on tool condition and machine tool vibrations [6]. An example of the typical scattering patterns provided from turned surfaces is shown in Figure 2.9. These saraples are taken with the laser incident perpendicular to the surface where two similar scattering patterns are formed on either side of the beam, designated as L (left) and R (right). Tay [11] has specified that the ratio for $d / D$, where $d$ is the diameter of the beam and $\mathrm{D}$ is the diameter of the workpiece, should be small in order to minimize the light scattering calısed by the curvature of the workpiece. 
M. A. Sc. Thesis McMaster University-Mechanical Engineering Drew A. Grandy

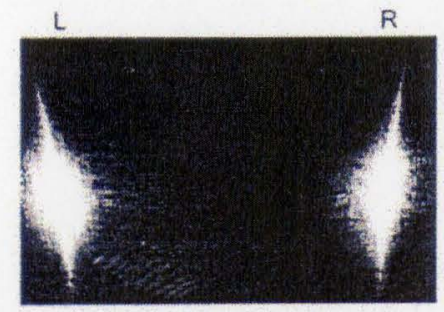

(a)

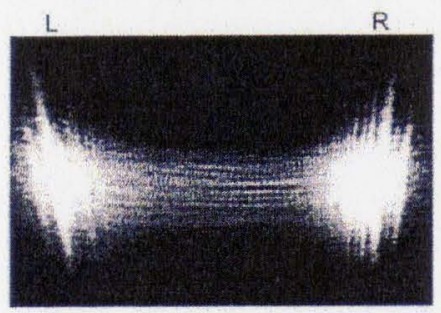

(c)

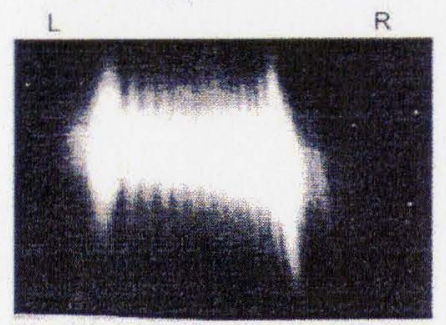

(e)

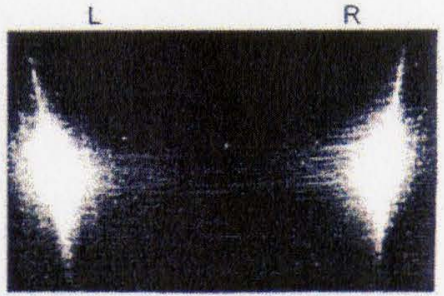

(b)

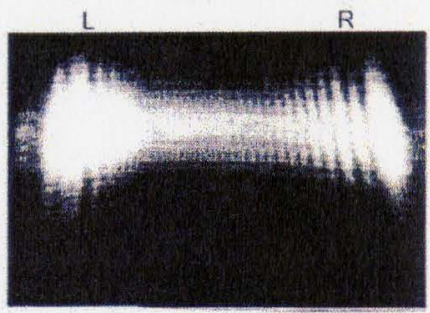

(d)

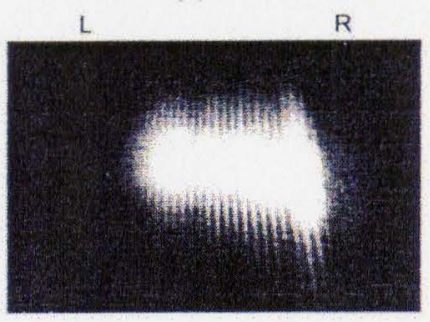

(f)

Figure 2.9: Typical Scatter Patterns From Various Turned Surface Standards (a) $50 \mu m R_{a}$ (b) $25 \mu m R_{a}$, (c) $12.5 \mu m R_{a}$ (d) $6.3 \mu m R_{a}$, (e) $3.2 \mu m R_{a}$, (f) $1.6 \mu m R_{a}[6]$

This example illustrates that diffraction is less distinct and specular scattering from the surface irregularities is far more predominant for grooves with larger pitch. When the pitch of the grooves decreases, the diffraction phenomenon becomes much more distinct. Through further analysis of the intensity distribution, the surface profile of the machined groove can be studied to provide further information about machining conditions and tool condition. Similar results have also been achieved more recently by Minoni [14] who developed a device for surface quality control for online applications 
M. A. Sc. Thesis McMaster University - Mechanical Engineering Drew A. Grandy incorporating fibre cptics to isolate most of the costly equipment away from the machining environment.

When trying $: 0$ implement laser scattering techniques for in-situ measurement, some major concernsi arise such as overall cost of the system, only highly reflective materials can be measured, effect of interference caused by debris created during the cutting process, effect of cutting fluids on the measurement surface, and variation of the offset distance caused by tool wear and machine tool vibration. Since the laser is to be mounted near the cutting tool, any vibrations of the workpiece would be transmitted to the beam speckle signnal. This could potentially lead to spurious results if the cutting conditions were not carefully monitored and maintained.

Tay [11] has presented a design to assist with the clearing of any debris and cutting fluid from the surface to be measured. The design incorporates an acrylic nozzle to the tip of the laser body, allowing compressed air to flow through the nozzle to clear the surface of any obstructions. Figure 2.10 is provided illustrating the proposed design. It is noted however that this design may have its limitations when clearing the surface of cutting fluid since the compressed air may introduce mist on the test surface and the measuring lens of the laser. The mist would diffract the light creating a problem when analyzing the speckle diffraction patterns. Tay has suggested that this should not be an issue, however extensive testing would be required to substantiate this. The results Tay obtained for dry turning were within $10 \%$ of conventional stylus measurements for a range of $R_{a}$ values between $0.005 \mu \mathrm{m}$ and $6 \mu \mathrm{m}$ [11]. 


\section{A. Sc. Thesis McMaster University - Mechanical Engineering Drew A. Grandy}

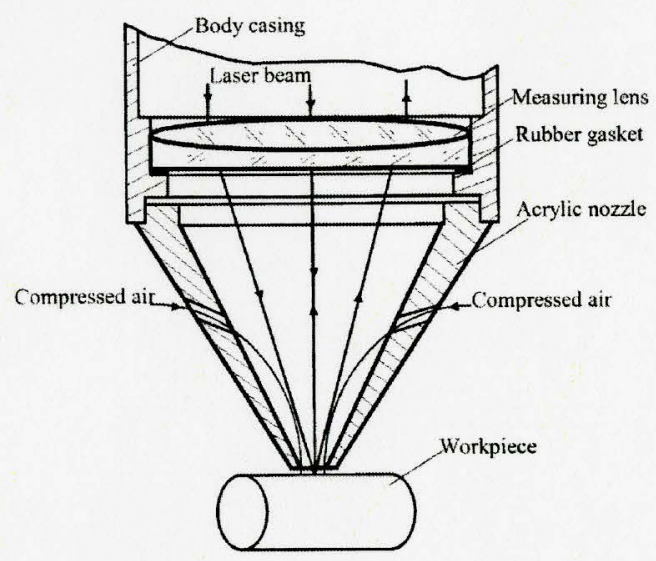

Figure 2.10: Schematic of Acrylic Nozzle to Assist Laser Measurement [11]

\subsubsection{Vision Based}

Perhaps the most recent development in optical surface roughness measurement techniques is the vision based approach. These methods assess surface roughness using texture features of image data collected from the test specimen. Lee et al. [15] has proposed a method for such measurements and have demonstrated the validity of their proposed method to achieve accurate $R_{a}$ readings; however the effects of light variation and material changes on their results have not been discussed.

A method of online tool condition assessment in milling operations using surface texture monitoring has been created by Bradly and Wong [16]. This method utilizes spatial and frequency domains for their assessment of surface features. Kumar et al. [17] used regression analysis to introduce a surface roughness parameter for image data which led to the work of Al-Kindi [18] who utilizes statistical analysis measures to evaluate acquired roughness parameters to assess their repeatability and validity. Al-Kindi 
M. A. Sc. Thesis McMaster University - Mechanical Engineering Drew A. Grandy

investigated the valdity of two different types of vision based surface roughness measurement techniques.

The first type: of vision based systems tested for validity by Al-Kindi was the Intensity-Topography' Compatible (ITC) model which assumes all light is reflected in all directions in a manner related to the property of the surface topography. This model implies that the light irradiance intensity of each point of the surface has a linear compatibility relationship with the surface topography. The discrete values of the grey scale are assumed tc be equally spaced to comply with the surface topography of the object. To create a valid roughness measurement, the grey scale of the image data must be normalized to covir the resulting range of the surface profile [18].

The second method Al-Kindi validated was the Light-Diffuse model. In this model it is assumed that the surface being measured fully complies with Lambert's law and hence the image intensity could be used to compute the surface normal vectors. These vectors can then be used to reconstruct the surface profile [18]. Sample outputs from the two models investigated by Al-Kindi, along with the stylus profilometer data are presented in Figure 2.11 for comparison. Al-Kindi demonstrated the validity of vision acquired data to messure surface roughness and concluded that both the ITC and light diffuse model proved adequate. 
M. A. Sc. Thesis McMaster University - Mechanical Engineering Drew A. Grandy
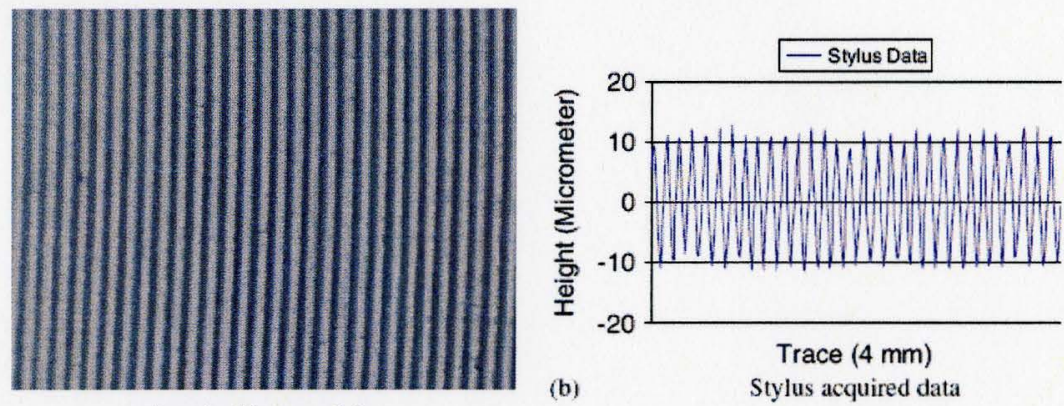

(a)

Acquired image of the reference specimen
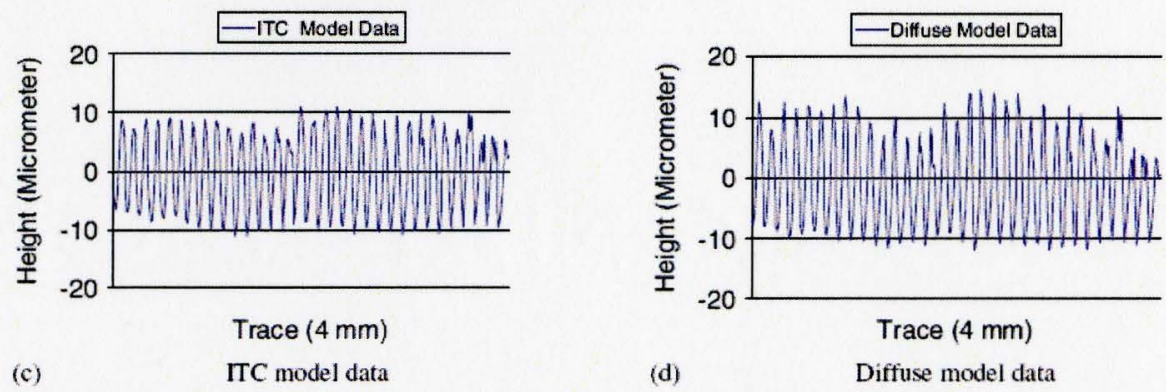

Figure 2.11: Sample Outputs of Acquired Data from Vision Based Measurements [18]

Vision based surface roughness measurement tools suffer from the same problems that hinder the implementation of all optical systems into online measurement environments. For these techniques to operate effectively the light source intensity must be carefully controlled and a highly reflective, clean surface must be ensured which severely limits the uses of these devices for online applications. Alternatively, secondary surface clearing devices could be implemented in coordination with the vision based systems, however space is limited within the machining environment and debris could be ejected onto the lens of the vision systems, again hampering their effectiveness. 


\subsection{Pneumatic Methods}

The use of pneumatics for online surface roughness measurement is ideal to overcome some of the limitations presented for the previous measuring methods. Using compressed air as the working medium directed at the surface of interest would evacuate the area of any coolant or debris while still allowing the collection of information about the surface topography. Similar to optical methods, pneumatic techniques are non-contact allowing the measurement of soft materials; however unlike the optical methods, air is further impervious to any material changes and the reflectivity of the material, allowing for online measurement of typical metals as well as plastics or other transparent materials.

Pneumatic gauging began as a method to measure form errors of parts through the measurement of the displacement of a surface from the nozzle tip. The principle of these gauges is simple and a typical apparatus used in the early development of these gauges is shown in Figure 2.12.

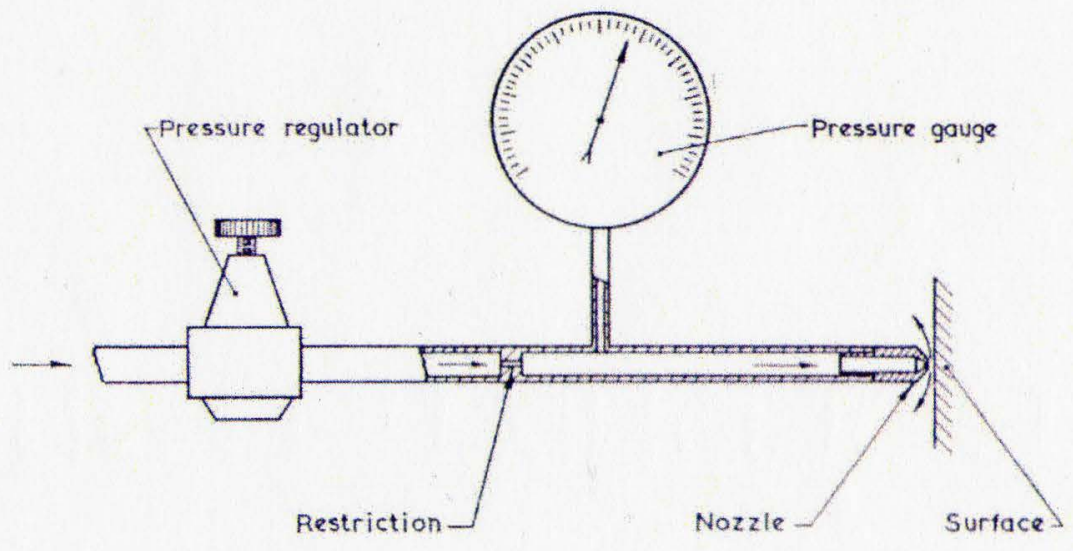

Figure 2.12: Typical Pneumatic Gauge Design [19] 
M. A. Sc. Thesis McMaster University - Mechanical Engineering Drew A. Grandy

In the early developments of pneumatic gauging systems, analogue pressure transducers were utilized such as Wheatstone bridges attached to a bellows and fixed resistor to obtain digital signals $[20,21]$. Techniques for speeding up pneumatic testing of dimensions spans back as far as 1966 in the work of Kurochkin and Tsidulko [22] when they proposed the idea that pneumatic gauging techniques could be applied for in-process measurement. Developments in pressure transducer technology have lead to surface characteristics being detected by pneumatic dimension measurement systems. These developments in sensor technology introduced the need to study the dynamic characteristics of ultra-precision air gauge systems. Rucki [23, 24, 25] and Zhang [26] both investigated methods to reduce air gauge uncertainty. The most influential parameter of the pneumatic gauging system was found to be the ratio of nozzle outer diameter $\left(d_{c}\right)$ to inner diameter $\left(d_{p}\right)$. Rucki [23] has found that a ratio of $d_{c} / d_{p}=1.5$ dramatically reduces the fluctuations of the backpressure signal for a constant surface displacement.

Wager [27] studied the surface effects in pneumatic gauging and compared the results of static tests and dynamic tests on cylindrical workpieces. During static tests, Wager investigated a rectangular nozzle head $(0.2 \mathrm{~mm} \mathrm{x} 2.5 \mathrm{~mm})$ that utilized an anvil to maintain a stand-off distance of $20 \mu \mathrm{m}$ and found a linear relationship between the roughness of the surface and the gauge readings for roughnesses ranging from $3.8 \mu \mathrm{m}$ to $22.9 \mu \mathrm{m} \mathrm{R}$. Wagner slaimed that the dynamic tests were able to confirm that the motion of a smooth work sujface past the gauge nozzle had very little effect on the pneumatic gauging circuit. Dynıımic effects were only detected for surface serrations greater than $12.7 \mu \mathrm{m}(500 \mu \mathrm{in}$.$) and at surface speeds on the order of 30.5 \mathrm{~m} / \mathrm{sec}(100 \mathrm{ft} / \mathrm{sec})$. From 
M. A. Sc. Thesis McMaster University - Mechanical Engineering Drew A. Grandy

this work Wager concluded that in-process dynamic gauging for relatively slow-speed smooth surface applications is feasible and extended research is needed in this area. It should be noted however that the pressure transducer used for Wager's experiments was quite primitive and involved the use of a Sheffield single-column Precisionaire flow gauge. A device of this nature would not be able to pick up the dynamic effects clearly.

Further developments have been made in the area of offline pneumatic gauge to surface roughness neasurement by many different researchers. Wang and Hsu [4] experimentally validited the assumption that the pressure within the transducer chamber is evenly distributed and that the pressure outside of the nozzle is equal to atmospheric pressure. More recently, computational fluid dynamic (CFD) research has also been completed by Chew [28] in dynamic gauging to measure the thickness of soft deposit layers on solid surfaces immersed in liquid environments. These same results can be used to verify the continuous flow of air from a pneumatic gauging system establishing a criticism-free foundation for the theoretical equations on which all comparative models are computed. Wang and Hsu [4] have been able to successfully design and create a surface roughness rneasuring head utilizing an anvil length to maintain a constant stand-off distance. T jis anvil remains in contact with the surface while raising the nozzle tip of the pneumatic gauge to maintain the appropriate standoff distance. A schematic of such a device is presented in Figure 2.13 to illustrate the proposed technique. 

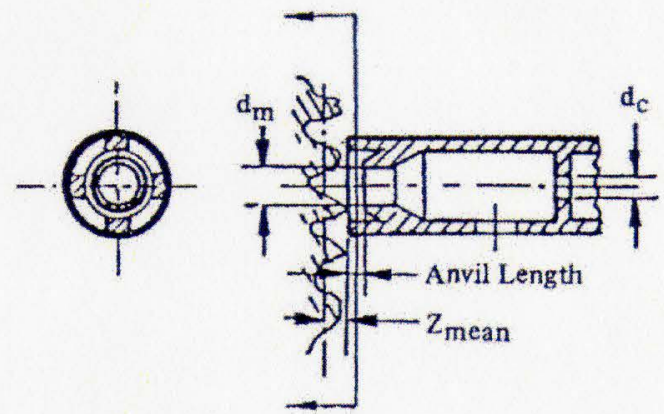

Figure 2.13: Schematic Illustrating Anvil Length [4]

The nozzle design presented from Wang and Hsu [4] can only be utilized for offline surface roughness measurements as the nozzle must be in contact with the workpiece. The anvil length ensures a spacing between the nozzle tip and the surface being measured, thus creating a reference for the back pressure signal to relate the roughness of the surface to the signal output. Some complications occurred while attempting to traverse the nozzle across the surface of a workpiece when chatter would occur caused by the input frequency from the surface and the mass of the nozzle. This was solved by adding mass to the nozzle; however this also increased the forces acting on the irregularities of the surface. Results obtained from this technique proved very reliable, repeatable, and accurate, however limited to very slow surface speeds of $6 \mathrm{~mm} / \mathrm{min}$. Signal processing techniques were then utilized to assess the frequency spectrum of the pressure signal and apply filters to create surface graphs. A comparison of the plot obtained from the pneumatic gauge and a stylus-type measuring system is shown in Figure 2.14. 
M. A. Sc. Thesis McMaster University - Mechanical Engineering Drew A. Grandy
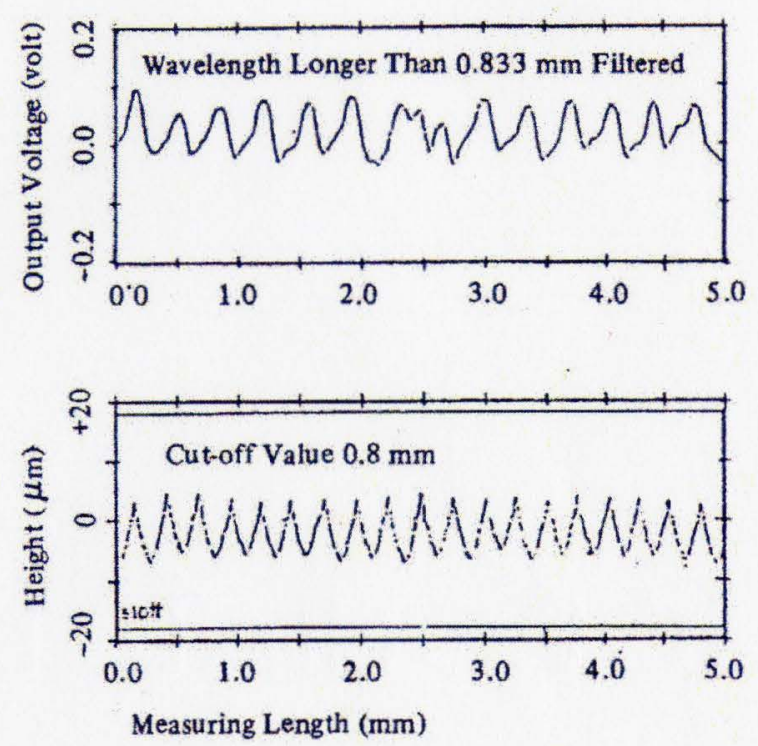

Figure 2.14: Comparison between Pneumatic (top) and Stylus (bottom) Measurements [4]

Variations of Wang and Hsu's design have been tested by several other researchers with similar results. Hamouda [29] developed a co-axial jet gauging system for surface roughness measurements. His design uses a primary and a secondary inlet air pressure where the secondary inlet pressure is greater than the primary inlet pressure. The jet is fed from the primary inlet pressure to the principal inner gauging nozzle which is surrounded with an annular coaxial shell fed by the secondary inlet pressure. By controlling both of the pressures independently, it was found that the sensitivity of the device could be varied to provide more accurate results. A schematic of this device is shown in Figure 2.15 where one can see how the anvil length is utilized to monitor the variation of pressure within the control chamber. 


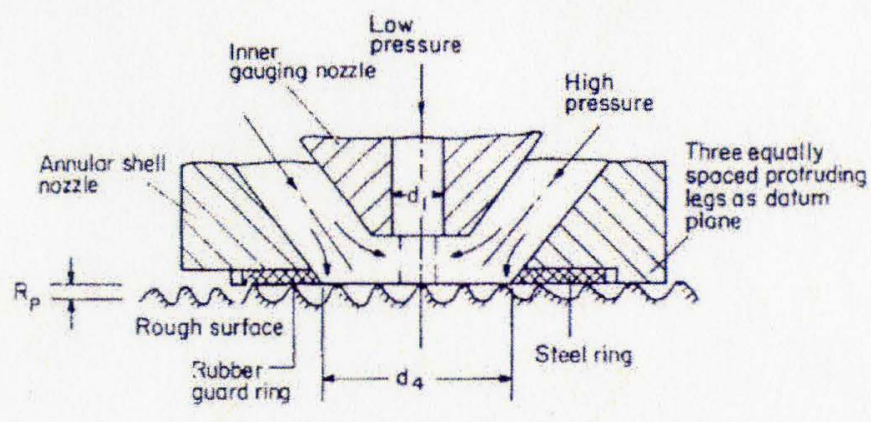

Figure 2.15: Co-axial Jet Gauging System [29]

Attempts to increase the sensitivity and investigate the effect of nozzle and orifice size as well as the traverse speed of the nozzle on the backpressure signals have been completed by Woolley [30]. Woolley's work uses very small nozzle diameters of $75 \mu \mathrm{m}$ and a control orifice diameter of $25 \mu \mathrm{m}$ resulting in an optimum stand-off distance of $1.17 \mu \mathrm{m}$ in order to detect $3 \mathrm{~mm}$ wide, $1.05 \mu \mathrm{m}$ deep grooves in a bearing thrust plate [30]. From his research he concluded that as the orifice size reduces, the sensitivity of the instrument increases however also decreasing the linear range of the instrument as would be expected from the equations (1.2) - (1.6) developed in Section 1.2. Figure 2.16 illustrates this effect, where (h) is the stand-off distance of the nozzle from the workpiece and $P_{d}$ is the pressure within the measuring chamber. 
M. A. Sc. Thesis McMaster University - Mechanical Engineering Drew A. Grandy

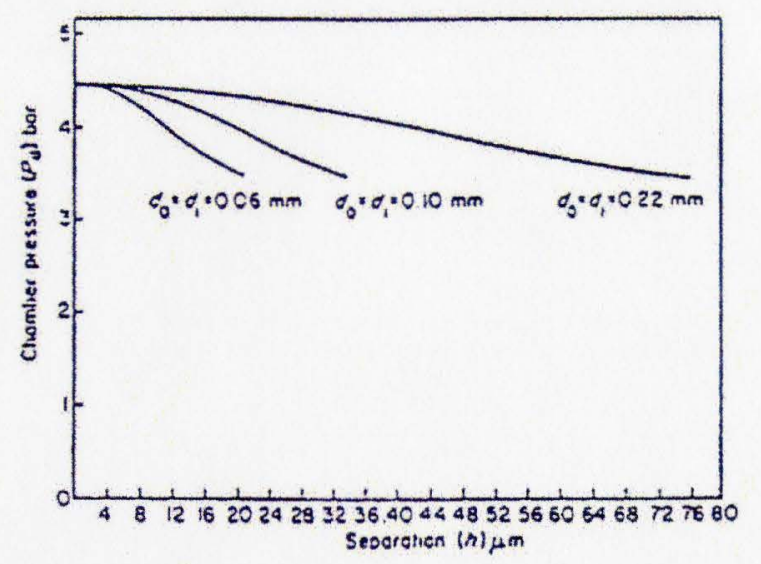

Figure 2.16: Effect of Orifice Size on Sensitivity [30]

It is clear that pneumatic gauging is capable of producing results similar to traditional stylus-type measurements; however more research must be done in order to create a system to be used for in-process measurement. All of the designs outlined above are limited to off-line measurement due to the requirement that parts of the nozzle must remain in contact with the workpiece, utilize stand-off distances that are unreasonable to implement into a machining center of in-situ measurements, and require surface speeds to be too slow for reasonable machining operations.

Recent developments in pneumatic gauging technology have lead to in-process measurement techniques to detect grinding wheel truing and dressing by monitoring hydrodynamic pressure $[31,32]$. These developments use the grinding fluid passing over the grinding wheel and measure pressure fluctuations to determine when the wheel requires dressing. Perhaps the most significant aspect of this research was the use of the frequency spectra to determine when the wheel needs to be dressed [32]. As the grinding 
M. A. Sc. Thesis McMaster University - Mechanical Engineering Drew A. Grandy progressed, researchers noticed that a frequency band within the spectra was rapidly changing in relation to the loading of the grinding wheel [32].

A review of currently available technologies for in-process surface roughness monitoring has been provided. Many of the problems associated with said technologies are a result of the devices being in contact with the measurement surface, the presence of foreign obstructions on the surface, slow surface speeds required for acquisition, and require control of displacements less than $2 \mu \mathrm{m}$ from the surface. All of these problems must be addressed ir order to implement a robust system into a machining center for online surface assessrnent. The preliminary work presented from the literature to monitor surfaces using pneumatic techniques will be used as a basis for the work presented in this thesis in order to develop a pneumatic system that can be incorporated into a machining center for in-process surface monitoring. 


\section{Chapter 3}

\section{Experimental}

The objectivs: of the work presented in this thesis is to develop a non-contact tool to monitor surfaces in-process using pneumatic techniques. Many of the systems reviewed in Chapter 2 have demonstrated the ability to characterize surfaces but are inappropriate for incorporation into a machining center due to the slow surface speeds required, small stanc-off distances, and features of the device requiring contact with the measured surface. This research is focused on developing a pneumatic system that is capable of assessing surfaces in-process while maintaining an adequate stand-off distance, is capable of characterizing surfaces at speeds similar to those used in machining operatiors, and is capable of withstanding the harsh environments in a machining center where cutting fluid and machining debris may be present.

The work has been split into two sections. The first is focused on the development of the pneumatic gauge and determining the range of roughness it is capable of detecting produced from diffesent machining operations. The second is to simulate an in-process monitoring application in a turning center where system parameters can be investigated to determine the operating envelope for typical parameters used during machining. Details on the equipment and techniques utilized to acquire and analyze the data are presented in this chapter. 


\section{A. Sc. Thesis McMaster University - Mechanical Engineering Drew A. Grandy}

\subsection{Experimental Set-up}

\subsubsection{Pneumatic Gauge}

The pneumatic system was created such that a number of parameters could be changed during testing to investigate their effects on the acquired signals in order to find the optimum set of parameters to acquire signals from the surfaces being measured. The body of the gauge was machined out of aluminum with access ports for the pressure transducer, supply line, and nozzle tip. Interchangeable attachments were also machined to allow the device to be mounted into a custom Electrical Discharge Machine (EDM) tool collet chuck as well as a turning center tool holder over the course of the experiments. Figure 3.1 displays the gauge set-up.

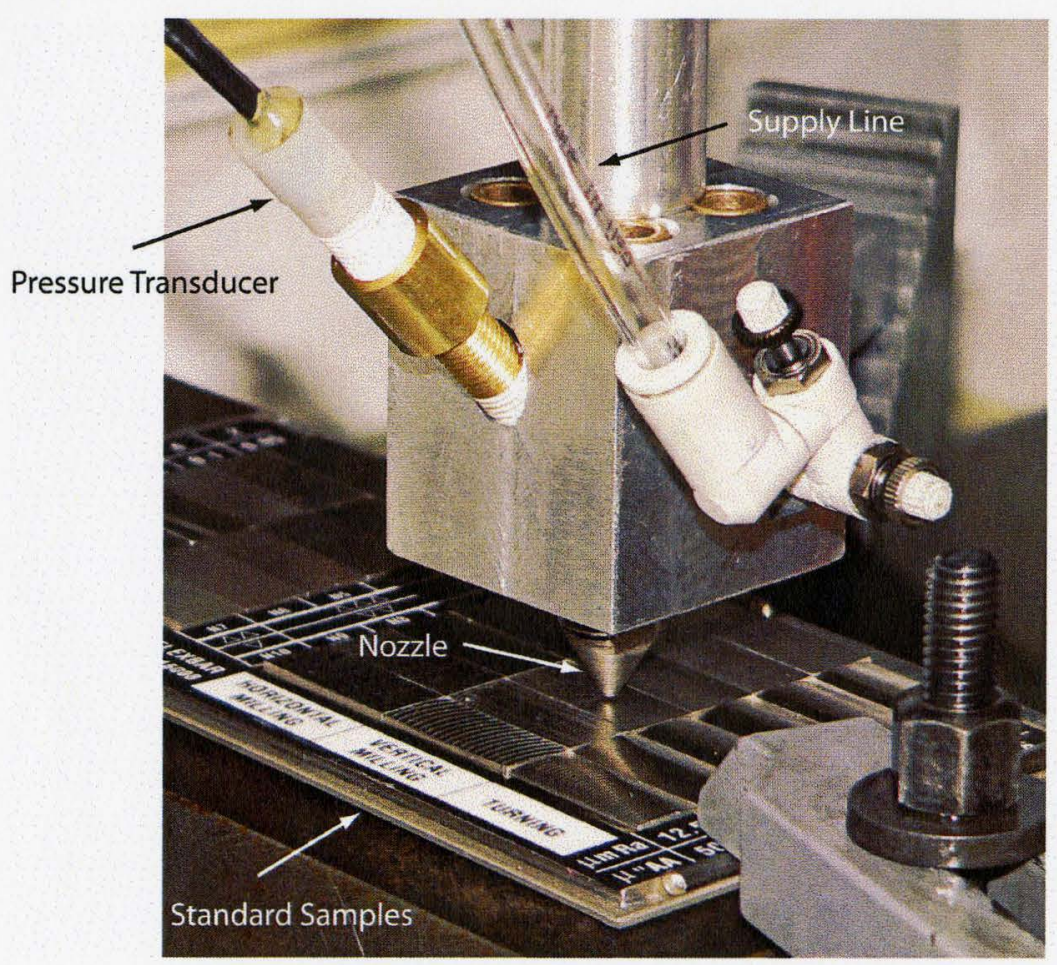

Figure 3.1: Pneumatic Gauge Set-Up 
M. A. Sc. Thesis McMaster University - Mechanical Engineering Drew A. Grandy

The pneumatic air line was filtered and then regulated using an Omega PRG101-60 to maintain a constant supply pressure to the system. The PRG101-60 can be regulated up to a pressure of $414 \mathrm{kPa}(60 \mathrm{psi})$ gauge and feeds the air through $6.34 \mathrm{~mm}$ (1/4 inch) PVC tubing into the main control volume through the control orifice. The control orifice is marufactured as an adapter from the supply line to the main body out of a 3/8-24 UNF bolt vihich was sealed to the body using a gasket and Teflon tape. Two different adapters were created having control orifice diameters of $0.825 \mathrm{~mm}$ and $0.51 \mathrm{~mm}$ to be used during testing.

The nozzle of the pneumatic gauge was originally created with a diameter of $1.5 \mathrm{~mm}$ as shown in Figure 3.1. The nozzle assembly was then adjusted to use a $1 / 4$ NPT to Luer-Loc adapter to accept stainless steel syringe tips to be utilized as nozzles once the bevels were removed from the needles. Adapting the assembly to accept needle tips provides a wide range of simple and accurate nozzle diameters to be used with the device during the experiments. The two nozzles used for testing were the $1.5 \mathrm{~mm}$ nozzle mentioned above and a 20 gauge needle with an inner nozzle diameter of $0.584 \mathrm{~mm}$.

\subsubsection{Machiines Used for Testing}

The two stą,es of experiments were performed in two different machining centers. The initial set-up was incorporated into an Agietron Impact 2 Ram EDM system with the focus on the development of the pneumatic gauging system. The EDM machine was selected for the tests involving the development of the gauging system due to its fine 
M. A. Sc. Thesis McMaster University - Mechanical Engineering Drew A. Grandy resolution. The EDM controller is capable of movements of $0.1 \mu \mathrm{m}$ increments, which is ideal for controlling the stand-off distance of the nozzle. Another advantage of the EDM is its ability to detect contact between two electrically conducting surfaces. Combining this feature and the ability to control motion within $0.1 \mu \mathrm{m}$, setting and controlling the stand-off distance could be done accurately.

The experiments completed on the EDM were conducted using a set of surface standards to ensure that the surfaces conform to industrial standards. A composite set of surface roughness standards that conform to S.A.E. and military specifications for visual and tactile inspection were used. The standard comparator is standardized to ANSI B46.1 and is accurate to within $\pm 10 \%$ of nominal values indicated excluding instrumental error. From these standards, the vertical milled and turned samples of $R_{a}$ values ranging between $12.5 \mu \mathrm{m}$ and $0.4 \mu \mathrm{m}$ were used as well as ground surfaces with $\mathrm{R}_{\mathrm{a}}$ values ranging between $1.6 \mu \mathrm{m}$ and $0.05 \mu \mathrm{m}$. Figure 3.2 is of the FLEXBAR surface standard implemented for these experiments. Physical characterization of these surfaces from a formtracer is also provided in Section 4.1. 


\section{A. Sc. Thesis McMaster University - Mechanical Engineering Drew A. Grandy}

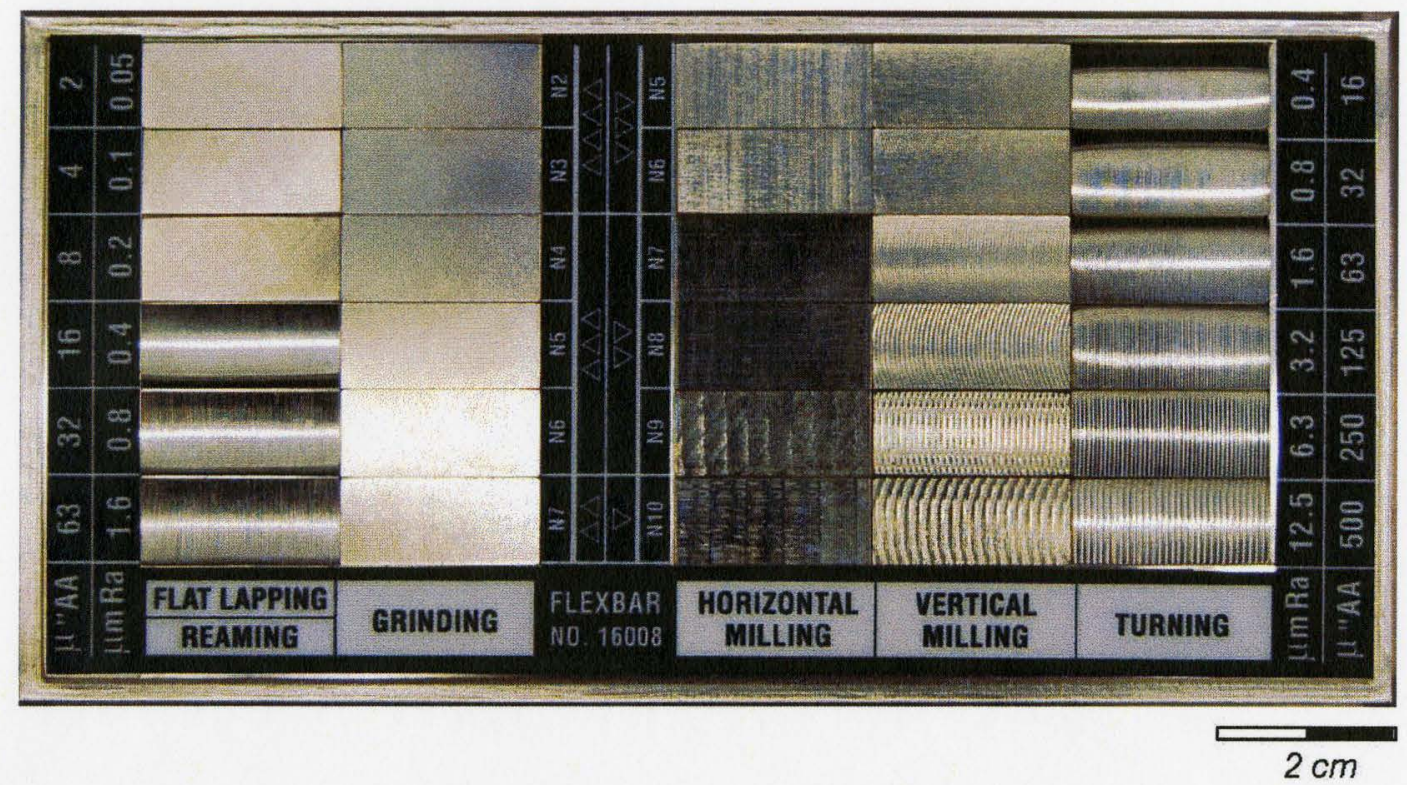

Figure 3.2: FLEXBAR Surface Standard Set

The second set of experiments was conducted in a Boehringer VDF180 turning center to simulate an in-process monitoring application. The pneumatic gauging system developed in stage one of the research was adapted to fit in a standard tool holder to allow the machine controller to control the motion of the device. The workpiece used for surface characterization was a Jominy bar turned using a constant feed rate. The important characteristic of a Jominy bar is that a continuously changing hardness occurs over the length of the sample which results in a change of roughness over the length of the bar once it is machined. The sample is discussed in further detail in Section 4.4.1. The apparatus used for these experiments is displayed in Figure 3.3. 


\section{A. Sc. Thesis McMaster University-Mechanical Engineering Drew A. Grandy}

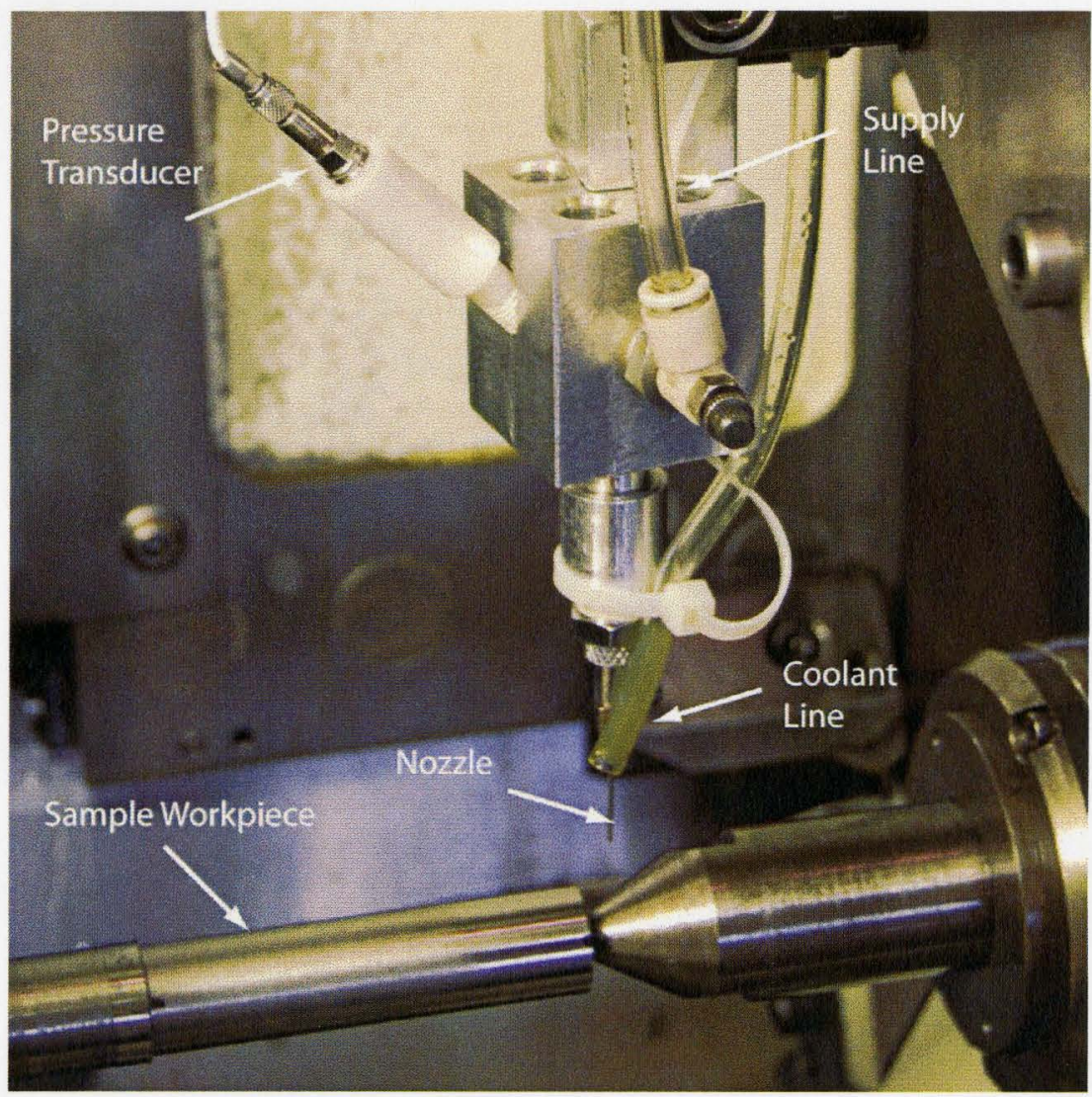

Figure 3.3: Pneumatic Gauge in a Turning Center

\subsection{Experimental Procedure}

Throughout the experiments performed, severable variables and hardware were changed to examine their effects on acquiring accurate backpressure signals to distinguish surface characteristics. Parameters pertaining to the development of the pneumatic gauging system were investigated while the gauging apparatus was set-up in the EDM to determine the optimum parameters to use during the in-process simulation in the turning center. System parameters related to the cutting operations were varied in the lathe experiments to find the limitations and the operating envelope of the developed 
M. A. Sc. Thesis McMaster University - Mechanical Engineering Drew A. Grandy gauging system. This section will outline the variables changed during each stage of experiments as they will be presented in Chapter 4 .

\subsubsection{Pneumatic Gauge Development}

The parameters investigated during the development of the pneumatic gauge were the pressure transducer type and sensitivity, nozzle and control orifice diameters, and supply pressure. The two sensors tested in these experiments were a microphone and a piezoelectric pressure transducer. Details of these two sensors are provided in the discussion of the results in Chapter 4. All of the backpressure signals were acquired using a nozzle feed rate of $400 \mathrm{~mm} / \mathrm{min}$ at a stand-off distance of $50 \mu \mathrm{m}$ determined by the optimum stand-off distance calculated from equation (1.5) of Chapter 1, using the appropriate nozzle and control orifice combinations. Further details will be found in the appropriate sections of the Results and Discussion in Chapter 4.

Once the gaugge had been developed and optimized, characterization of different surfaces could begir. This process used three sets of standard roughness samples containing six roughriesses each. A vertical milled and a turned set of standards having roughnesses ranging trom $12.5 \mu \mathrm{m}$ down to $0.4 \mu \mathrm{m} \mathrm{R}_{\mathrm{a}}$ and a ground set of standards with roughness ranging from $1.6 \mu \mathrm{m}$ down to $0.05 \mu \mathrm{m} \mathrm{R}_{\mathrm{a}}$ were used for these experiments. These surfaces were all characterized physically using a Mitutoyo CS-5000 Formtracer and then compared to the pneumatic backpressure characterization to determine the application envelope and limitations of the pneumatic gauge. 
M. A. Sc. Thesis McMaster University - Mechanical Engineering Drew A. Grandy

\subsubsection{In-process Simulation}

The in-procesis simulation experiments focus on determining the effects of the process on the backpressure signals and finding the limits at which the developed system is capable of operating. To do this, the tests began by using a stationary workpiece while feeding the nozzle across the surface in order to relate the signals back to those acquired on the EDM. The Joniny sample has a roughness range from $1.1 \mu \mathrm{m}$ to $6.8 \mu \mathrm{m} \mathrm{R}_{\mathrm{a}}$. On the stationary workpiece tests, the effects of nozzle feed rate are investigated to find the optimum operational range.

Following the stationary tests, signals were acquired from a rotating workpiece with the nozzle stationary as well as fed along the surface of the sample. Many parameters such as stınd-off distance, workpiece surface speed, nozzle feed rate, supply pressure, and locatior. along the bar were varied again to find the allowable operating envelope of the developed gauging system. Lastly, cutting fluid was introduced to the workpiece in the form of a jet aimed directly at the location of the pneumatic gauging nozzle to determine if the compressed air is capable of evacuating the coolant from the surface of the workpiece while still being able to characterize the surface of the Jominy bar.

\subsubsection{Data A:quisition and Analysis}

All backpressure signals acquired from the experiments outlined above were acquired using a National Instruments data acquisition system coupled with LabView software. Specifications for the data acquisition system are provided in Table 3.1. 
M. A. Sc. Thesis McMaster University - Mechanical Engineering Drew A. Grandy

Multiple signals were acquired for each roughness sample in order to investigate any variability that might occur between signals taken from the same surface. All data analysis was handled using Matlab and a developed script to breakup and filter the signals, take the Fast Fourier Transforms (FFT), and plot the pressure signals and frequency spectrum.

Table 3.1: Data Acquisition System Specifications

\begin{tabular}{l|l}
\hline \multicolumn{1}{c|}{ Component } & \multicolumn{1}{c}{ Details } \\
\hline PC Specifications & $\begin{array}{l}\text { AMD X2 Processor } \\
2 \text { GB Ram } \\
4 \times 250 \text { GB WD Hard drive in RAID-0 }\end{array}$ \\
Data Acquisiticn Card & $\begin{array}{l}\text { National Instruments PCI-6115, 64MS onboard memory } \\
4 \text { Channel Simultaneous Sampling } \\
10 \mathrm{MS} / \mathrm{s} \text { Max Sampling Rate }\end{array}$ \\
Sampling Rate & $\begin{array}{l}20 \mathrm{kHz} \\
\text { Software }\end{array}$ \\
& $\begin{array}{l}\text { LabView 8.2 } \\
\text { DAQMx 8.2 Hardware Drivers }\end{array}$ \\
\hline
\end{tabular}

All of the backpressure signals have been filtered using a third order Butterworth infinite impulse response (IIR) high pass filter with a cut-off frequency of $5 \mathrm{~Hz}$. It was decided to filter the signal below $5 \mathrm{~Hz}$ in order to minimize pressure fluctuations caused by waviness and any dynamic effects introduced from the pressure transducer. All of the pressure signals were normalized to the same length equivalent to a sample length of ten seconds. These samples were then run through a script to take the FFT averaging the results across five windows using the Hamming window type to obtain information in the 
M. A. Sc. Thesis JMcMaster University - Mechanical Engineering Drew A. Grandy frequency domain. Dominant frequencies and corresponding amplitudes were then acquired from the frequency domain to be used during surface characterization.

Further details for all of the experiments performed are provided in appropriate sections of Chapter 4. 


\section{Chapter 4}

\section{Results and Discussion}

The goal of this research was to develop and optimize a non-contact system that can be used to characterize and monitor the roughness of a moving surface for real world in-process applications. As shown in Figure 4., the developed device can provide a direct representation of the measured surface in both the physical and frequency domains. This system is capable of distinguishing different surface topographies, ie. a surface created from a milling process versus a surface created in a turning process with the same $R_{a}$ value, able to characterize surfaces with roughnesses as low as $0.8 \mu \mathrm{m} \mathrm{R}_{\mathrm{a}}$, and is impervious to obstructions on the surface such as debris and cutting fluid. The approach used to develop and test the limitations of the device is illustrated in Figure 4.2 as a flowchart.
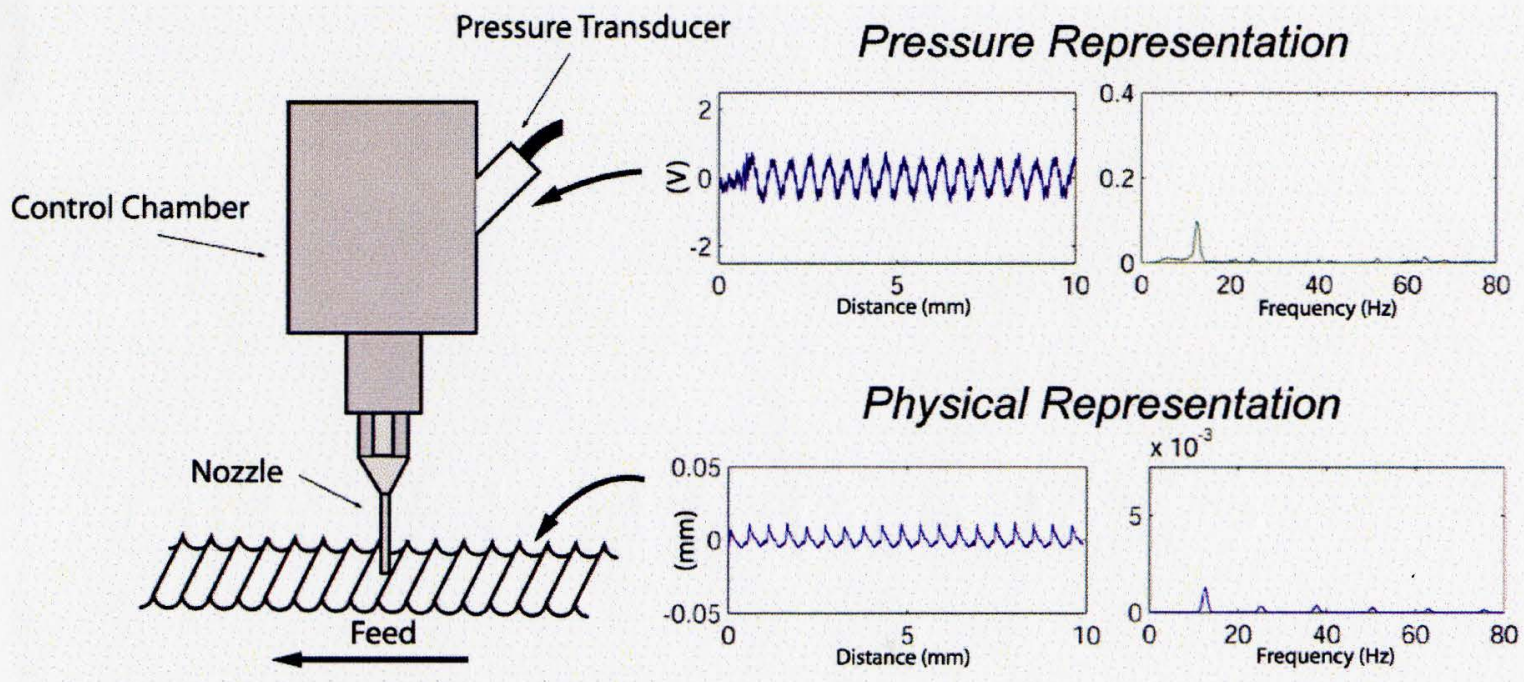

Figure 4.1: Schematic of Surface Characterization using Pneumatic Techniques 
M. A. Sc. Thesis McMaster University - Mechanical Engineering Drew A. Grandy

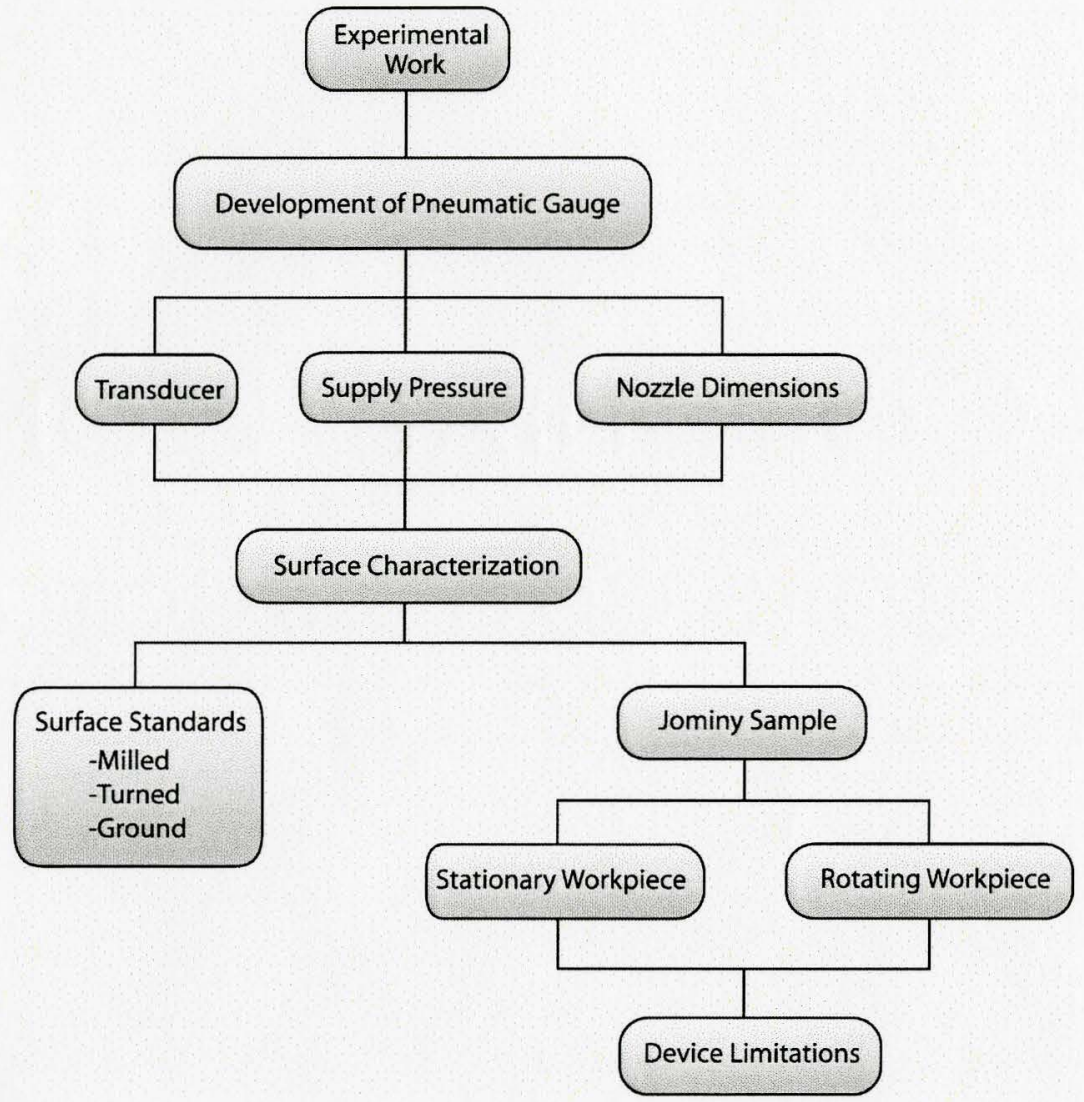

Figure 4.2: Flowchart Outlining the Experimental Results Presented in Chapter 4

\subsection{Analysis of Surface Standards Using Tactile Measurement}

In order to assess the capabilities of the developed device, an analysis of the surfaces that the device will be measuring was done. For these experiments, the FLEXBAR surface standard set was used as described in Section 3.1 to ensure that all of the surfaces conform to industrial standards. In this section, these surfaces will be analyzed using a stylus measurement system for comparison to the pressure signals presented in Section 4.3. 
M. A. Sc. Thesis McMaster University - Mechanical Engineering Drew A. Grandy

4.1.1 Milled Surface Standard

Tactile measurements acquired using a stylus has been the industry standard for characterizing surfaces and their roughnesses for many years. Therefore, to obtain the physical topography and other parameters from these standards, stylus measurements were taken and analyzed for each surface using a Mitotoyo Formtracer CS-5000. All stylus measurements were taken using the parameters outlined in Table 4.1. A cut-off length of $2.5 \mathrm{~mm}$ is used for roughness greater than $2 \mu \mathrm{m} \mathrm{R} \mathrm{R}_{\mathrm{a}}$ and $0.8 \mathrm{~mm}$ for roughness below $2 \mu \mathrm{m} R_{\mathrm{a}}$ as sug gested in Whitehouse [1].

Table 4.1: Stylus Measurement Parameters

\begin{tabular}{|c|c|c|c|}
\hline \multicolumn{2}{|c|}{ Stylus Parameters } & \multicolumn{2}{|c|}{ Acquisition Parameters } \\
\hline Length of Tip: & $6.5 \mathrm{~mm}$ & Measurement Speed: & $0.1 \mathrm{~mm} / \mathrm{sec}$ \\
\hline Tip Materıal: & Diamond & Measurement Pitch: & $1 \mu \mathrm{m} / \mathrm{sample}$ \\
\hline Tip Form: & $40^{\circ}$ Cone & Measurement Length: & $18 \mathrm{~mm}$ \\
\hline Radius of 'Tip: & $5 \mu \mathrm{m}$ & Cut-off Length: & $2.5 \mathrm{~mm} / 0.8 \mathrm{~mm}$ \\
\hline
\end{tabular}

Once the stylus measurements were acquired, they were then converted into the time domain assuming a feed rate of $400 \mathrm{~mm} / \mathrm{min}$ and the FFT was taken to gain information into the f:equency domain. Converting the signals into the time domain by assuming a feed rate of $400 \mathrm{~mm} / \mathrm{min}$ was done to allow direct comparison to the pneumatic signals acquired from these standards at a feed rate of $400 \mathrm{~mm} / \mathrm{min}$. 
M. A. Sc. Thesis McMaster University - Mechanical Engineering Drew A. Grandy

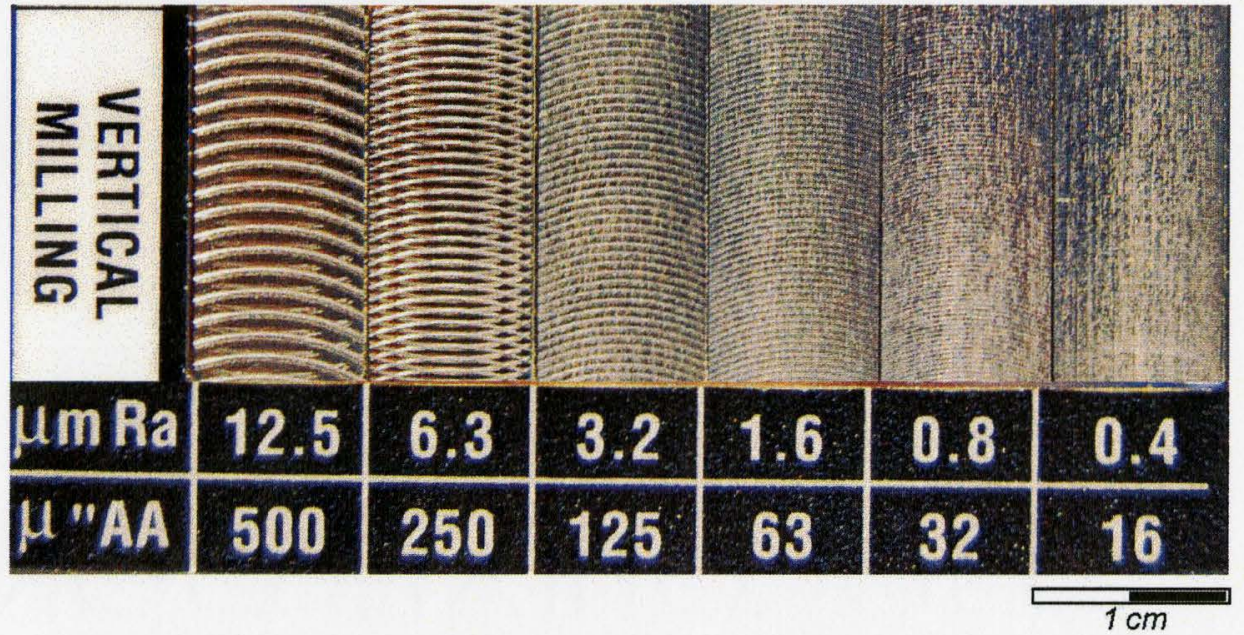

Figure 4.3: Vertical Milled Surface Standards
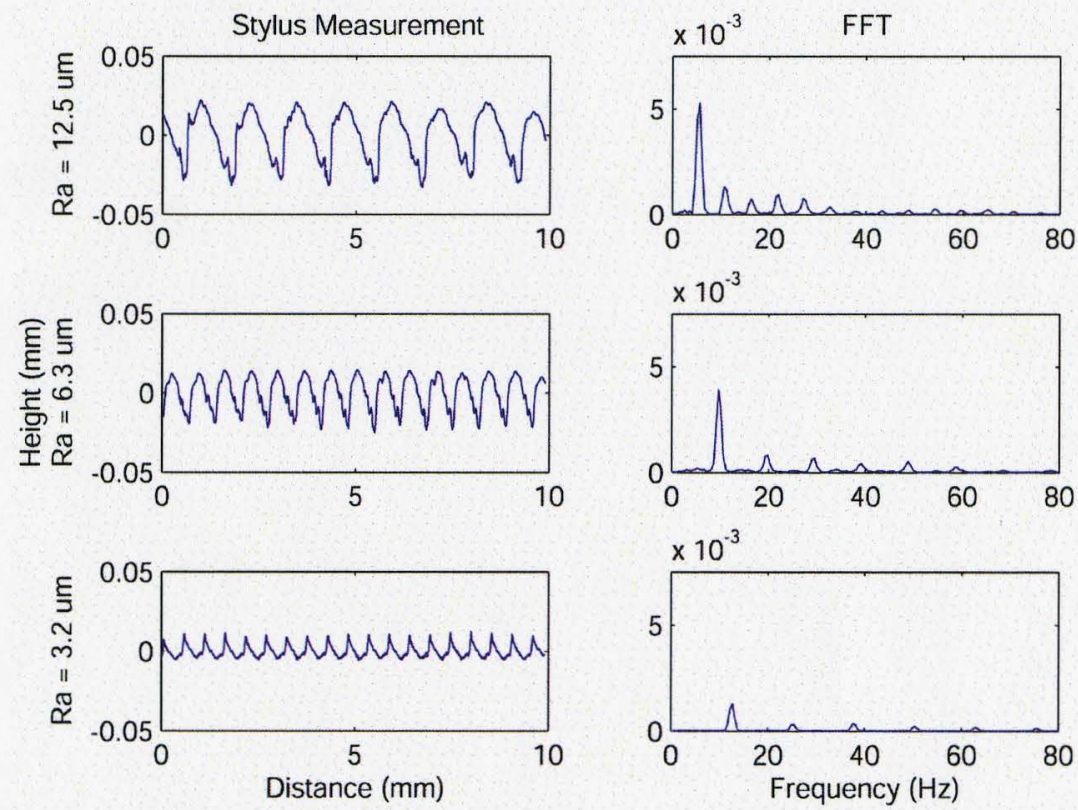

Figure 4.4: Stylus Measurements from Milled Standards (12.5-3.2 $\left.\mu m R_{a}\right)$ 

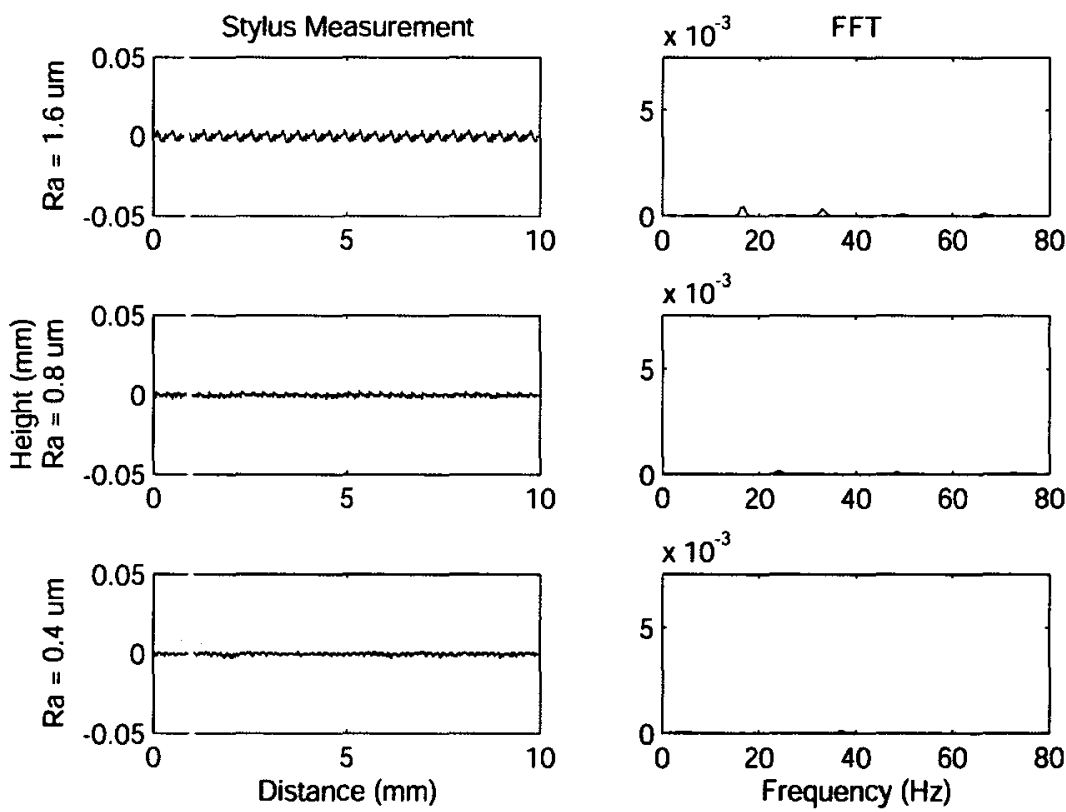

Figure 4.5: Stylus Measurements from Milled Standards (1.6-0.4 $\left.\mu m R_{a}\right)$

As seen in Figures 4.4 and 4.5, there are distinct characteristics for each of the surfaces. The $12.5 \mu \mathrm{m}$ and $6.3 \mu \mathrm{m} \mathrm{R}_{\mathrm{a}}$ samples have a negative skewness compared to the surfaces with lower rcughnesses, as well as evidence of back cutting on the trailing edge. On the $3.2 \mu \mathrm{m} R_{a}$ sample and smaller, the skewness becomes more positive with a decreasing peak to valley distance. Further distinguishing characteristics can be found in the frequency domair where the dominant frequency increases while the amplitude at these frequencies is $d \epsilon$ creasing for smaller $R_{a}$ values as would be expected when a slower feed rate is used to criate smoother surfaces. Table 4.2 outlines the calculated $R_{a}$ values and corresponding dominant frequencies that have been calculated using a feed rate of $400 \mathrm{~mm} / \mathrm{min}$. 
M. A. Sc. Thesis McMaster University - Mechanical Engineering Drew A. Grandy

Table 4.?: Calculated $R_{a}$ values and Dominant Frequencies for Milled Standards

\begin{tabular}{|c|c|c|c|}
\hline $\begin{array}{c}\text { Standard } \\
R_{a} \\
(\mu \mathrm{m})\end{array}$ & $\begin{array}{c}\text { Cutoff } \\
\text { Length } \\
(\mathrm{mm})\end{array}$ & $\begin{array}{c}\text { Calculated } \\
R_{a} \\
(\mu \mathrm{m})\end{array}$ & $\begin{array}{c}\text { Dominant } \\
\text { Frequency } \\
(\mathrm{Hz})\end{array}$ \\
\hline 12.5 & 2.5 & 13.4 & 5.34 \\
\hline 6.3 & 2.5 & 9.5 & 9.66 \\
\hline 3.2 & 2.5 & 3.2 & 12.46 \\
\hline 1.6 & 0.8 & 1.5 & 16.54 \\
\hline 0.8 & 0.8 & 0.7 & 24.16 \\
\hline 0.4 & 0.8 & 0.5 & 37.13 \\
\hline
\end{tabular}

It should also be noted that the amplitude of the FFT for the $R_{a}$ values of $0.8 \mu \mathrm{m}$ and $0.4 \mu \mathrm{m}$ are very low as well as the peak to valley distance of the stylus measurement when compared to the higher roughness. This will be used to identify the limitations of the pneumatic device to determine the range of roughnesses which can be clearly identified using pneunatic techniques.

\subsubsection{Turned Surface Standards}

Similar to the milled standards, the same assessment was done for the stylus measurements of the urned standards. Again the frequency domain was realized by the same conversion to the time domain assuming a feed rate of $400 \mathrm{~mm} / \mathrm{min}$ across the surface and then taking the FFT of the signal. 


\section{A. Sc. Thesis McMaster University - Mechanical Engineering Drew A. Grandy}

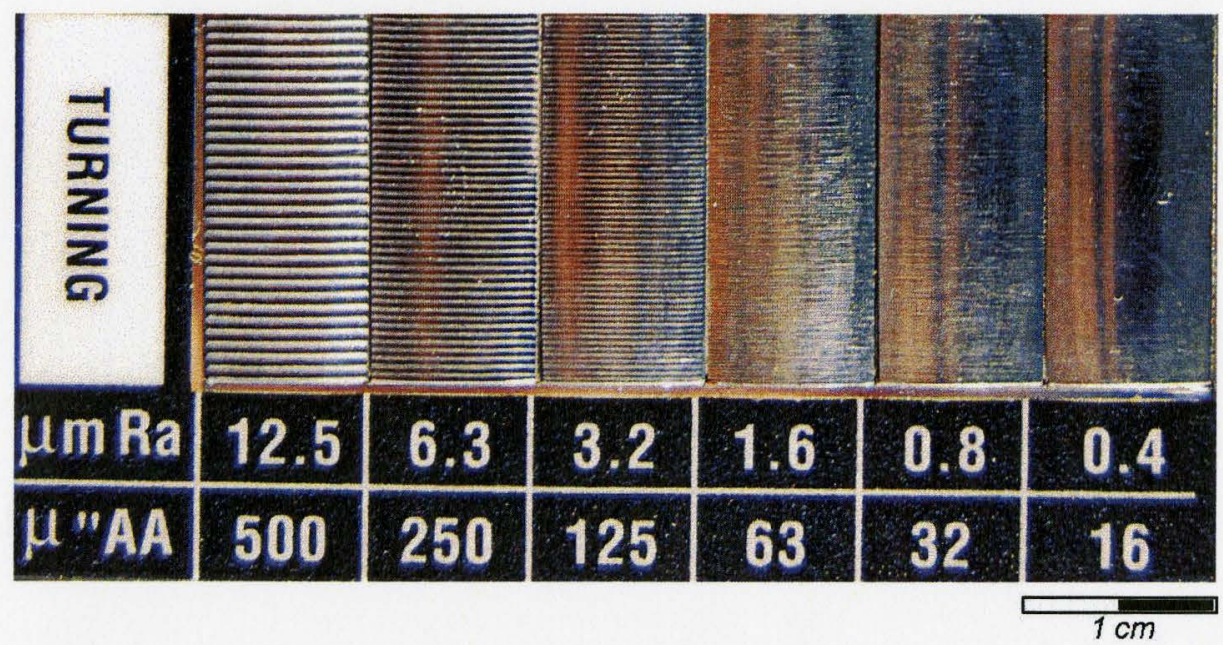

Figure 4.6: Turning Surface Standards
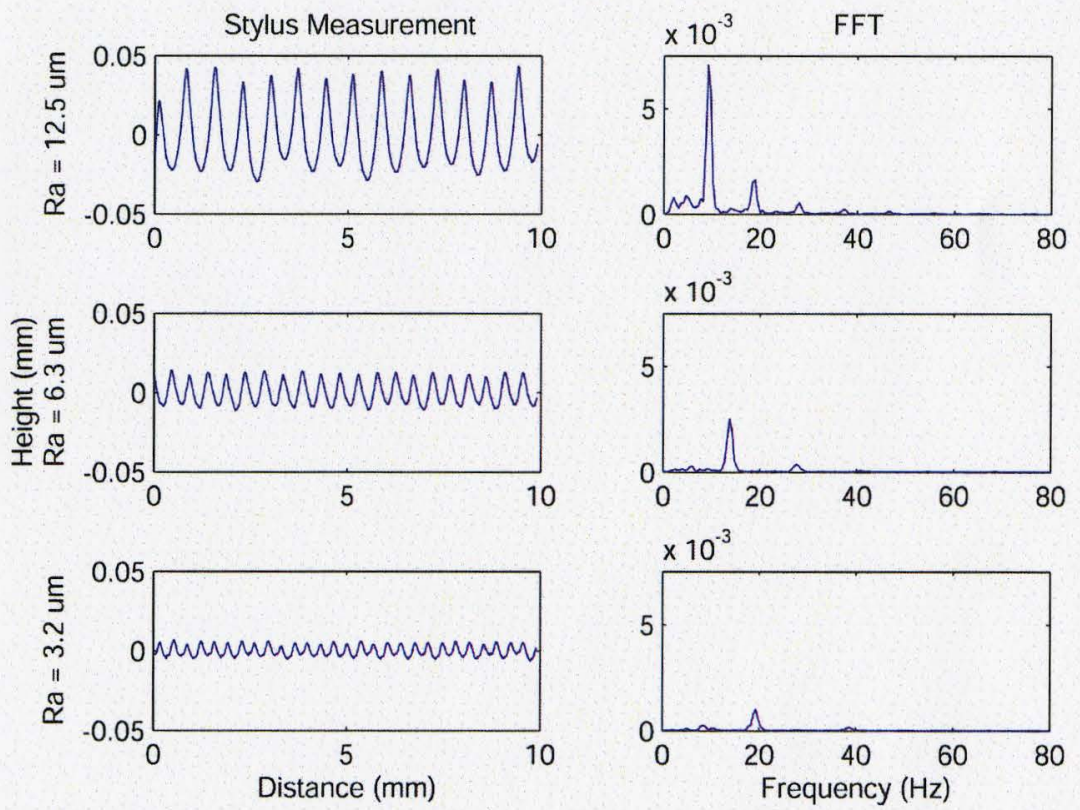

Figure 4.7: Stylus Measurements from Turned Standards (12.5-3.2 $\left.\mu \mathrm{m} R_{a}\right)$ 
M. A. Sc. Thesis McMaster University - Mechanical Engineering Drew A. Grandy
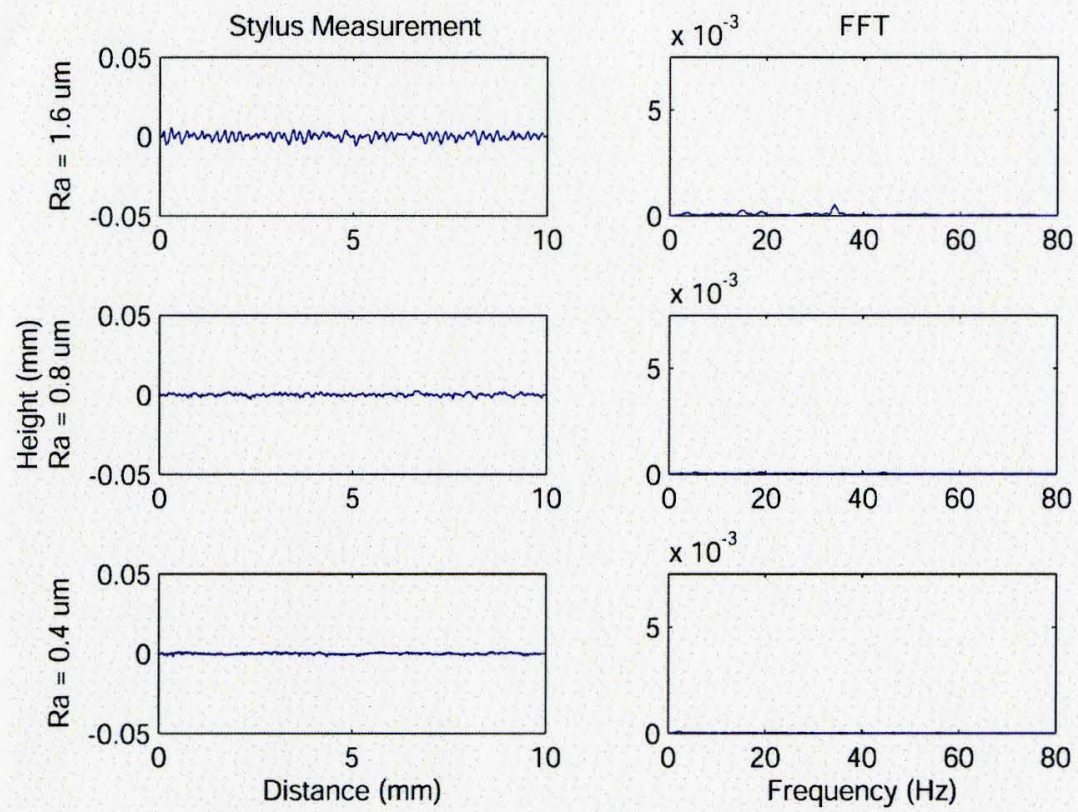

Figure 4.8: Stylus Measurements from Turned Standards (1.6-0.4 $\mu m R_{a}$ )

Perhaps the most interesting characteristic when comparing the turned standards to the milled standards is how the surfaces differ for the same $R_{a}$ values. In the higher $R_{a}$ values such as $12.5 \mu \mathrm{m}$ and $6.3 \mu \mathrm{m} \mathrm{R}_{\mathrm{a}}$, we can see that the peaks of the cusps created from the cutting tool are much more positively skewed and have a larger peak to valley distance than those of the milled standard. In the frequency domain, these surfaces have been created using a higher feed rate resulting in a higher dominant frequency when compared to the milled standards of the same $R_{a}$ value.

For the turned standards of $1.6 \mu \mathrm{m}$ to $0.4 \mu \mathrm{m} \mathrm{R}_{\mathrm{a}}$ shown in Figure 4.9 with an increased scale for the frequency domain, we can observe that the surfaces begin to include more frequency content with similar amplitudes to the dominant frequency 
M. A. Sc. Thesis McMaster University - Mechanical Engineering Drew A. Grandy caused by the feed rate of the cutting tool used to generate the surface conceivable due to ploughing effects. This is very apparent in the $1.6 \mu \mathrm{m}$ sample where the surface has higher frequency components as well as the lower frequency components as shown in Figure 4.9 by observing the frequency domain beside the stylus measurement. For the 0.8 $\mu \mathrm{m} \mathrm{R}_{\mathrm{a}}$ and $0.4 \mu \mathrm{m} \mathrm{R}_{\mathrm{a}}$ turned samples, it becomes very difficult to distinguish a dominant frequency within the surface and as a result, it will be a difficult task to verify the findings from the pneumatic gauge for these standards.
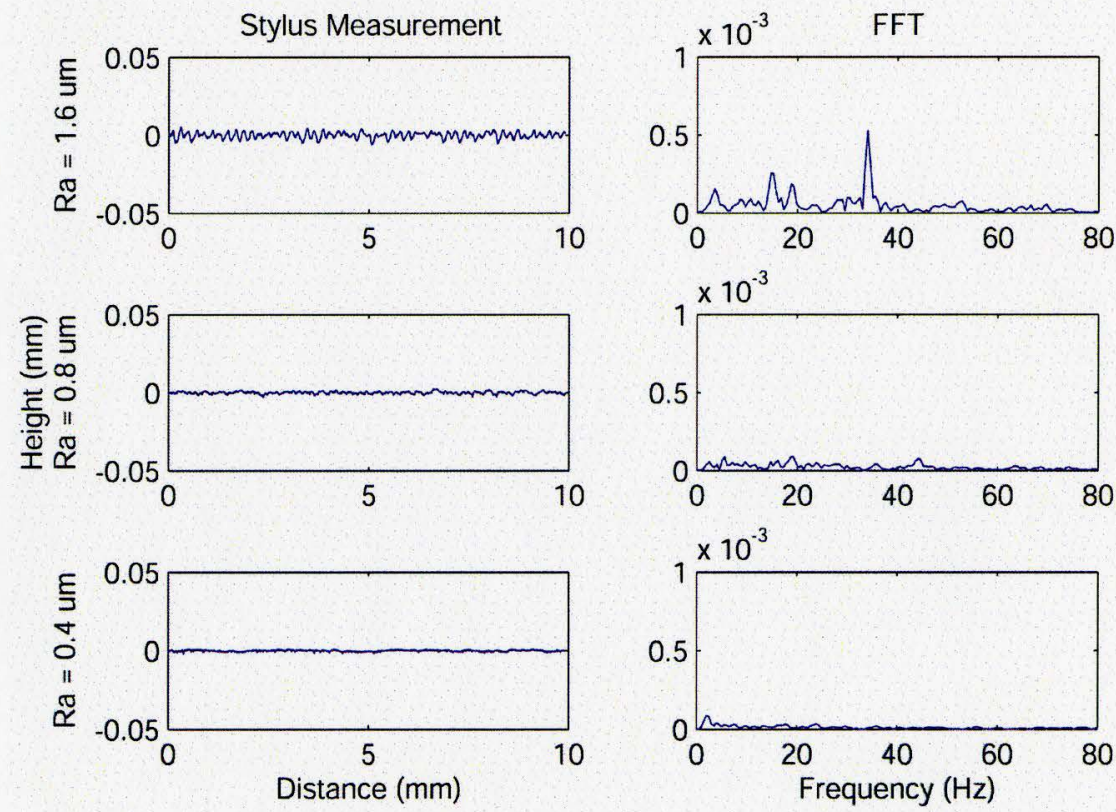

Figure 4.9: Highlighted Frequency Domain for Stylus Measurements from Turned Standards (1.6-0.4 $\left.\mu m R_{a}\right)$ 
M. A. Sc. Thesis McMaster University - Mechanical Engineering Drew A. Grandy

Table 4.3: Calculated $R_{a}$ values and Dominant Frequencies for Turned Standards

\begin{tabular}{|c|c|c|c|}
\hline $\begin{array}{c}\text { Sample } \\
R_{a} \\
(\mu \mathrm{m})\end{array}$ & $\begin{array}{c}\text { Cutoff } \\
\text { Length } \\
(\mathrm{mm})\end{array}$ & $\begin{array}{c}\text { Calculated } \\
R_{a} \\
(\mu \mathrm{m})\end{array}$ & $\begin{array}{c}\text { Dominant } \\
\text { Frequency } \\
(\mathrm{Hz})\end{array}$ \\
\hline 12.5 & 2.5 & 17.7 & 9.15 \\
\hline 6.3 & 2.5 & 6.4 & 14.24 \\
\hline 3.2 & 2.5 & 2.7 & 19.33 \\
\hline 1.6 & 0.8 & 1.6 & 33.57 \\
\hline 0.8 & 0.8 & 0.6 & NA \\
\hline 0.4 & 0.8 & 0.4 & NA \\
\hline
\end{tabular}

\subsubsection{Ground Surface Standards}

To identify the operating envelope of the pneumatic system, the ground standards were used from the FLEXBAR standard sample. These samples have $R_{a}$ values of $1.6 \mu \mathrm{m}, 0.8 \mu \mathrm{m}, 0.4 \mu \mathrm{m}, 0.2 \mu \mathrm{m}, 0.1 \mu \mathrm{m}$, and $0.05 \mu \mathrm{m}$. Again, the ground samples were analyzed in a similar fashion to the previous standards in order to have the stylus measurement as well as the FFT for the frequency domain. As expected, the magnitudes in the frequency dornain are much smaller than those found on the milled and turned surfaces, and have been displayed with a scale that is an order of magnitude smaller. 
M. A. Sc. Thesis McMaster University-Mechanical Engineering Drew A. Grandy

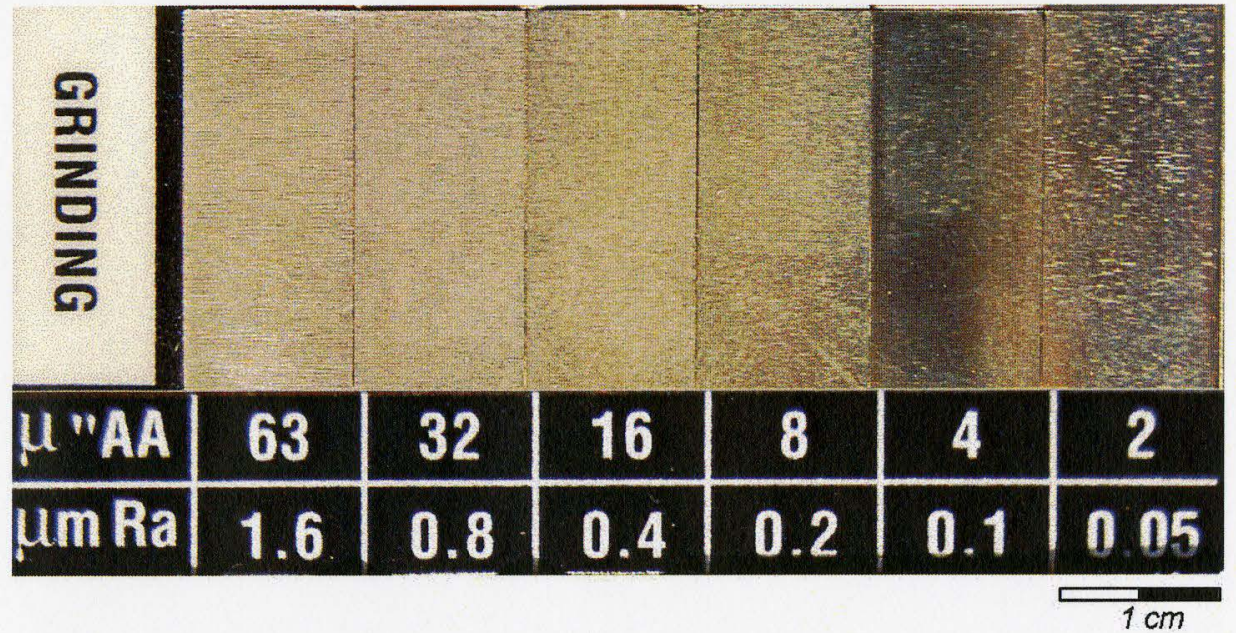

Figure 4.10: Ground Surface Standards
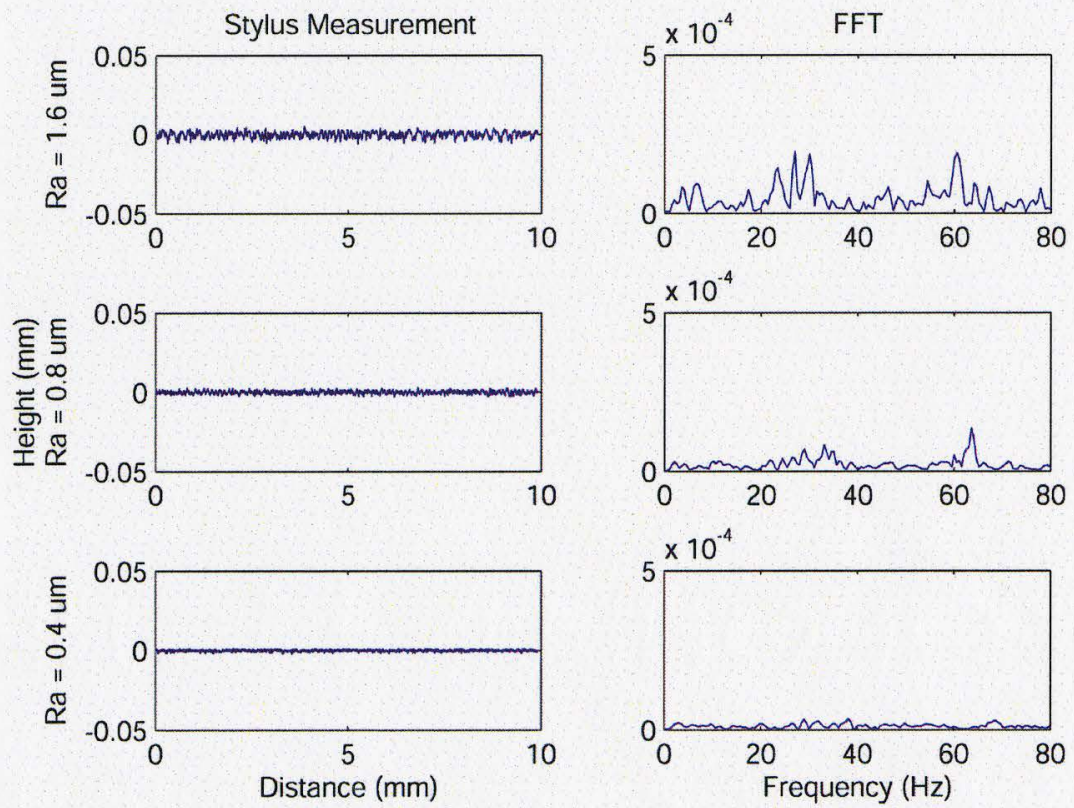

Figure 4.11: Stylus Measurements from Ground Standards (1.6-0.4 $\left.\mu m R_{a}\right)$ 


\section{A. Sc. Thesis McMaster University - Mechanical Engineering Drew A. Grandy}
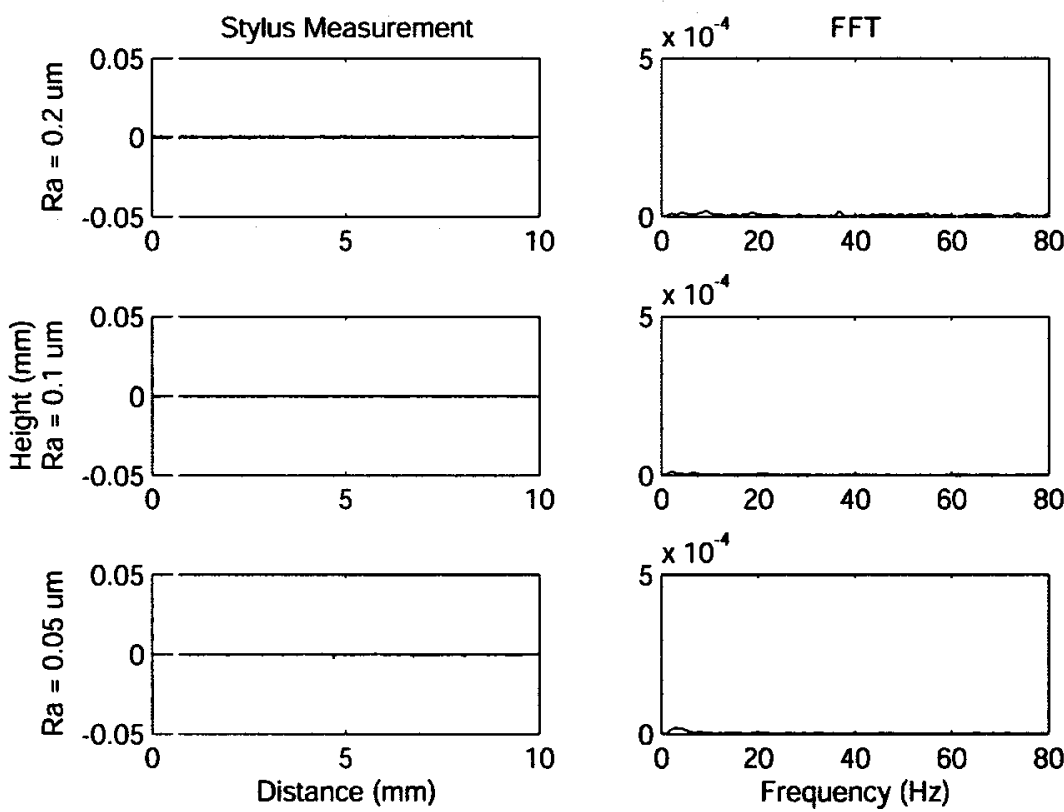

Figure 4.12: Stylus Measurements from Ground Standards $\left(0.2-0.05 \mu m R_{a}\right)$

From Figures 4.11 and 4.12 it can be seen that there are no dominant frequencies on the surface. Instead there is a larger combination of frequencies which define these surfaces. Due to the small $R_{a}$ values and the combination of frequencies that make up the ground surfaces in grinding, and as tools do not have defined cutting edges like in turning and milling, it becornes very difficult to characterize these samples through comparison of the dominant frequencies and their magnitudes.

\subsection{Development of Pneumatic Gauge for Surface Roughness Assessment}

During the course of this research, the design and optimization of the pneumatic gauge was conducted with the goal of characterizing surfaces using non-contact methods. Variables such as the influence of the type and sensitivity of the pressure transducer, 
M. A. Sc. Thesis McMaster University - Mechanical Engineering Drew A. Grandy

nozzle diameter, control orifice diameter, and supply pressure have been investigated in order to optimize the system for the analysis of different surfaces. By adjusting these parameters and analyzing the results we are able to verify the theory that has been outlined in Section 1.2, where the basic principles of the pneumatic gauge were discussed, and validate our findings when relating these results to the actual surfaces being measured.

\subsubsection{Pressure Transducer Comparison}

The pressure transducer is a very critical element of the pneumatic roughness assessment system. With a transducer that is inappropriate for the sensitivity and frequency response of the sensor, the results will not represent the back pressure fluctuations created by the moving surface accurately. For this reason, it is important to match the transducer capabilities to the expected results from the pneumatic system. For comparison, two different transducers were utilized and the results were analyzed to determine the better suited transducer to match the sensitivity of the developed pneumatic gauge. An omni-directional electret microphone capsule was selected for the initial experiments and then compared to the results obtained using a piezoelectric pressure transducer. The microphone is a Sennheiser KE 4-211-8 electret microphone capsule with a frequency response of $20 \mathrm{~Hz}$ to $20 \mathrm{kHz}$ and a sensitivity of $6.3 \mathrm{mV} / \mathrm{Pa}$. The piezoelectric pressure transducer is a PCB ICP Dynamic Pressure Sensor Model 112A22 with a low frequency response of $0.5 \mathrm{~Hz}$ and a sensitivity of $0.0145 \mathrm{mV} / \mathrm{Pa}$ 
M. A. Sc. Thesis McMaster University - Mechanical Engineering Drew A. Grandy

$(14.5 \mathrm{mV} / \mathrm{kPa})$. The :echnical data sheets for both sensors can be found in Appendix A for additional information.

For these tests, the parameters for the pneumatic sensor presented in Table 4.4 were used along with the milled standard samples from the FLEXBAR surface standards where $D_{n}$ is the nozzle diameter, $D_{c}$ is the control orifice diameter, $P_{s}$ is the supply pressure, $\mathrm{K}_{\mathrm{s}}$ is the sensitivity of the sensor, SOD is the stand-off distance of the nozzle, F is the feed rate of the system, and $\mathrm{V}$ is the approximate volume of the variable pressure chamber.

Table 4.4: Pressure Sensor Comparison Experiment Parameters

\begin{tabular}{|c|c|}
\hline Dn & $1.5 \mathrm{~mm}$ \\
\hline Dc & $0.825 \mathrm{~mm}$ \\
\hline Ps & $69 \mathrm{kPa}(10 \mathrm{psi})$ \\
\hline Ks & $0.395 \mathrm{kPa} / \mu \mathrm{m}$ \\
\hline SOD & $50 \mu \mathrm{m}$ \\
\hline F & $400 \mathrm{~mm} / \mathrm{min}$ \\
\hline V & $300 \mathrm{~mm}^{3}$ \\
\hline
\end{tabular}


M. A. Sc. Thesis McMaster University - Mechanical Engineering Drew A. Grandy
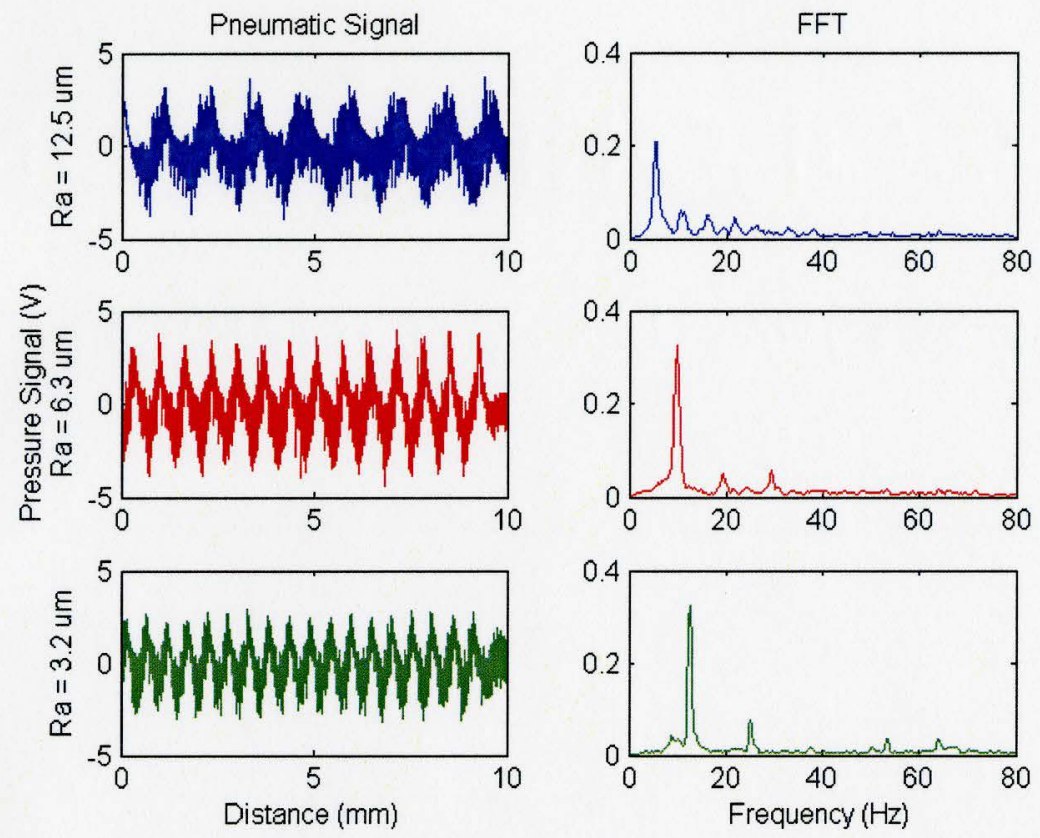

Figure 4.13: Microphone Signal for Milled Standards $\left(12.5-3.2 \mu \mathrm{m} R_{a}\right), P_{s}=69 \mathrm{kPa}$
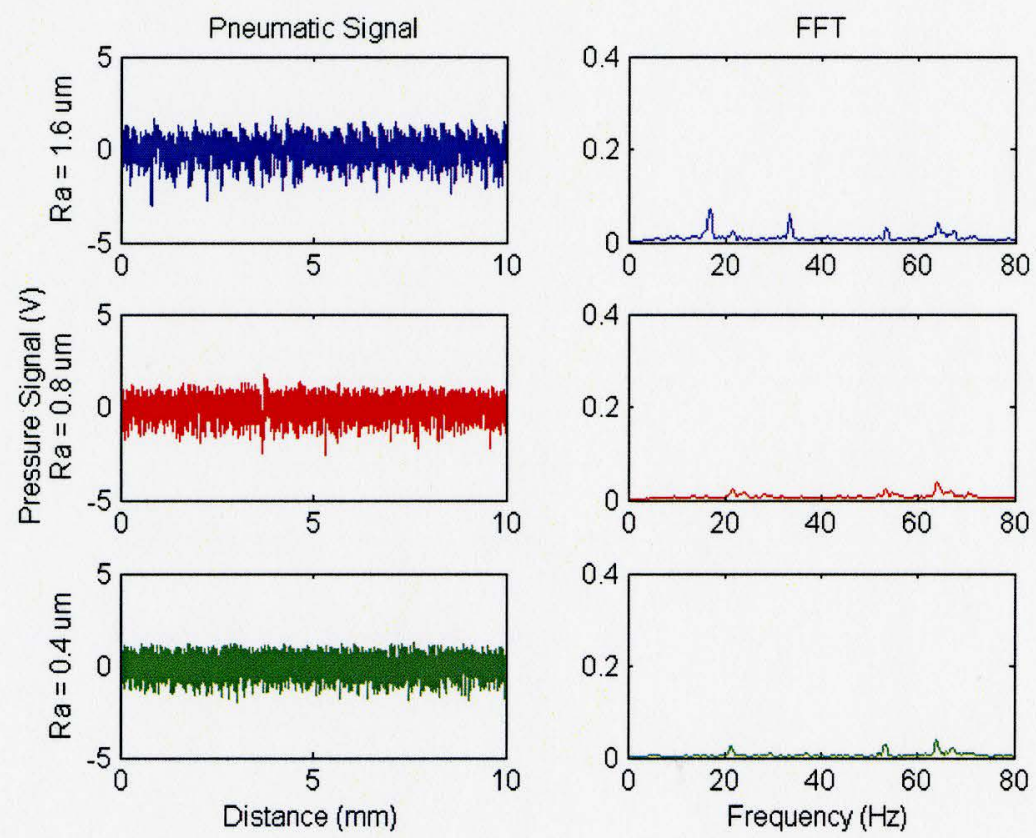

Figure 4.14: Microphone Signal for Milled Standards (1.6-0.4 $\left.\mu \mathrm{m} R_{a}\right), P_{S}=69 \mathrm{kPa}$ 
M. A. Sc. Thesis McMaster University - Mechanical Engineering Drew A. Grandy
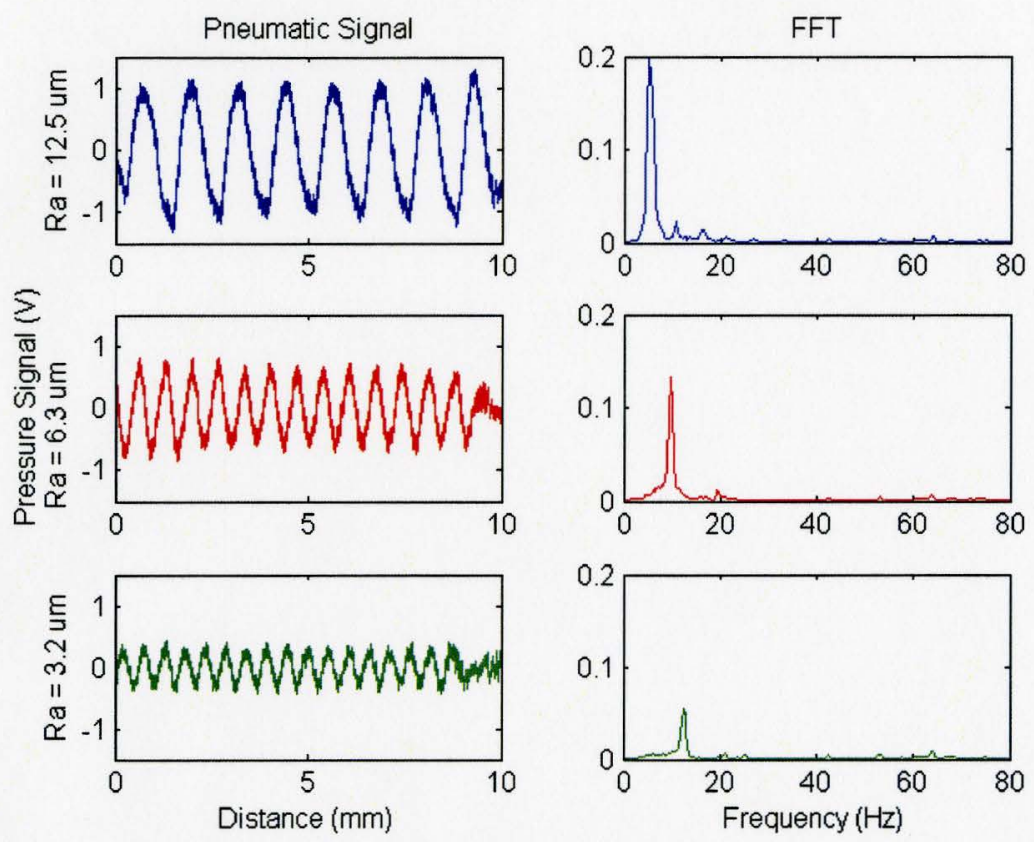

Figure 4.15: Piezoelectric Pressure Transducer Signal for Milled Standards (12.5-3.2 $\left.\mu \mathrm{m} R_{a}\right), P_{s}=69 \mathrm{kPa}$
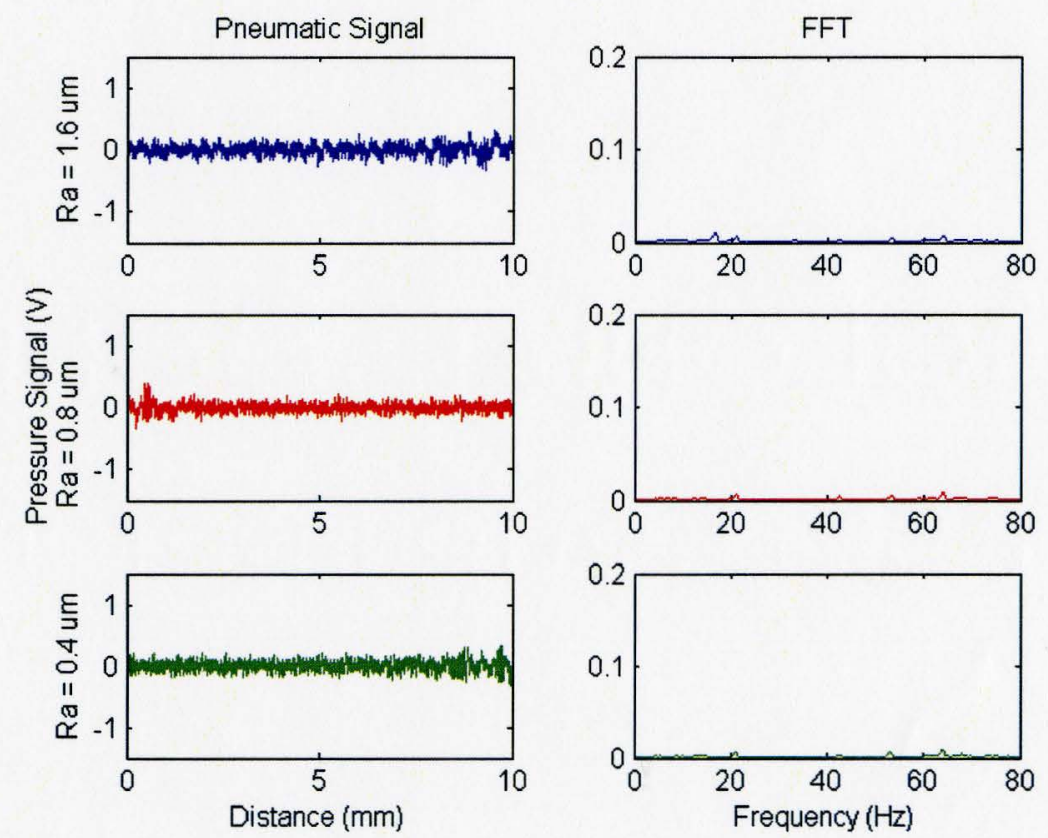

Figure 4.16: Piezoelectric Pressure Transducer Signal for Milled Standards (1.6-0.4 $\left.\mu \mathrm{m} R_{a}\right), P_{s}=69 \mathrm{kPa}$ 
M. A. Sc. Thesis McMaster University - Mechanical Engineering Drew A. Grandy

When comparing Figures 4.13 and 4.14 to Figures 4.15 and 4.16, it should be noted that the scales for the plots created from the microphone are twice as large as those created from the piezoelectric transducer. This is simply because the sensitivity of the microphone is much greater than that of the pressure transducer. For comparisons, the relative variation between each of the signals corresponding to the different roughnesses will be discussed as well as the overall quality of the signal, instead of the differences in magnitude between the two different sensors.

It has been found that although the sensitivity of the pressure transducer is much lower than that of the microphone, its lower frequency response is much more beneficial for characterizing the roughness of the surfaces. Furthermore, for surfaces with larger $R_{a}$ values, the microphone would saturate the pressure signal because the back pressures created were much too large for the sensitivity of the microphone. This issue could be solved by using a lower supply pressure, however this is not beneficial for clearing obstructions from the surface. In Figure 4.17 it can be seen that for the same surface, the microphone signal introduces characteristics into the pressure signal as a result of the pressure fluctuations being too large for the sensitivity of the microphone. In the section of the signal following a pressure spike, highlighted by an arrow, there is evidence of a logarithmic decay and a discontinuity in the back pressure signal before the microphone begins to acquire acsurate data again. This phenomenon is a result of the dynamic characteristic of the microphone. 

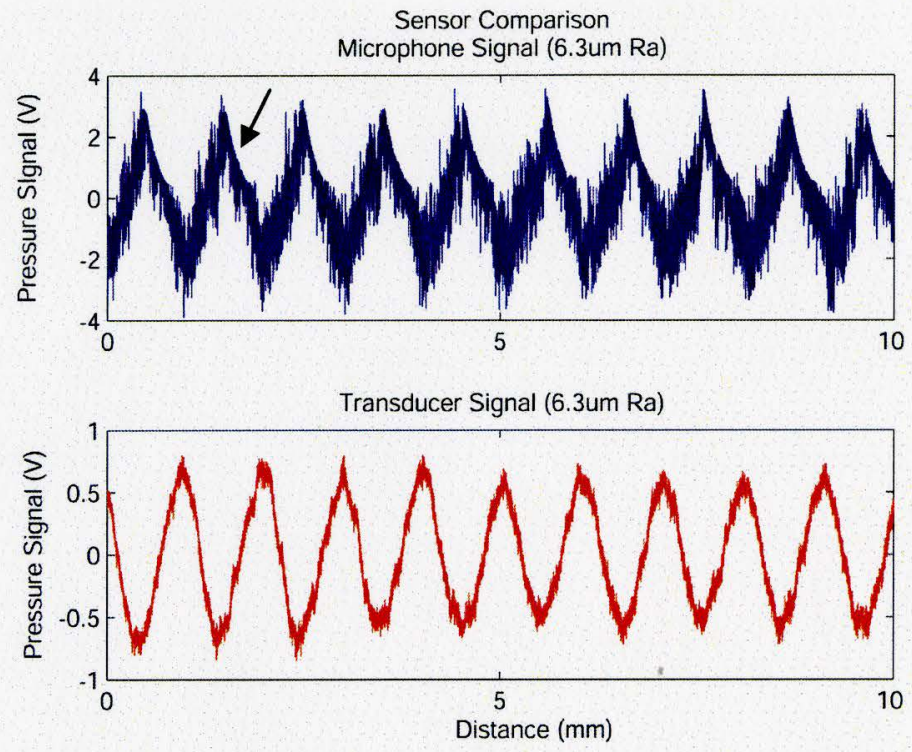

Figure 4.17: Microphone vs. Piezoelectric Pressure Transducer Raw Signal Comparison

Evidence of the issues caused by the frequency response of the microphone can be seen when comparing the dominant frequency amplitudes in the frequency domain of the signals generated from the $12.5 \mu \mathrm{m}$ surface and the $6.3 \mu \mathrm{m}$ surface in Figure 4.13. When comparing the frequency domain of the pressure signals to the frequency domain created from the stylus measurements in Figure 4.4, it is expected that the amplitude at the dominant frequency would be larger in the $12.5 \mu \mathrm{m}$ sample than that of the $6.3 \mu \mathrm{m}$ sample. This is not the case for the signals obtained using the microphone but has been verified with the piezoelectric pressure transducer signals. A possible explanation of the signal being smaller from the microphone could be a result of two possible explanations. Firstly, the sensitivity of the microphone is large enough that the changes in the backpressure being created are too large for the microphone to handle and secondly, the dominant frequencies of these signals are occurring at frequencies significantly lower 
M. A. Sc. Thesis McMaster University - Mechanical Engineering Drew A. Grandy than the $20 \mathrm{~Hz}$ minimum range specified for the microphone, resulting in a lower amplitude signal. Refer to Appendix A for the dynamic characteristics of the microphone to see how the amplitude of the signal is increasing to the plateau occurring between 20 $\mathrm{Hz}$ and $20 \mathrm{kHz}$. This phenomenon is analogous to the effects caused by a band pass filter where the magnitude of the signals leading up to the lowpass frequency is increasing to the limit set for the frequency band. These findings make the pressure transducer more appropriate for a larger range of roughness and as a result, all of the data which are presented following this section refer to the piezoelectric pressure transducer. Further research could be done into higher speed operations or surfaces with lower $R_{a}$ values where the microphone could perhaps be more beneficial.

\subsubsection{Effects of Nozzle and Control Orifice Dimensions}

The diameters of the nozzle and control orifice have a significant effect on the gauging characteristics and the overall sensitivity of the system. It is known from the theory [3] that an increase in sensitivity will result in an increase of the time constant as well. This section will focus on maintaining the sensitivity and optimum standoff distance of the gaugirig system while decreasing the nozzle diameter in order to obtain signals with less noise for better characterization of surfaces with lower $R_{a}$ values. 


\section{A. Sc. Thesis McMaster University - Mechanical Engineering Drew A. Grandy}

Table 4.5: Dimensions of the Nozzles used for Comparison

\begin{tabular}{|c|c|c|c|c|}
\hline Name & $\begin{array}{c}\mathbf{D}_{\mathbf{n}} \\
(\mathrm{mm})\end{array}$ & $\begin{array}{c}\mathbf{D}_{\mathbf{c}} \\
(\mathrm{mm})\end{array}$ & $\begin{array}{c}\mathbf{P}_{\mathbf{s}} \\
(\mathrm{kPa})\end{array}$ & $\begin{array}{c}\mathbf{K}_{\max } \\
(\mathrm{kPa} / \mu \mathrm{m})\end{array}$ \\
\hline 1.5Dn0825Dc & 1.50 & 0.825 & 138 & 0.79 \\
\hline 20GDn05Dc & 0.58 & 0.510 & 138 & 0.80 \\
\hline
\end{tabular}

The names given to the nozzles are derived from the parameters present in each. $15 \mathrm{Dn} 0825 \mathrm{Dc}$ is the larger of the two nozzles while $20 \mathrm{GDn} 05 \mathrm{Dc}$ is the smaller and is created using a 20 giage stainless steel needle tip. The supply pressure is maintained at $138 \mathrm{kPa}(20 \mathrm{psi}) \mathrm{fcr}$ both sets of comparison and the theoretical sensitivities of the systems are within $1 \%$ of each other. Again for these tests, the milled surface standards are being used as the testing surface.

The signals generated using the larger nozzle are presented in Figures 4.18 and 4.19 where it is clear that for the larger $R_{a}$ values, the dominant frequency caused from the surface is easily distinguished. Problems arise when trying to characterize the surfaces with $R_{a}$ valıes around $1.6 \mu \mathrm{m}$ and lower where the dominant frequency created from the actual surface is around the same magnitude as the noise being generated by the air flowing through the nozzle. This noise is present in all of the samples being acquired using the $15 \mathrm{Dn} 082: \mathrm{Dc}$ nozzle and are clearly visible as the bands occurring in the waterfall plot around $21 \mathrm{~Hz}, 42 \mathrm{~Hz}, 52 \mathrm{~Hz}$, and $63 \mathrm{~Hz}$ in Figure 4.20 . Since the rougher (larger $\mathbf{R}_{\mathbf{a}}$ ) surfaces have such a large magnitude in the frequency domain, a more detailed view of the surfaces with $R_{a}$ values $3.2 \mu \mathrm{m}$ down to $0.4 \mu \mathrm{m}$ is displayed in Figure 4.21. 

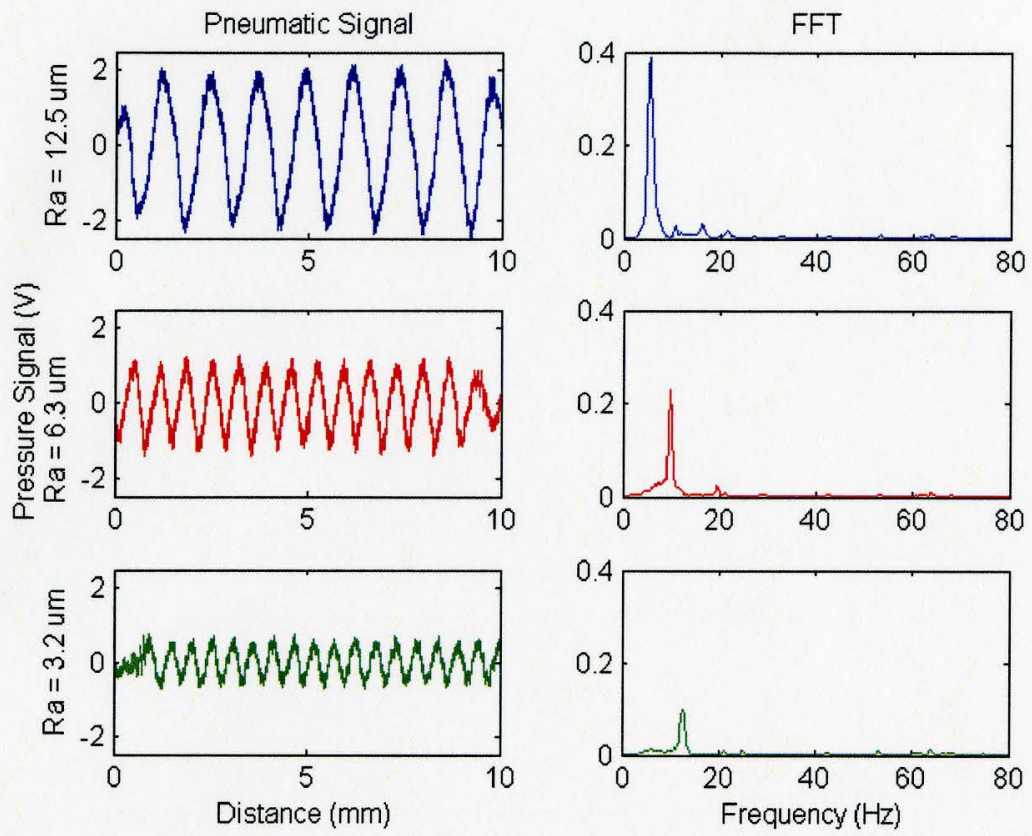

Figure 4.18: Milled Standard Signals (12.5-3.2 $\left.\mu \mathrm{m} R_{a}\right)$ $P s=138 \mathrm{kPa}, \mathrm{Dn}=1.5 \mathrm{~mm}, D c=0.825 \mathrm{~mm}$
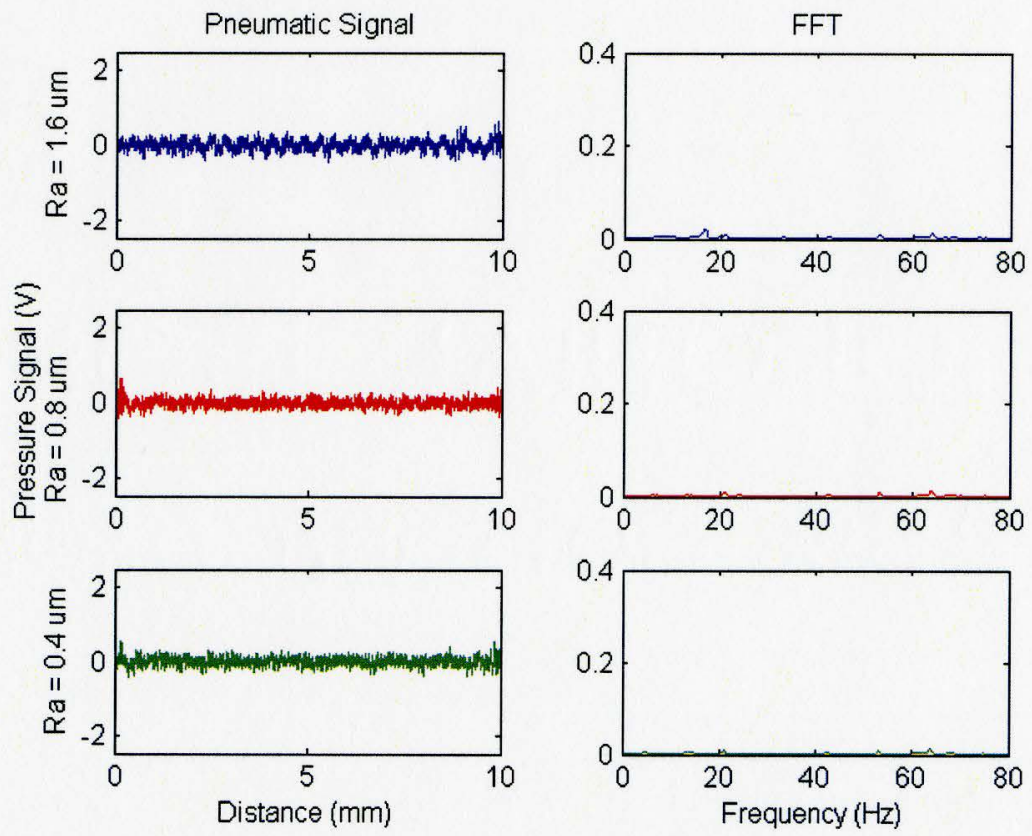

Figure 4.19: Milled Standard Signals (1.6-0.4 $\left.\mu m R_{a}\right)$ $P s=138 \mathrm{kPa}, D \mathrm{D}=1.5 \mathrm{~mm}, D c=0.825 \mathrm{~mm}$ 
M. A. Sc. Thesis McMaster University - Mechanical Engineering Drew A. Grandy

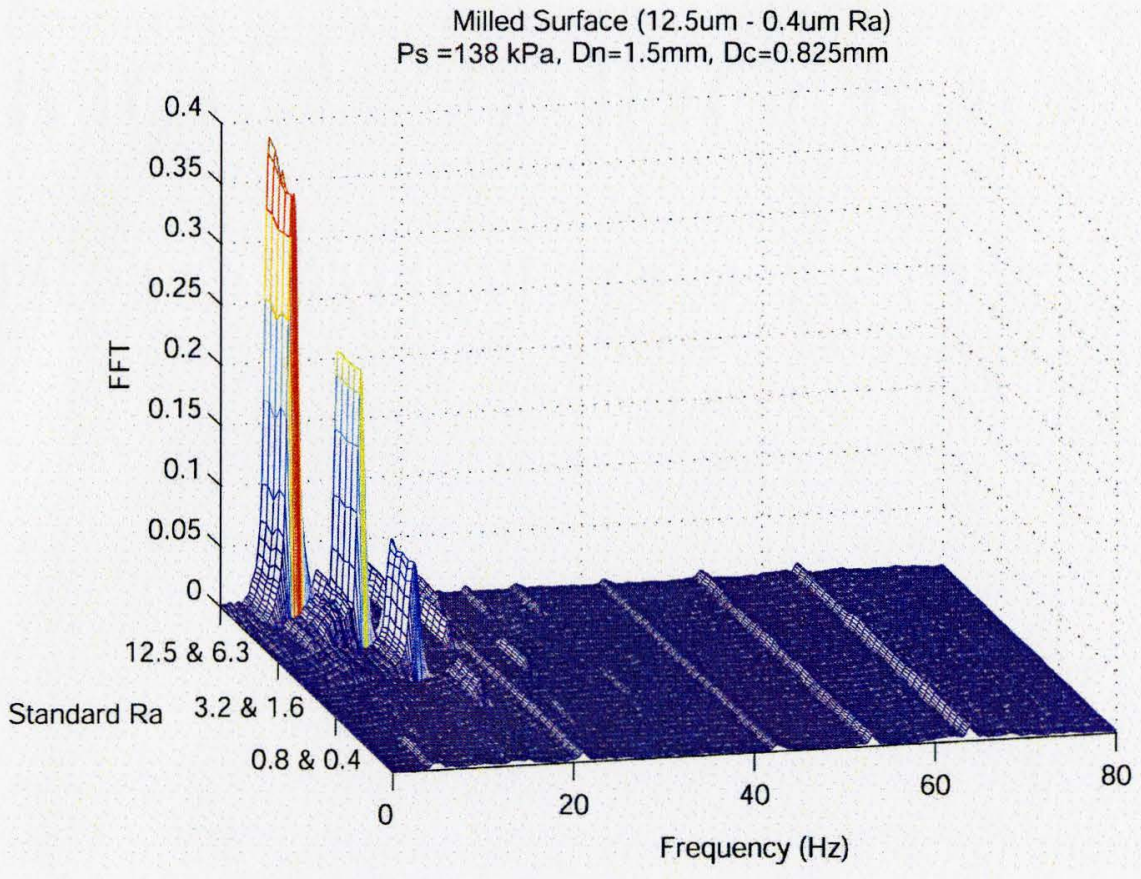

Figure 4.20: FFT Waterfall Plot from Milled Surface Standards (12.5-0.4 $\left.\mu m R_{a}\right)$

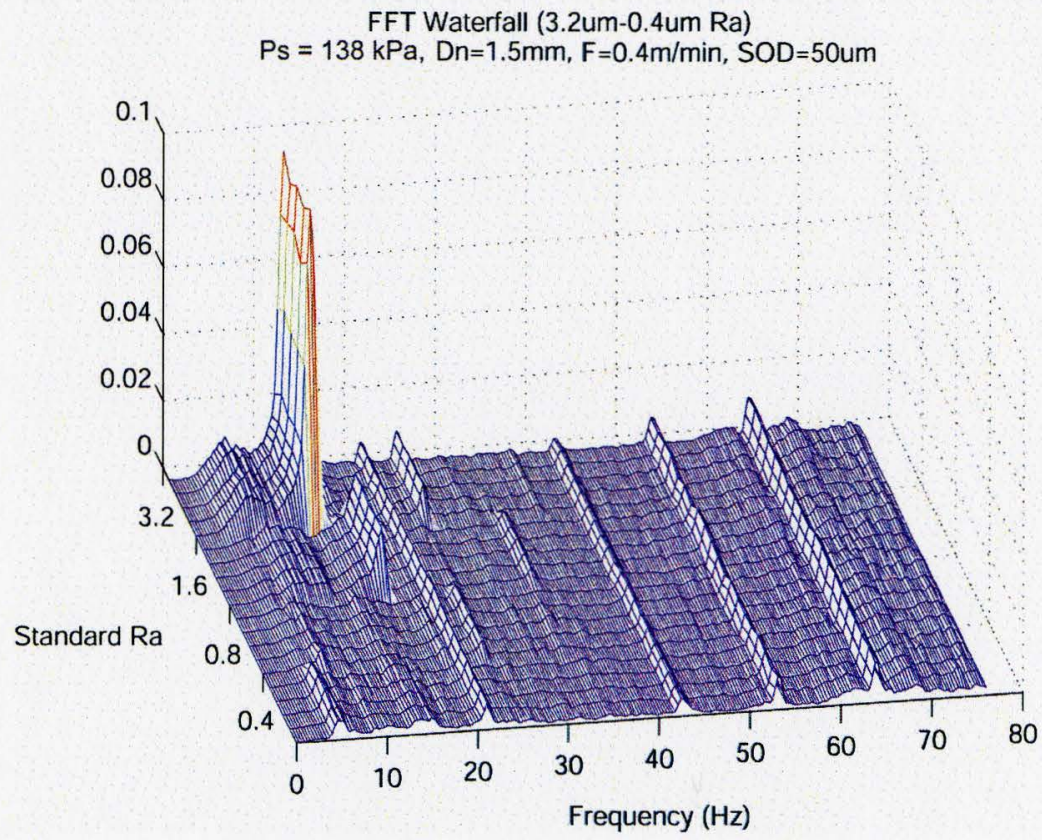

Figure 4.21: FFT Waterfall Plot from Milled Surface Standards (3.2-0.4 $\left.\mu m R_{a}\right)$ 
M. A. Sc. Thesis McMaster University - Mechanical Engineering Drew A. Grandy

Although the majority of the frequency bands occur at higher frequencies than the band we are interested in for characterizing the surface roughness, the band occurring around $21 \mathrm{~Hz}$ is close enough to the frequencies expected for the $0.8 \mu \mathrm{m} \mathrm{R} \mathrm{R}_{\mathrm{a}}$ surface that the dominant frequency is hidden by the jet noise. It is because of this that the smaller 20GDn05Dc nozzle was implemented to minimize the noise occurring within the signal. Since the larger $R_{a}$ surfaces can be clearly defined using the larger nozzle, only the smaller $R_{a}$ surfaces are presented in Figure 4.22 for the 20GDn05Dc nozzle.
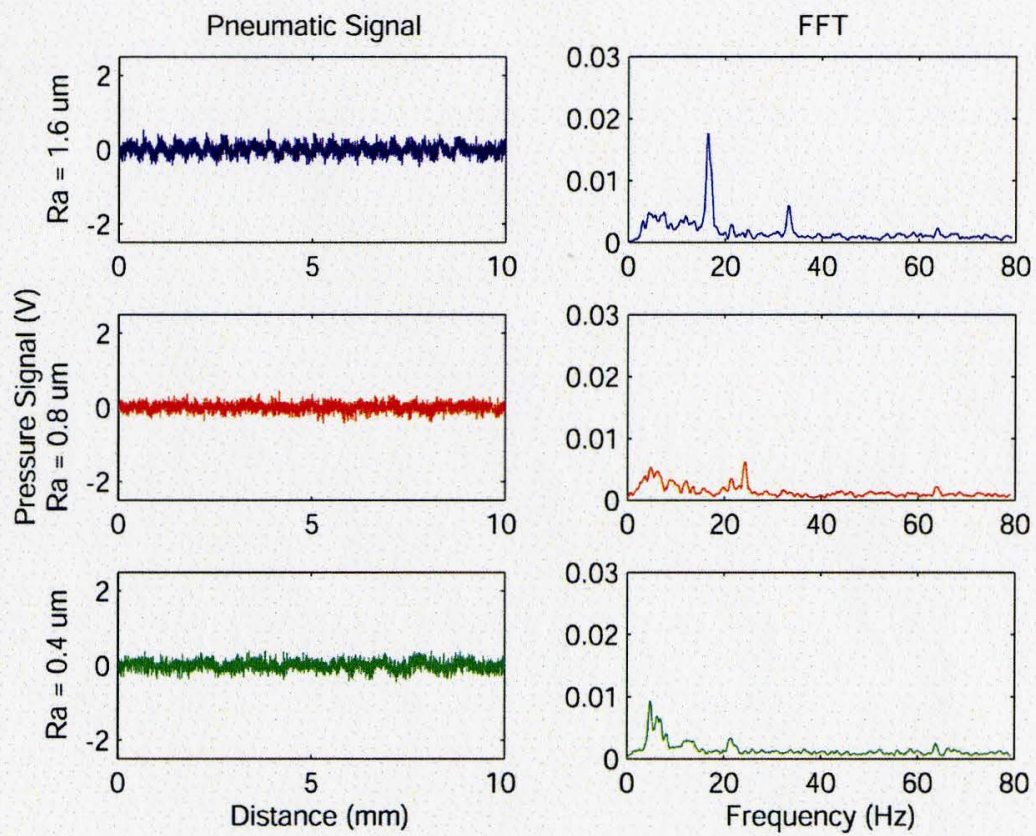

Figure 4.22: Milled Standard Signals (1.6-0.4 $\left.\mu m R_{a}\right)$ $P s=138 \mathrm{kPa}, \mathrm{Dn}=0.58 \mathrm{~mm}, D c=0.51 \mathrm{~mm}$

Visually, the raw pressure signal shows little to no variation from the signals acquired using the larger nozzle. The most significant changes can be seen in the 
M. A. Sc. Thesis McMaster University - Mechanical Engineering Drew A. Grandy frequency domain where the noise has been reduced significantly by about $86 \%$. A direct comparison in the frequency domain is displayed in the following figure.
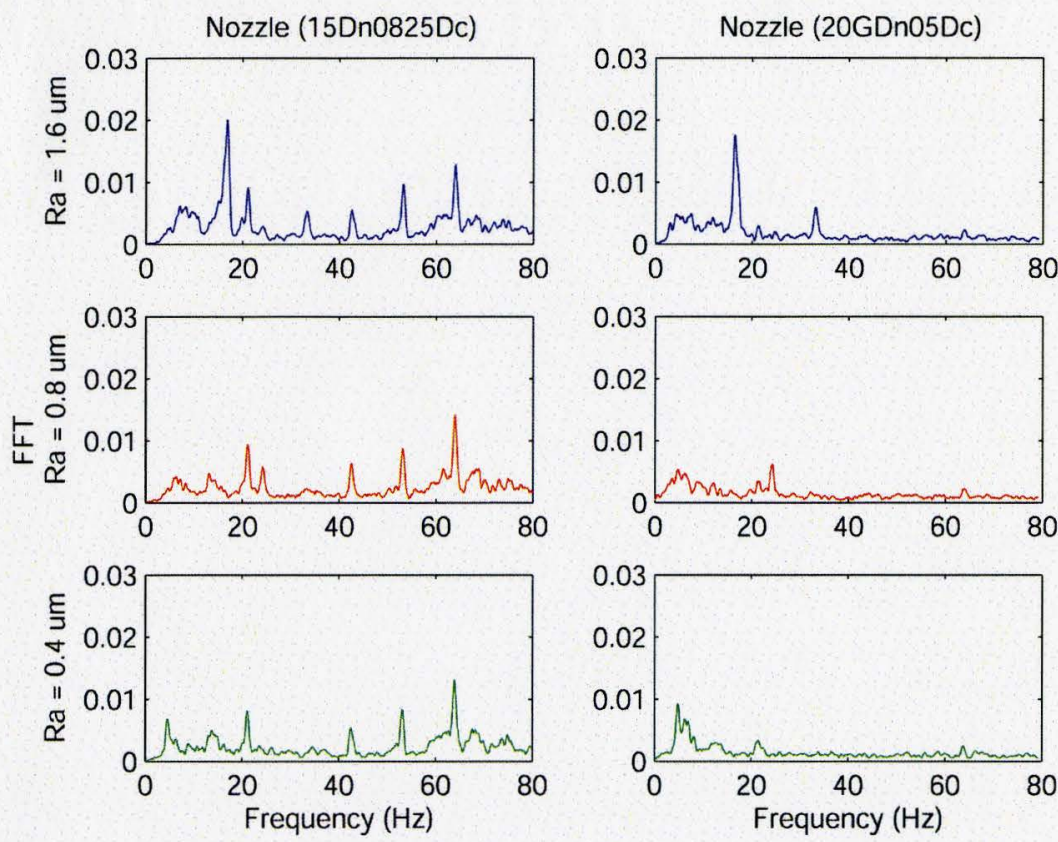

Figure 4.23: Frequency Domain Comparison of the Two Nozzles Used on Lower $R_{a}$ Values

The noise has been reduced significantly allowing the dominant frequencies that are produced by the moving surface to be clearly displayed. The magnitudes of these dominant frequencies have also remained constant between the two nozzles as a result of maintaining the sensitivity of the gauge by adjusting the control orifice diameter accordingly for the change in nozzle diameter. 
M. A. Sc. Thesis McMaster University - Mechanical Engineering Drew A. Grandy 4.2.3 Effects of Supply Pressure on Sensor Sensitivity

It is expected that a change in supply pressure is linearly related to a change in gauge sensitivity as seen in Section 1.2. A test was performed to verify that the proposed sensing device conforms to this. From equation (1.6), by doubling the supply pressure we can expect to double the sensitivity of the gauge. Verification of this is shown in Figure 4.24 where the raw pressure signals acquired and frequency domains from the $6.3 \mu \mathrm{m} \mathrm{R}_{\mathrm{a}}$ milled surface are shown using a supply pressure of $69 \mathrm{kPa}(10 \mathrm{psi})$ and $138 \mathrm{kPa}(20 \mathrm{psi})$.
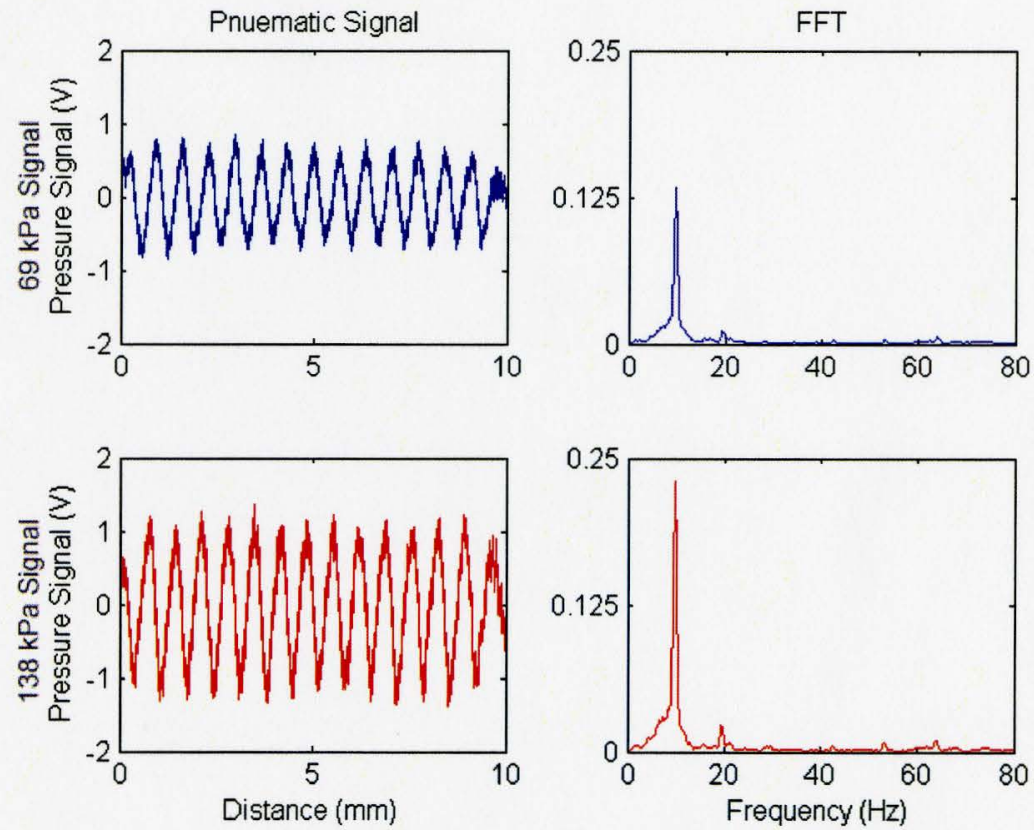

Figure 4.24: Effect of Supply Pressure on Signal Strength (Milled Sample $R_{a}=6.3 \mu \mathrm{m}$ ) 
M. A. Sc. Thesis McMaster University - Mechanical Engineering Drew A. Grandy

Table 4.6: Effects of Supply Pressure on Peak to Valley Distance and Dominant Frequency Amplitude

\begin{tabular}{|c|c|c|c|}
\hline & \multicolumn{2}{|c|}{ Peak to Vailey Distance (V) } & \\
\hline & $69 \mathrm{kPa}$ & $138 \mathrm{kPa}$ & \\
\hline peak 1 & 1.63 & 2.54 & \\
\hline peak 2 & 1.50 & 2.51 & \\
\hline peak 3 & 1.39 & 2.59 & X larger \\
\hline$A V G$ & 1.51 & 2.55 & 1.7 \\
\hline
\end{tabular}

\begin{tabular}{|c|c|c|c|}
\hline \multirow[b]{2}{*}{$\boldsymbol{R}_{a}$} & \multicolumn{3}{|c|}{$\begin{array}{c}\text { Dominant Frequency } \\
\text { Amplitude } \\
\end{array}$} \\
\hline & $69 \mathrm{kPa}$ & $138 \mathrm{kPa}$ & $X$ larger \\
\hline 12.5 & 0.20 & 0.39 & 1.93 \\
\hline 6.3 & 0.13 & 0.23 & 1.73 \\
\hline 3.2 & 0.05 & 0.10 & 1.78 \\
\hline & & $\boldsymbol{A} \boldsymbol{V} \boldsymbol{G}$ & 1.8 \\
\hline
\end{tabular}

A comparisor. of the peak to valley distance in the backpressure signal caused by the cusps on the surfice passing the nozzle as well as the dominant frequency amplitudes is displayed in Table 4.6. Experimentally, doubling the supply pressure resulted in an increase in the peak to valley distance of 1.7 times on average and an increase of about 1.8 times in the frequency domain which is slightly less than the expected 2 times from theory. A reason for this could possibly lie in the fact that the amplitude increase in the linear region of the pneumatic characteristic curve is increased as a result of the change in supply pressure. As a result of this, the region which we are operating about on the characteristic curve would have a larger effect on the pressure variations read by the pneumatic gauge. We are assuming that the gauge is operating in a linear régime on the characteristic curve $c$ nd that the air is remaining incompressible, while in reality this may not be entirely true. The increase in supply pressure will cause an increase in the compressibility of the air as the backpressure enters the control volume. Thus when the cusps on the surface being measured are causing the average distance to change between the nozzle and the surface, the change in pressure will not necessarily reflect a linear relationship at higher pressures due to the compressibility of the air. This would only be 
M. A. Sc. Thesis McMaster University - Mechanical Engineering Drew A. Grandy

emphasized by the increase of supply pressure. A more in depth study on the limitations of the supply pressure is performed in Section 4.4 in determining the operating envelope of the pneumatic systism.

\subsection{Pneumatic Characterization of Surface Standards}

The surface standards detailed in Section 4.1 were characterized using the developed pneumatic gauge by examining the backpressure signals as well as their frequency domain. Many of the important physical details of the surface standards found previously through siylus measurements will now be compared to the results obtained from the pneumatic system. The three different surfaces being tested are representative of vertical milling, turning, and grinding operations with $R_{a}$ values ranging from $12.5 \mu \mathrm{m}$ down to $0.05 \mu \mathrm{m}$. Al of the backpressure signals obtained within this section have been collected through the use of the piezoelectric pressure transducer, standoff distance of $50 \mu \mathrm{m}$, and using a supply pressure of $138 \mathrm{kPa}(20 \mathrm{psi})$ for reasons discussed in Section 4.2. All of the signals have been acquired over a $10 \mathrm{~mm}$ section of each sample with the nozzle traversing the workpiece back and forth at a feed rate of $400 \mathrm{~mm} / \mathrm{min}$. Due to the acceleration and deceleration of the nozzle at the beginning and end of the sample, some low frequency noise $(<5 \mathrm{~Hz})$ is expected in the signal, so a third order Butterworth infinite impulse response (IIR) high pass filter with cut-off frequency of $5 \mathrm{~Hz}$ was used on the data to eliminate this. 
M. A. Sc. Thesis JMcMaster University - Mechanical Engineering Drew A. Grandy

4.3.1 Pneumatic Assessment of Milled Surface

The standards, being used for the reference surfaces represent ideal surfaces and are ideal for characterization through pneumatic gauging as these standards have been approved by ANSI standards.

For the standards with $R_{a}$ values of $12.5 \mu \mathrm{m}, 6.3 \mu \mathrm{m}$, and $3.2 \mu \mathrm{m}$, the 15Dn0825Dc nozzle configuration was used for characterization. As seen in the optimization of the gauge, the larger nozzle is more than adequate to detect the fluctuations of the cusps in the surface as seen in Figure 4.25. Samples of $1.6 \mu \mathrm{m}$, $0.8 \mu \mathrm{m}$, and $0.4 \mu \mathrm{m} \mathrm{R} \mathrm{R}_{\mathrm{a}}$ have been acquired and presented using the 20GDn05Dc nozzle to eliminate any jet noise occurring around the dominant frequencies of the surfaces. Since the set of samples at the lower end of roughness have much smaller amplitudes in the frequency domain, the FFT plots in Figure 4.26 are presented on a smaller scale to help discern the dominant requencies. 
M. A. Sc. Thesis McMaster University - Mechanical Engineering Drew A. Grandy
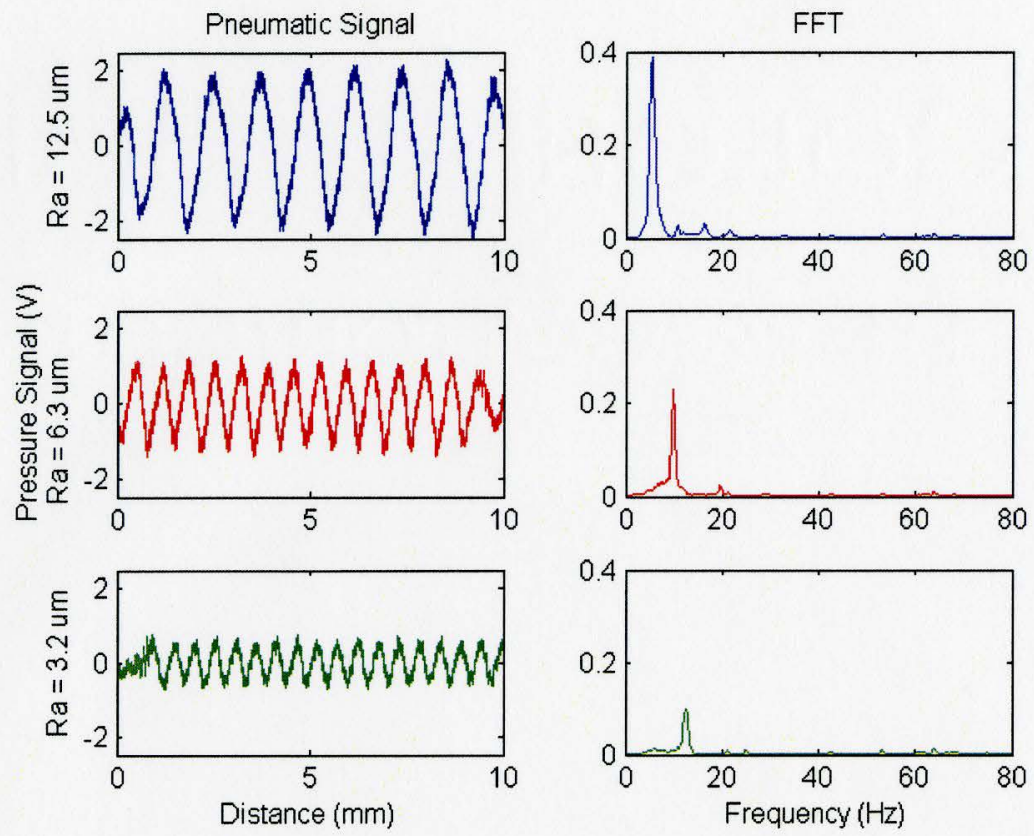

Figure 4.25: Backpressure Signals from Milled Standards (12.5-3.2 $\left.\mu m R_{a}\right)$ $P s=138 \mathrm{kPa}, D n=1.5 \mathrm{~mm}, D c=0.825 \mathrm{~mm}$
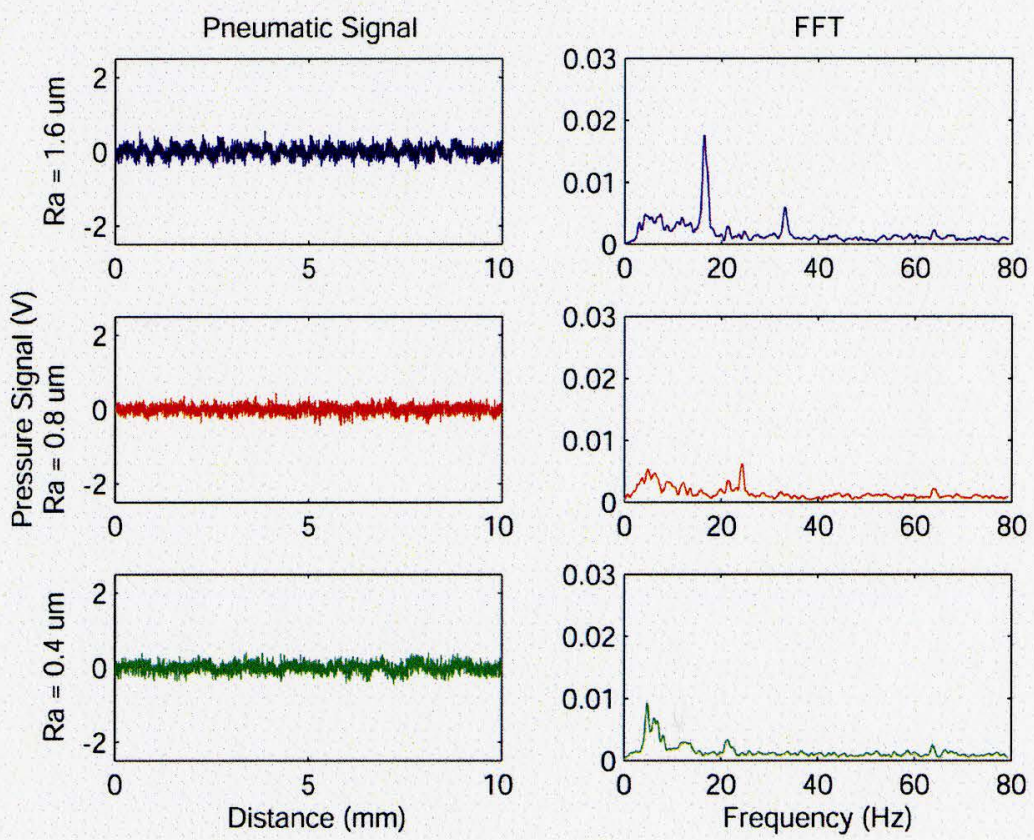

Figure 4.26: Backpressure Signals from Milled Standards (1.6-0.4 $\left.\mu m R_{a}\right)$ $P s=138 \mathrm{kPa}, D n=0.58 \mathrm{~mm}, D c=0.51 \mathrm{~mm}$ 
M. A. Sc. Thesis McMaster University - Mechanical Engineering Drew A. Grandy

When comparing the pneumatic signals to the stylus results, many of the surface characteristics are distinguishable between the different standards. Visually, the raw pressure signals can be distinguished down to $1.6 \mu \mathrm{m} \mathrm{R}_{\mathrm{a}}$ where the peaks in the signal are clearly defined and can be verified that they are caused by the surface passing beneath the nozzle in the frequency domain. As expected, we can see the peak to valley distance and the amplitude of the dominant frequency of the pressure signal decreasing as the roughness is decreast $\mathrm{d}$ in a similar manner to the stylus measurements. As a comparison, dominant frequencie:s of the pressure signals are compared to those obtained from the stylus measurements in Table 4.7. From these results, the pneumatic gauge can detect the surface to less than $3 \%$ variation. Some of the variation could be a result of the acceleration and deceleration of the nozzle as it passes over the standard surface.

Table 4.7: Dominant Frequency Comparison from Milled Surface Standards

\begin{tabular}{|c|c|c|c|}
\cline { 2 - 3 } \multicolumn{1}{c|}{} & Stylus & Pressure & \multicolumn{1}{c|}{} \\
\hline $\begin{array}{c}\text { Standard } \\
R_{a} \\
(\mu \mathrm{m})\end{array}$ & $\begin{array}{c}\text { Dominant } \\
\text { Frequency } \\
(\mathrm{Hz})\end{array}$ & $\begin{array}{c}\text { Dominant } \\
\text { Frequency } \\
(\mathrm{Hz})\end{array}$ & $\begin{array}{c}\text { \% Error } \\
(\%)\end{array}$ \\
\hline 12.5 & 5.34 & 5.48 & 2.66 \\
\hline 6.3 & 9.66 & 9.46 & 2.10 \\
\hline 3.2 & 12.46 & 12.28 & 1.44 \\
\hline 1.6 & 16.54 & 16.78 & 1.45 \\
\hline 0.8 & 24.16 & 24.19 & 0.12 \\
\hline 0.4 & 37.13 & $\mathrm{NA}$ & $\mathrm{NA}$ \\
\hline
\end{tabular}


M. A. Sc. Thesis McMaster University-Mechanical Engineering Drew A. Grandy
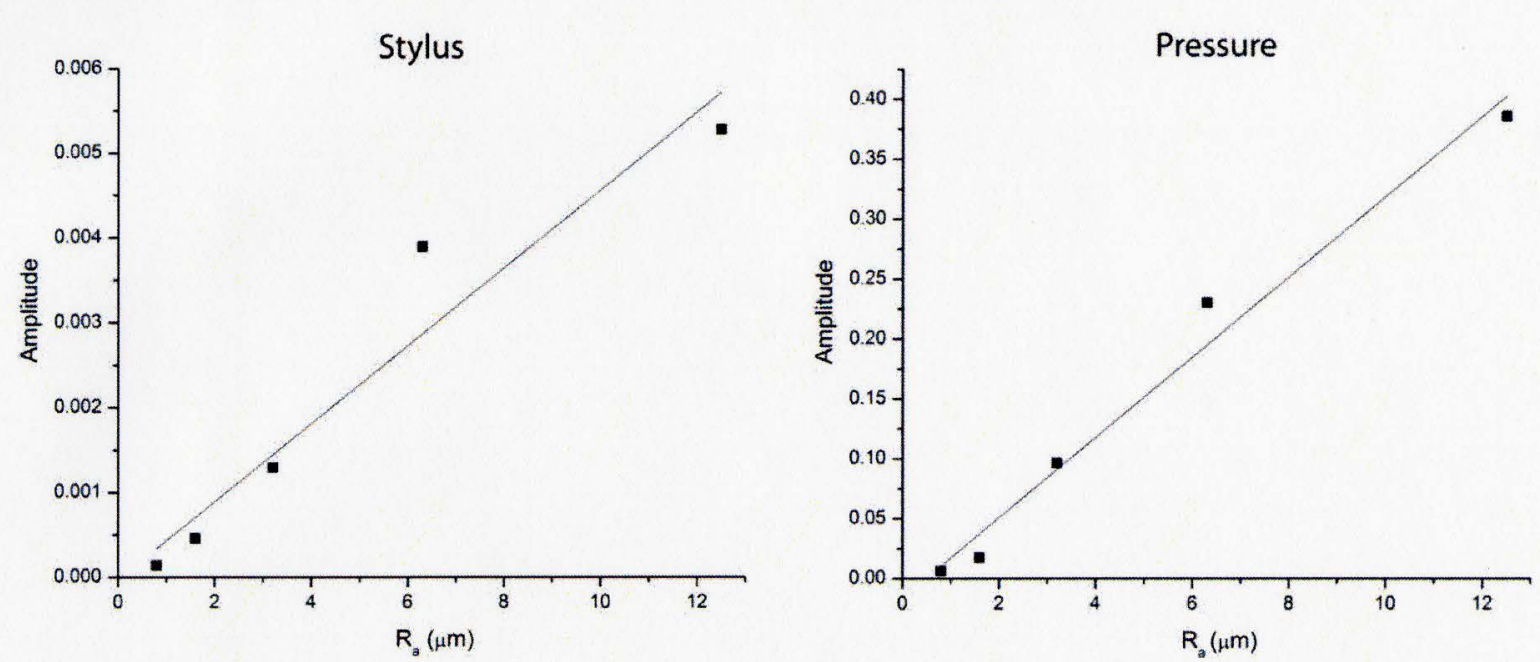

Figure 4.27: Amplitudes at Dominant Frequencies Comparison for Milled Surface Standards

Comparing the pressure signals to the stylus measurements validates that the pneumatic system is capable of detecting changes in the surface roughness of a milled surface using non-contact methods. For visual comparisons, the stylus signals and the pressure signals are displayed together for select samples in Figure 4.28.
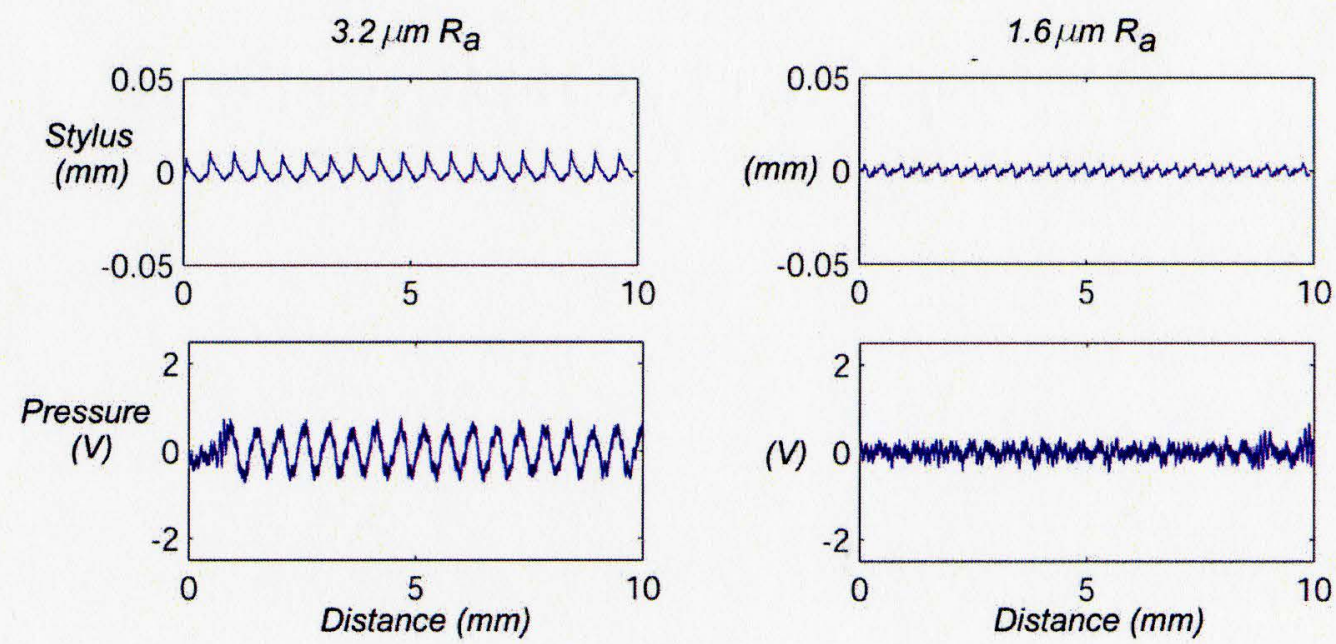

Figure 4.28: Stylus and Pressure Signal Comparison of Milled Surfaces (3.2 $\mu \mathrm{m}$ and $\left.1.6 \mu \mathrm{m} R_{a}\right)$ 
M. A. Sc. Thesis McMaster University - Mechanical Engineering Drew A. Grandy

Repeatability of the device has also been tested by acquiring five signals from the same roughness sample and analyzing them together in the frequency domain to check for any fluctuations in the amplitudes occurring at the dominant frequencies. Waterfall plots of the frequency domains from the five samples taken for each of the roughness standards has been created and presented together in Figures 4.29 and 4.30 to visually display the variations between the surfaces. Each of the bands created in the frequency domain are a result cf these five samples containing the same dominant frequency. In Figure 4.29 it is clear that very little fluctuation occurs between signals taken from the same surface because very minimal changes in amplitude occur across the dominant frequency band for each of the five samples. From observing the waterfall plots, the changes occurring in the frequency domain as a result of the different surface features are also very clear and distinct. 


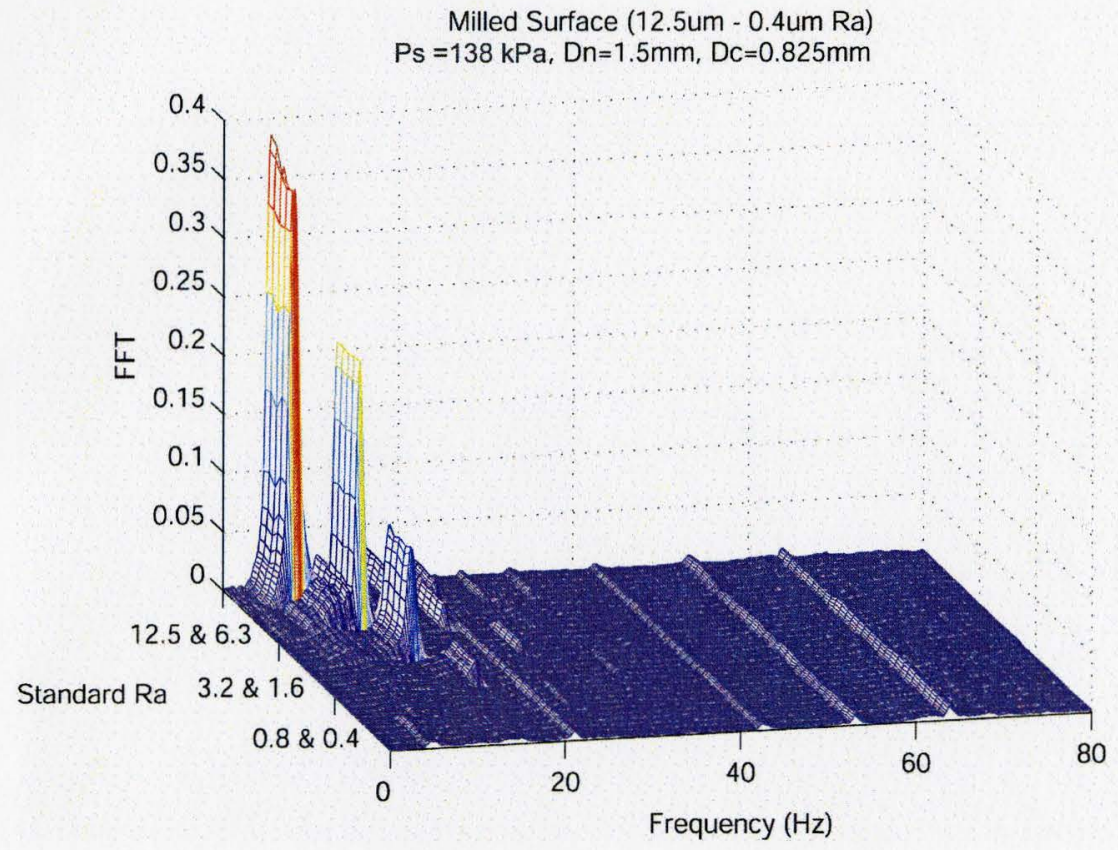

Figure 4.29: FFT Waterfall Plot from Milled Surface Standards $P S=138 \mathrm{kPa}, D \mathrm{n}=1.5 \mathrm{~mm}, \mathrm{Dc}=0.825 \mathrm{~mm}$

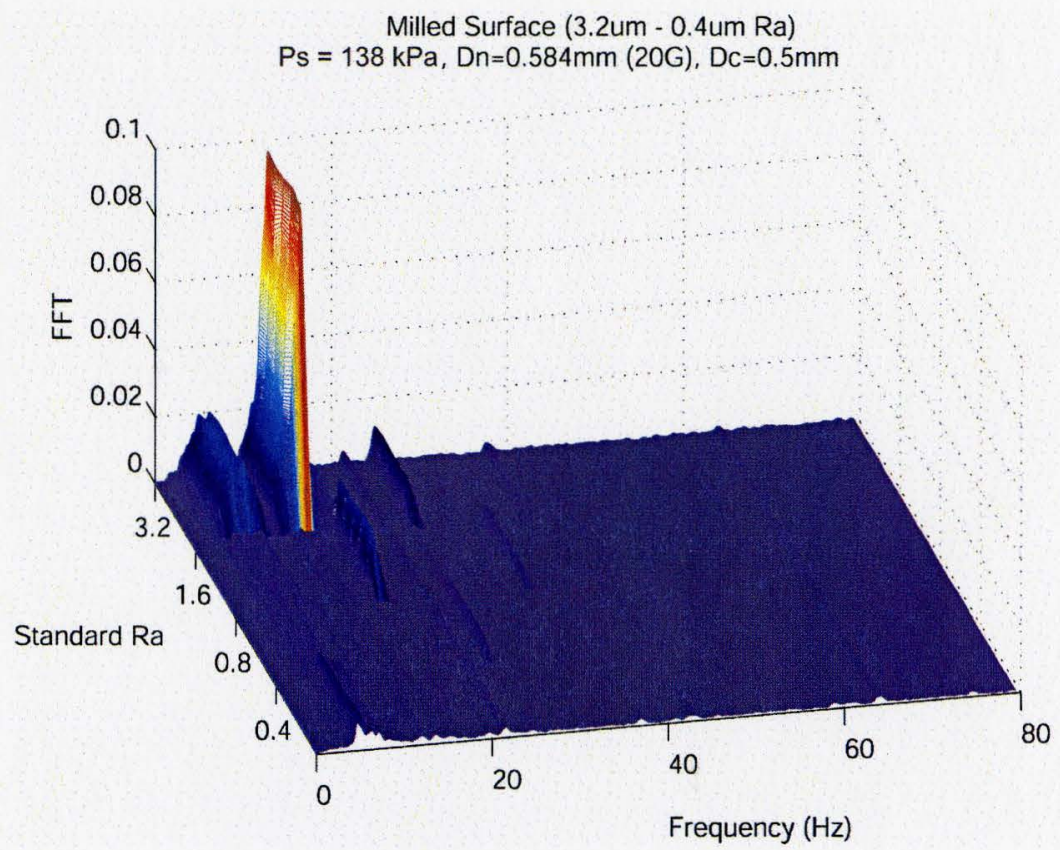

Figure 4.30: FFT Waterfall Plot of Milled Standards for Lower $R_{a}$.Values $P s=138 \mathrm{kPa}, D n=0.58 \mathrm{~mm}, D c=0.51 \mathrm{~mm}$ 
M. A. Sc. Thesis McMaster University - Mechanical Engineering Drew A. Grandy

Figure 4.30 is helpful in determining the limitations of the pneumatic device when finding the bounds of the $\mathrm{R}_{\mathrm{a}}$ range detectable by the sensor. It is clear that in the sensors current state, it is incapable of detecting milled surfaces below $0.8 \mu \mathrm{m} \mathrm{R}_{\mathrm{a}}$ through these methods of characterization.

\subsubsection{Pneumatic Assessment of Turned Surfaces}

The pneumatic signals obtained from the turned standards have been analyzed using the same techriques that were used for analyzing the milled standards. As seen in the stylus measurements presented in Figures 4.7 and 4.8 from Section 4.1.2, the turned surfaces tend to become quite noisy in the frequency domain as the $R_{a}$ values decrease, making it difficult to compare the pressure measurements to the stylus measurements by means of the dominant frequency. An important characteristic of the turned surfaces that was not present in the milled surfaces is that the peak to valley distance is not constant across any of the standards. Thus, as the nozzle is traversing across the turned surfaces, the backpressure fluctuations will not remain constant and peak to valley distance of the pressure signals will vary accordingly. Similar to the milled samples, the larger 15Dn0825Dc nozzle is sufficient to characterize the $12.5 \mu \mathrm{m}, 6.3 \mu \mathrm{m}$, and $3.2 \mu \mathrm{m} \mathrm{R}_{\mathrm{a}}$ surfaces while the sinaller 20GDn05Dc nozzle is required for the $1.6 \mu \mathrm{m}, 0.8 \mu \mathrm{m}$, and $0.4 \mu \mathrm{m} \mathrm{R}_{\mathrm{a}}$ surfaces. 
M. A. Sc. Thesis McMaster University - Mechanical Engineering Drew A. Grandy
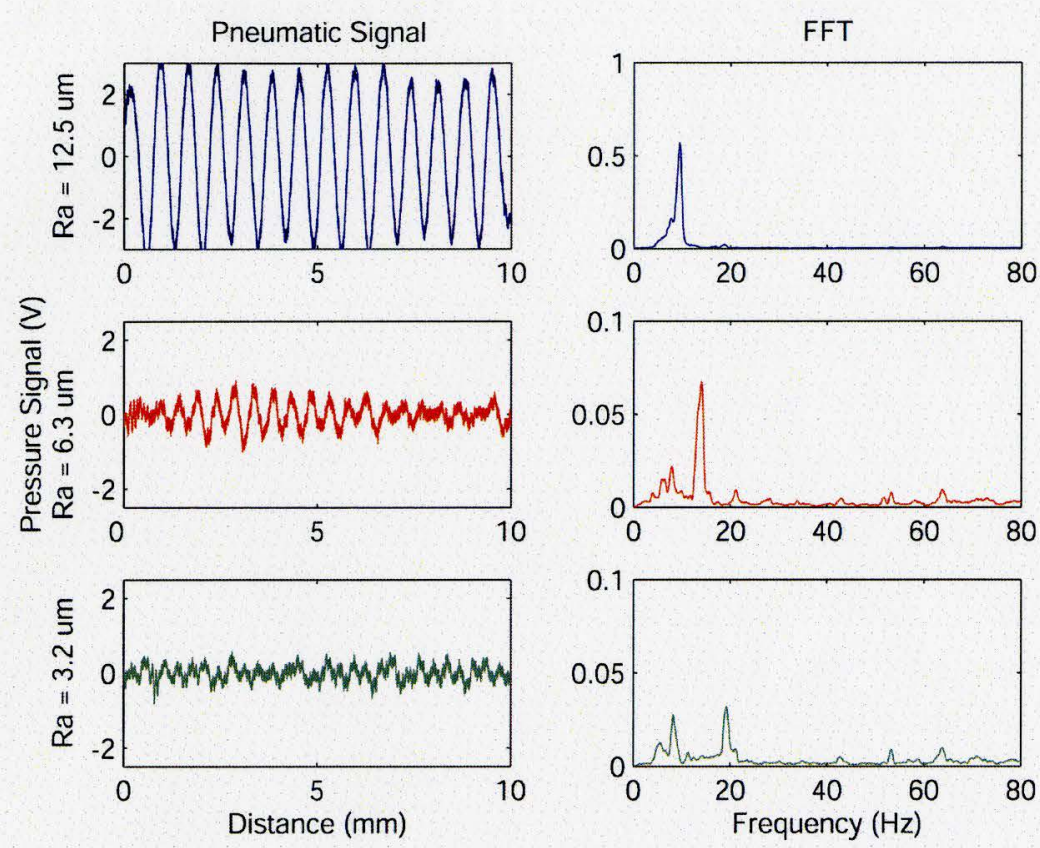

Figure 4.31: Backpressure Signals from Turned Standards (12.5-3.2 $\left.\mu m R_{a}\right)$ $P s=138 \mathrm{kPa}, D \mathrm{n}=1.5 \mathrm{~mm}, \mathrm{Dc}=0.825 \mathrm{~mm}$

The first thing that is noticeable in the pressure signals corresponding to the turned surfaces is that the $12.5 \mu \mathrm{m}$ pressure fluctuations are much larger than any of the other signals and as a result, the FFT for this signal has been plotted on a larger scale in Figure 4.31. The large amplitude of the raw pressure signal helps emphasize the variations in the peak to valley distance that is present in both the stylus and backpressure measurements from the surface. In Figure 4.32, the stylus measurements have been plotted along with the pneumatic measurements of the $12.5 \mu \mathrm{m}$ and $3.2 \mu \mathrm{m}$ surfaces for comparison. 

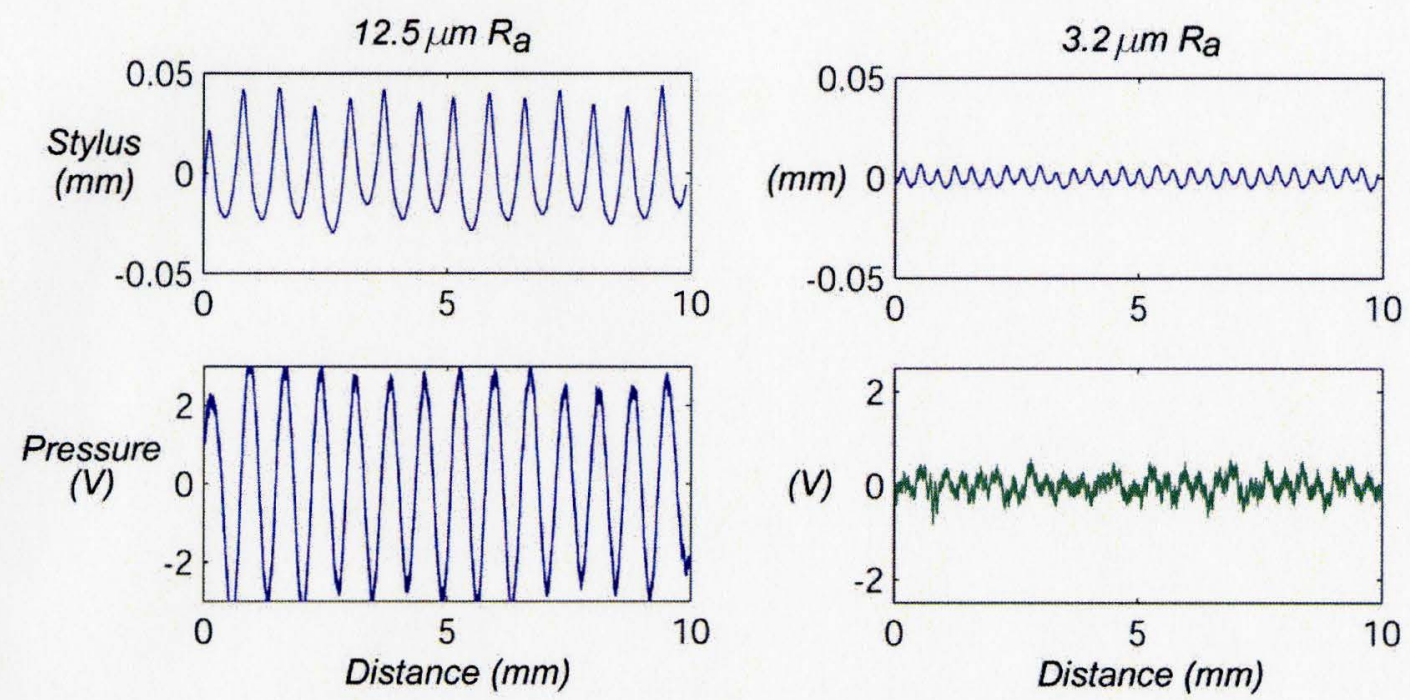

Figure 4.32: Stylus and Pressure Signal Comparison of Turned Surfaces (12.5 $\mu m$ and $\left.3.2 \mu m R_{a}\right)$

When comparing the signals directly, it is clear that the pneumatic system is capable of detecting the changes in the surface directly. The variation of the pressure signals is verified using the stylus measurements and then again by comparing the dominant frequencies from both of the signals. As seen in Table 4.8, the percent error of the dominant frequencies is slightly higher that $3 \%$ for the $12.5 \mu \mathrm{m} \mathrm{R}_{\mathrm{a}}$ signal and less than $1.5 \%$ for the other samples.

Table 4.8: Dominant Frequency Comparison from Turned Surface Standards

\begin{tabular}{|c|c|c|c|}
\cline { 2 - 3 } \multicolumn{1}{c|}{} & Stylus & Pressure & \multicolumn{1}{c|}{} \\
\hline $\begin{array}{c}\text { Standard } \\
R_{a} \\
(\mu \mathrm{m})\end{array}$ & $\begin{array}{c}\text { Dominant } \\
\text { Frequency } \\
(\mathrm{Hz})\end{array}$ & $\begin{array}{c}\text { Dominant } \\
\text { Frequency } \\
(\mathrm{Hz})\end{array}$ & $\begin{array}{c}\text { \% Error } \\
(\%)\end{array}$ \\
\hline 12.5 & 9.15 & 9.46 & 3.39 \\
\hline 6.3 & 14.24 & 14.04 & 1.40 \\
\hline 3.2 & 19.33 & 19.23 & 0.52 \\
\hline 1.6 & 33.57 & 34.01 & 1.31 \\
\hline
\end{tabular}


M. A. Sc. Thesis McMaster University-Mechanical Engineering Drew A. Grandy
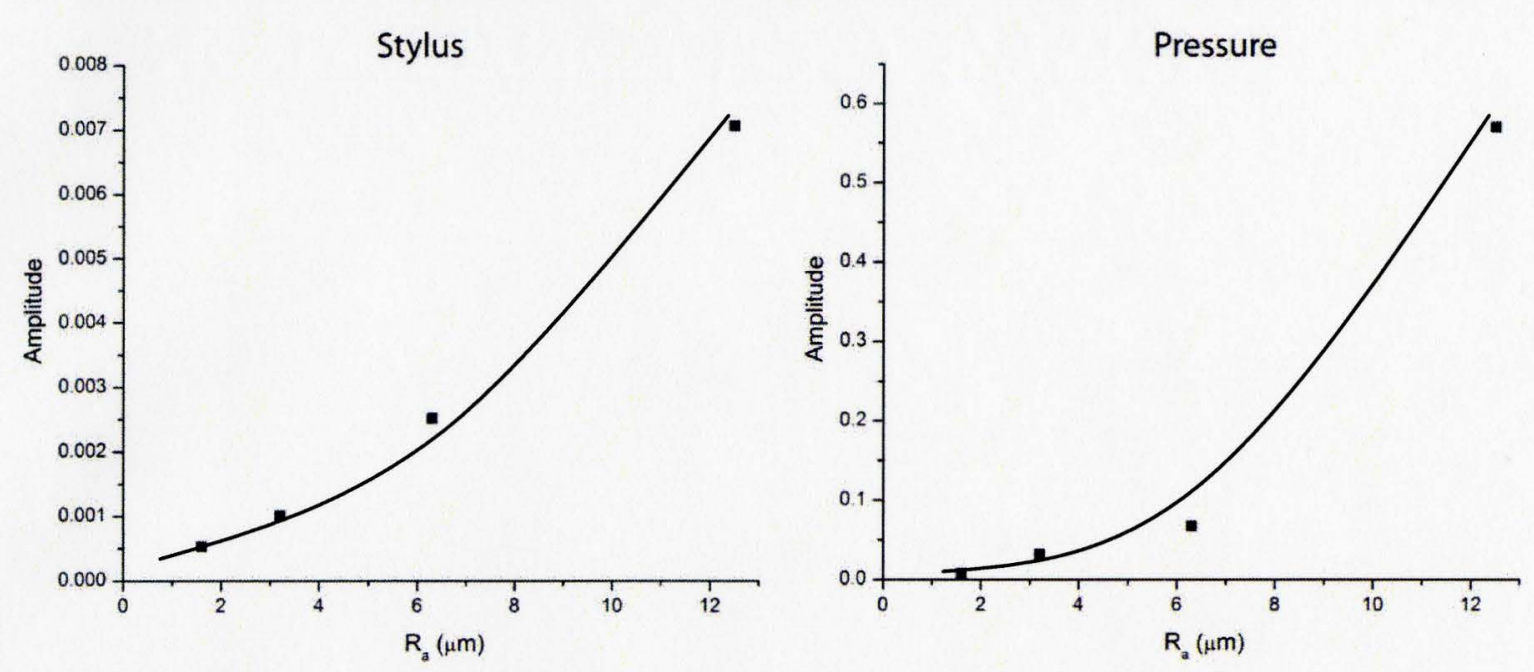

Figure 4.33: Amplitudes at Dominant Frequencies Comparison for Turned Surface Standards
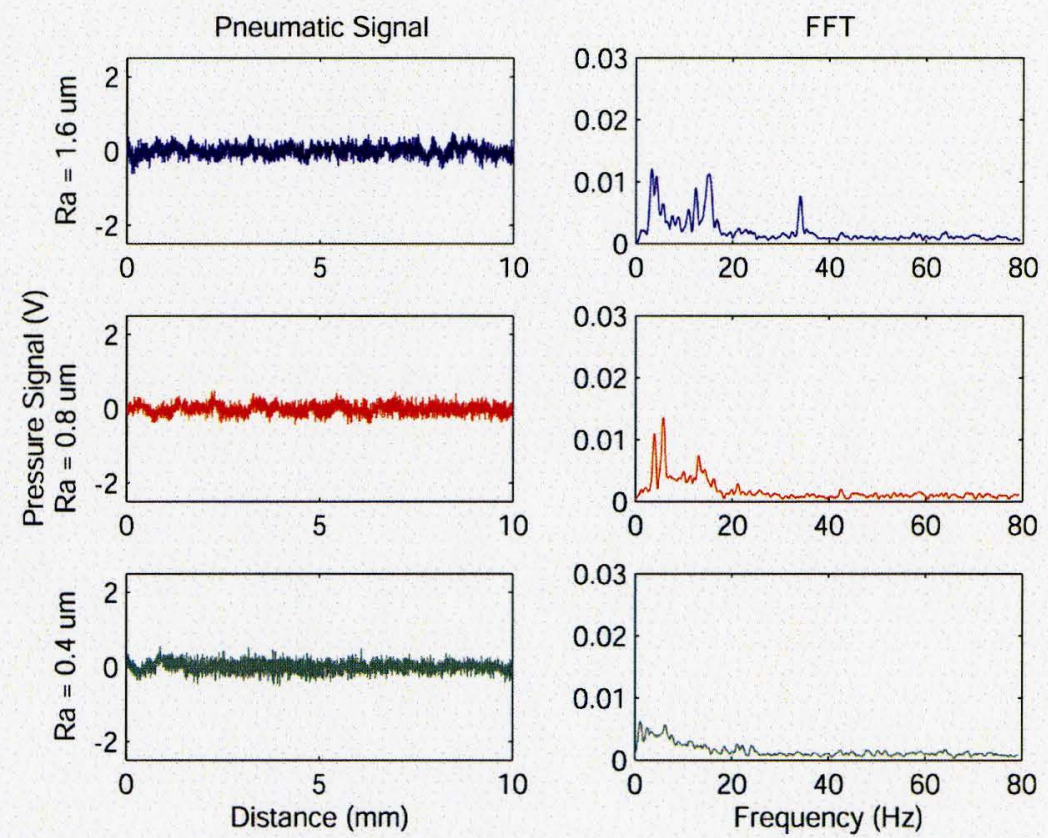

Figure 4.34: Backpressure Signals from Turned Standards (1.6-0.4 $\left.\mu m R_{a}\right)$ $P s=138 \mathrm{kPa}, \mathrm{Dn}=0.58 \mathrm{~mm}, D c=0.51 \mathrm{~mm}$ 


\section{A. Sc. Thesis McMaster University - Mechanical Engineering Drew A. Grandy}

It is much more difficult to select a single dominant frequency for the standards below $1.6 \mu \mathrm{m}$ because the surfaces have a much more distributed frequency content with very small amplitudes as found in the stylus measurements. Although we cannot distinguish a dominant frequency from the signals for the smaller $R_{a}$ values, it is possible to see where the major contributing frequencies lie by using multiple signals to create a waterfall plot of the frequency domain.

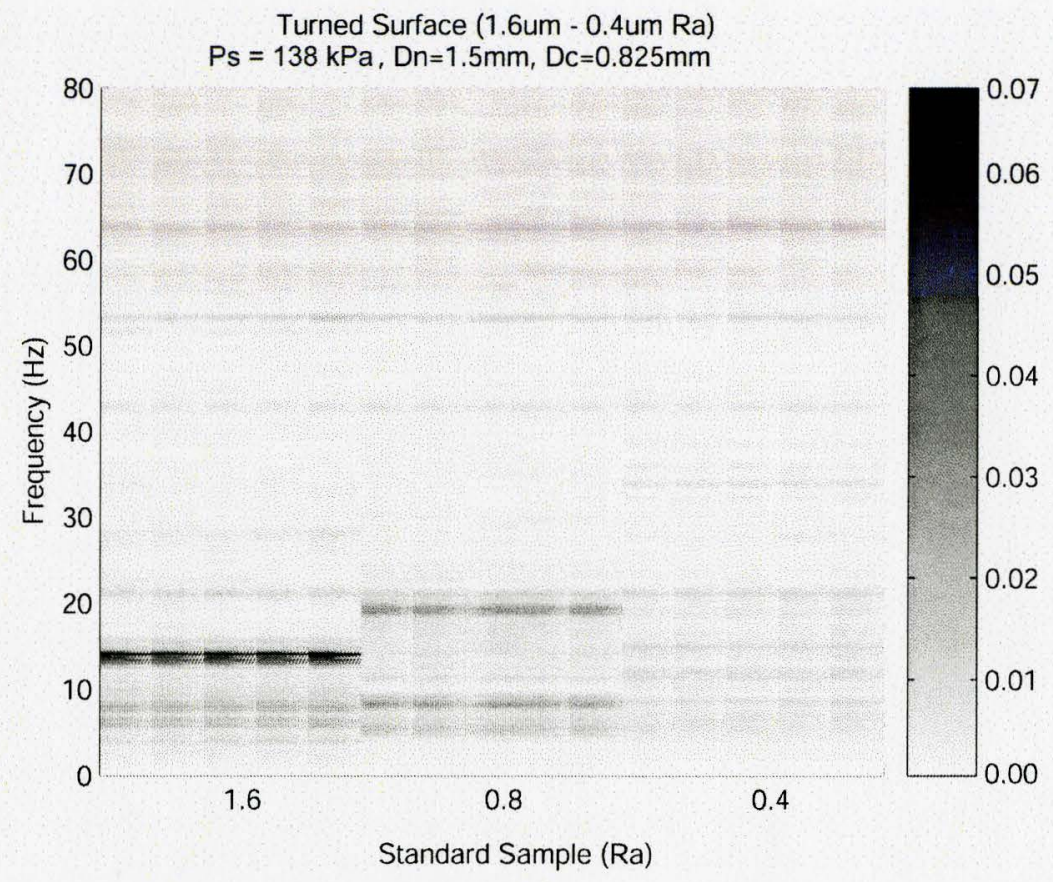

Figure 4.35: Topographic view of FFT Waterfall Plot from Turned Surface Standards

The topographic view of the frequency domain in Figure 4.35 clearly demonstrates the frequency bands that are present in the pneumatic signal as a result of the characteristics of the surfaces being measured. These can be confirmed with the stylus measurements presented in Figure 4.8 from Section 4.1.2. It is also clear that the signals 
M. A. Sc. Thesis McMaster University - Mechanical Engineering Drew A. Grandy

obtained from the $0.4 \mu \mathrm{m} \mathrm{R}_{\mathrm{a}}$ sample do not stand out against the other noise present within the signals, a gain proving the limit of the pneumatic system to be capable of detecting surfaces with roughnesses at or above $0.8 \mu \mathrm{m} R_{\mathrm{a}}$.

\subsubsection{Pneumatic Aisessment of Ground Surfaces}

The ground surface standards have been selected to test the ability of the pneumatic system to characterize surfaces that have been generated using tools without a distinct cutting edge 10 create evenly spaced serrations to the work surface like the milled and turned surfaces. Since ground surfaces typically do not contain a clear dominant frequency as seen in Section 4.1.3, the methods proposed for signal analysis will be truly tested. Another factcr which causes difficulty for the pneumatic system is that ground surfaces typically have a low $R_{a}$ values and as seen in the previous tests, it was found that the pneumatic device is only capable of detecting surfaces down to $0.8 \mu \mathrm{m} \mathbf{R}_{\mathrm{a}}$. Similarly to the previous tests, since the ground standards have $R_{a}$ values that are below $1.6 \mu \mathrm{m} R_{a}$, the 20GDn05Dc nozzle has been used with a supply pressure of $138 \mathrm{kPa}(20 \mathrm{psi})$, the piezoelectric pressure transducer, a standoff distance of $50 \mu \mathrm{m}$, and a nozzle feed rate of $400 \mathrm{~mm} / \mathrm{min}$. 
M. A. Sc. Thesis McMaster University - Mechanical Engineering Drew A. Grandy
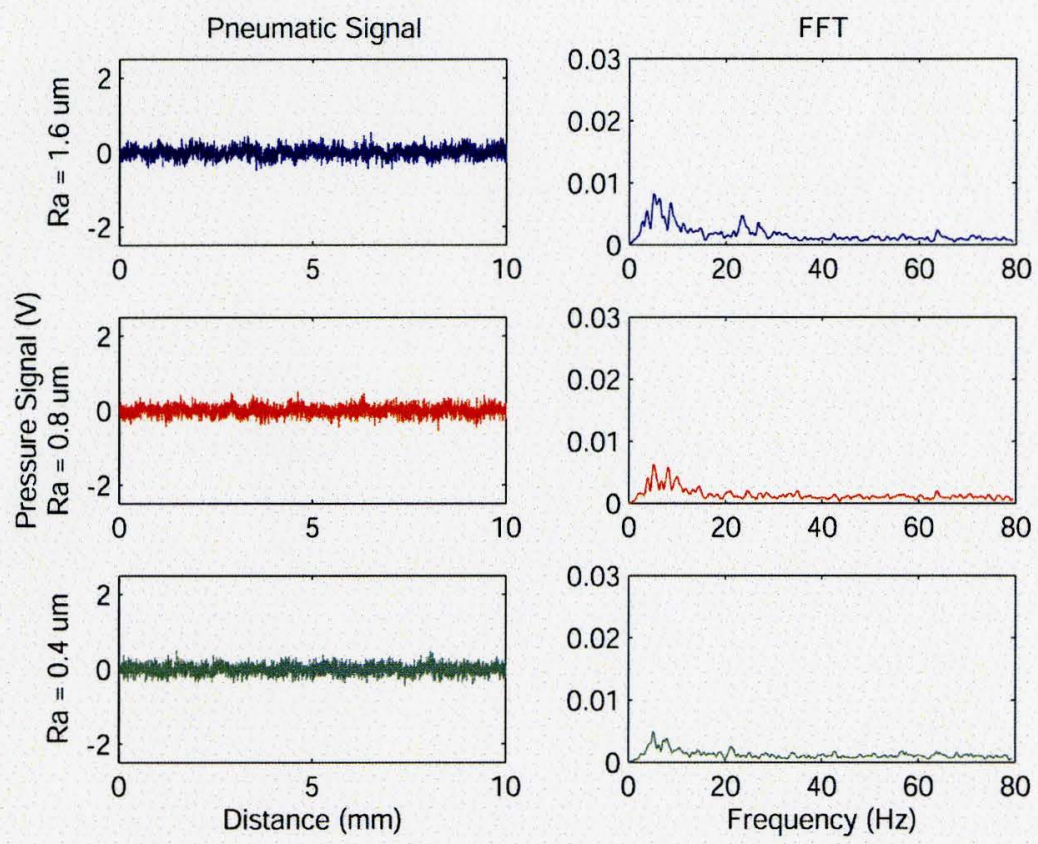

Figure 4.36: Backpressure Signals from Ground Standards (1.6-0.4 $\left.\mu m R_{a}\right)$ $P s=138 \mathrm{kPa}, \mathrm{Dn}=0.58 \mathrm{~mm}, D c=0.51 \mathrm{~mm}$
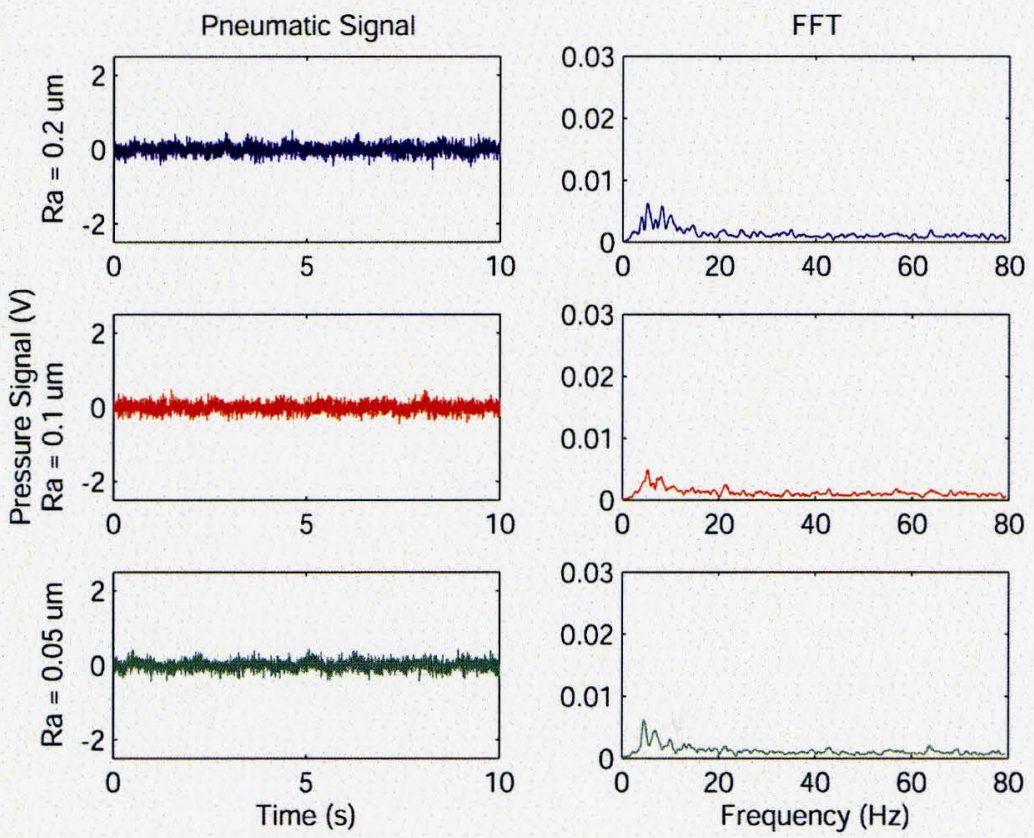

Figure 4.37: Backpressure Signals from Ground Standards $\left(0.2-0.05 \mu m R_{a}\right)$ $P s=138 \mathrm{kPa}, D n=0.58 \mathrm{~mm}, D c=0.51 \mathrm{~mm}$ 
M. A. Sc. Thesis McMaster University - Mechanical Engineering Drew A. Grandy

Visually it is very difficult to distinguish the back pressure signals acquired from the ground surfaces except for the $1.6 \mu \mathrm{m} \mathrm{R}_{\mathrm{a}}$ sample where the frequency content between 20 and $40 \mathrm{~Hz}$ is different from the other samples. This characteristic can be verified by comparing the stylus measurement for the $1.6 \mu \mathrm{m} \mathrm{R}_{\mathrm{a}}$ sample in Figure 4.11 from Section 4.1.3. Another interesting feature of the ground surfaces from the stylus measurements is that the frequency content of the signal occurring between 60 and $80 \mathrm{~Hz}$ is slightly shifting in o the higher frequency range while decreasing in magnitude as the $R_{a}$ values are dropping in each of the standards. In the back pressure signals acquired there is a peak in the frequency domain occurring around $65 \mathrm{~Hz}$ in all of the signals with slightly varying amplitudes for the different surfaces, however there is not enough evidence to directly relate this to measurement surface. When looking at the waterfall plot of the frequency domain of the backpressure signals in Figure 4.38, it is quite clear that only the $1.6 \mu \mathrm{m} / \mathrm{R}_{\mathrm{a}}$ sample can be clearly defined using the analysis techniques proposed for the pneumatic gauging system. 
M. A. Sc. Thesis McMaster University - Mechanical Engineering Drew A. Grandy

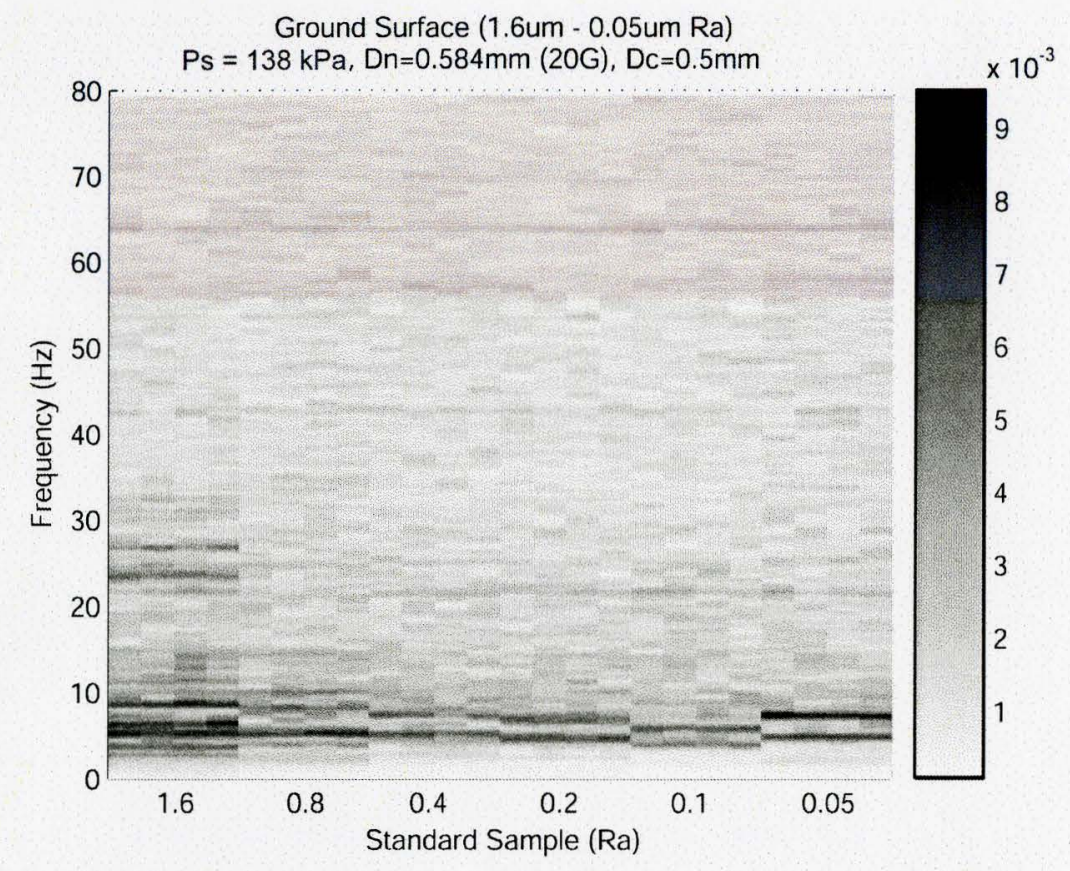

Figure 4.38: Ground Surface Waterfall Topography of the Frequency Domain

For ground surfaces, it is clear that a more sensitive pneumatic system and/or more advanced analysis methods must be developed to obtain repeatable accurate results. Methods such as wavelet decomposition into the frequency domain and multivariate analysis could be some solutions to distinguishing slight variation in the backpressure signal for surfaces that have $\mathrm{R}_{\mathrm{a}}$ values lower than $1.6 \mu \mathrm{m}$.

\subsection{Pneumatic Characterization of a Jominy Sample in a Turning Environment}

In the experiments involving the FLEXBAR surface standards, a major contributor to the variation between the surfaces of different $R_{a}$ values was that the samples had been created using different feed rates resulting in different dominating frequencies. Typically in real world applications, the surfaces that would be monitored 
M. A. Sc. Thesis McMaster University - Mechanical Engineering Drew A. Grandy are created using the same cutting parameters and variation in the roughness often occur with tool wear, the presence of built-up edge, or variations in the workpiece material over time. In order to inıplement a pneumatic system, such as the one developed in this research, into real world situations, it is important to characterize how the device will operate under real world conditions. For these experiments, a cylindrical Jominy bar was cut in a lathe using typical cutting conditions resulting in a varying roughness over the length of the workpiece while maintaining the same dominant frequency caused by the feed rate of the cuttirig tool.

\subsubsection{Jominy Bar Workpiece}

A Jominy bar: is a cylindrical piece of steel of diameter of $\sim 25 \mathrm{~mm}$ that has been heated to the austenitising temperature and quenched from one end with a controlled and standardized jet of water resulting in a nonlinear, continuously changing hardness along the length of the workpiece. As a result, when the part is cut in a lathe, the roughness will continuously vary across the workpiece due to the change in hardness. Figure 4.39 displays how the hardness drops across the sample causing an increase in roughness over the length of the samiple. A major contributor to the increase of roughness is because of the instability of the built-up edge on the cutting tool as the hardness decreases. This unique feature of the Jominy bar allows for a wide range of roughnesses on a single workpiece and eliminates any variation that might come from mounting different samples of various roughnesses. 
M. A. Sc. Thesis McMaster University - Mechanical Engineering Drew A. Grandy
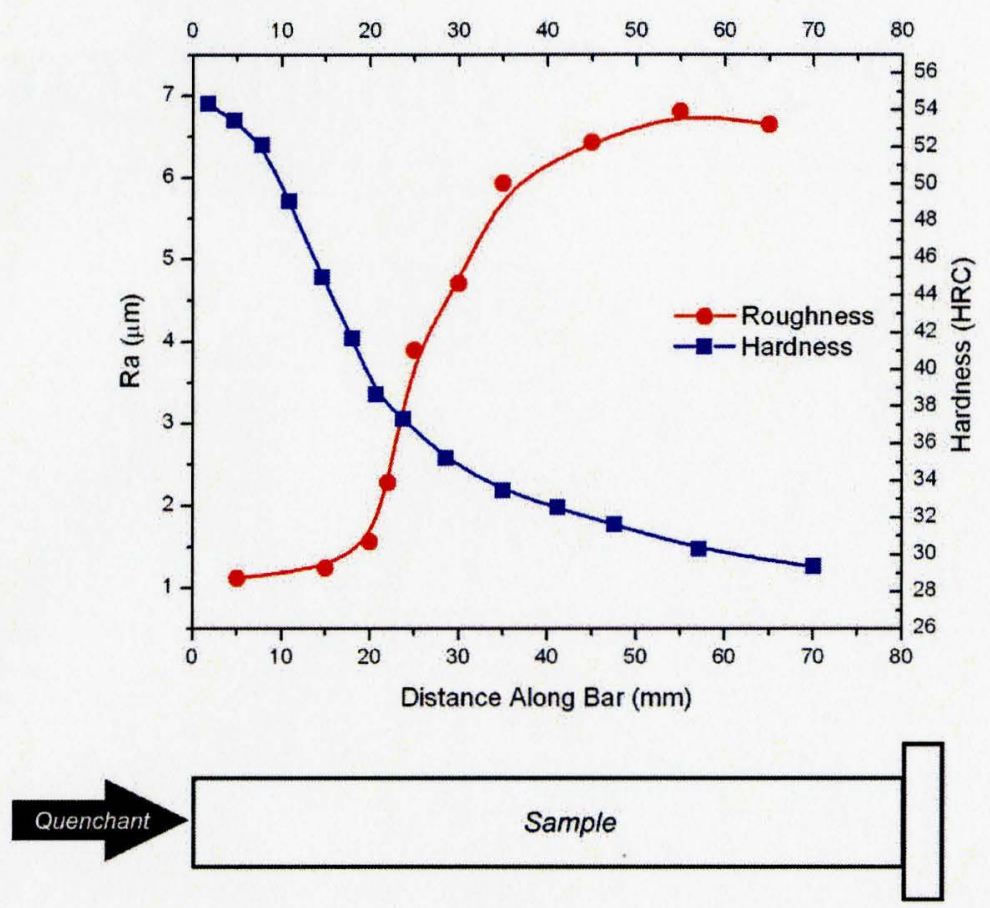

Figure 4.39: Hardness and Roughness along the Jominy Sample

To prepare the workpiece for the experiments, the piece was held between centers and a truing pass was taken followed by the finishing pass for the final surface characteristics that was measured using the pneumatic gauging system. The cutting parameters used for preparing the sample are presented in Table 4.9 and are typical of those used during turning operations. 


\section{A. Sc. Thesis McMaster University-Mechanical Engineering Drew A. Grandy}

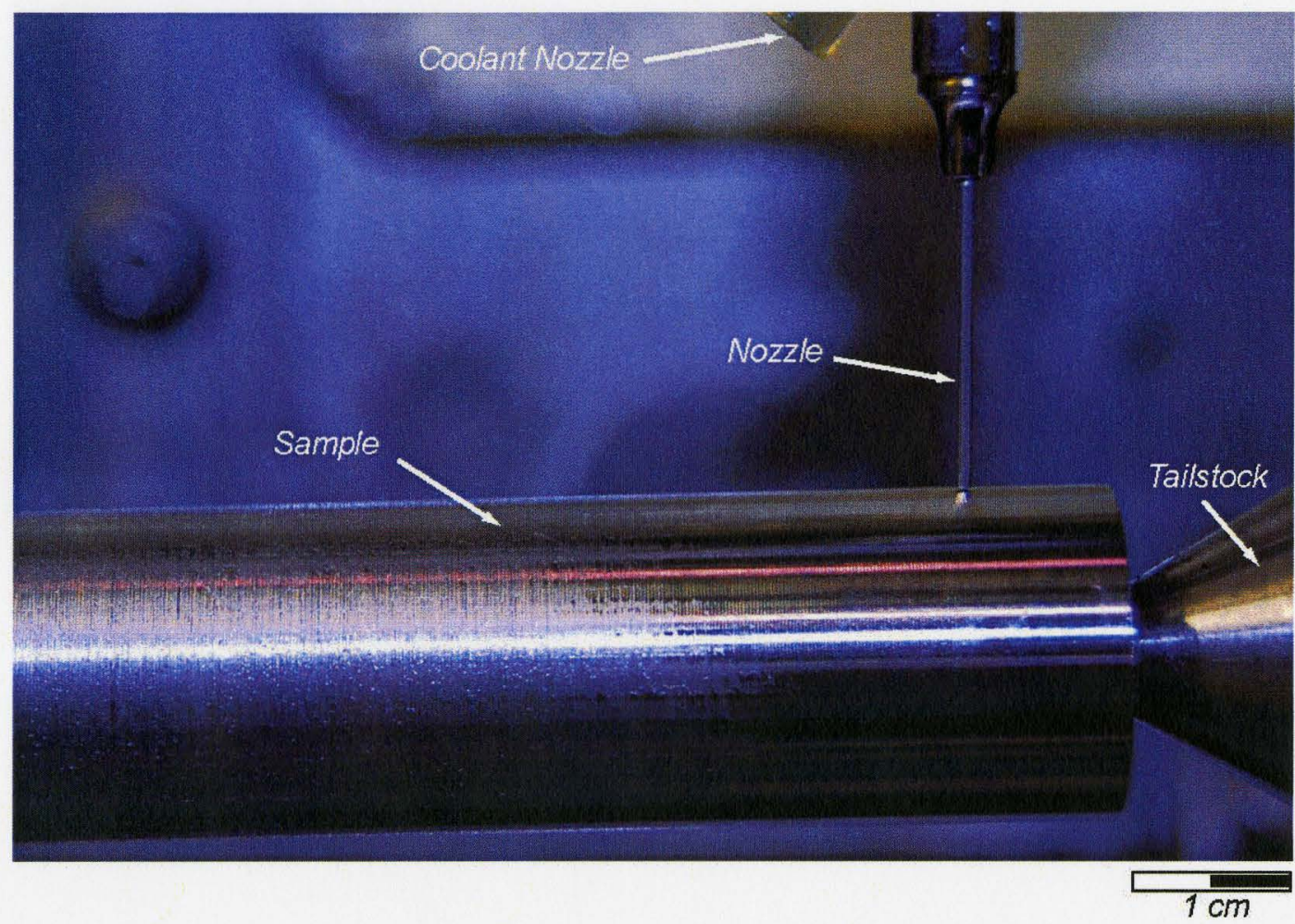

Figure 4.40: Jominy Sample and Pneumatic Nozzle Setup

Table 4.9: Cutting Parameters used for Jominy Sample

\begin{tabular}{l|r}
\hline \hline Workpiece Diameter (D) & $25 \mathrm{~mm}$ \\
Cutting Speed (V) & $30 \mathrm{~m} / \mathrm{min}$ \\
Feed Rate (f) & $0.2 \mathrm{~mm} / \mathrm{rev}$ \\
Depth of Cut (d) & $0.1 \mathrm{~mm}$ \\
Tool Nose Radius (r) & $800 \mu \mathrm{m}$ \\
Cutting Fluid & Dry \\
\hline \hline
\end{tabular}

Similar to the surface standards that were used for analysis in Section 4.1, the Jominy sample was first characterized using the Mitotoyo Formtracer CS-5000 to get a physical comparison for the pneumatic backpressure signals. From the stylus measurements, the frequency domain of the sample was calculated by assigning a feed 
M. A. Sc. Thesis McMaster University - Mechanical Engineering Drew A. Grandy rate of $100 \mathrm{~mm} / \mathrm{min}$ to convert the measurements into the time domain, as this was the feed rate used for the nozzle during the pneumatic assessment of the stationary Jominy sample. The FFT's of the signals were then calculated to represent the frequency domain for comparison to the pneumatic signals.

Table 4.10: Calculated $R_{a}$ Values Along the Jominy Sample, Cutoff Length of $0.8 \mathrm{~mm}$

\begin{tabular}{||c|c||}
\hline Distance $(\mathbf{m m})$ & $\begin{array}{c}\text { Average } \\
\boldsymbol{R}_{\boldsymbol{a}}(\boldsymbol{\mu} \boldsymbol{m})\end{array}$ \\
\hline 5 & 1.12 \\
15 & 1.24 \\
20 & 1.56 \\
22 & 2.28 \\
25 & 3.89 \\
30 & 4.71 \\
35 & 5.93 \\
45 & 6.43 \\
55 & 6.81 \\
65 & 6.64 \\
\hline
\end{tabular}
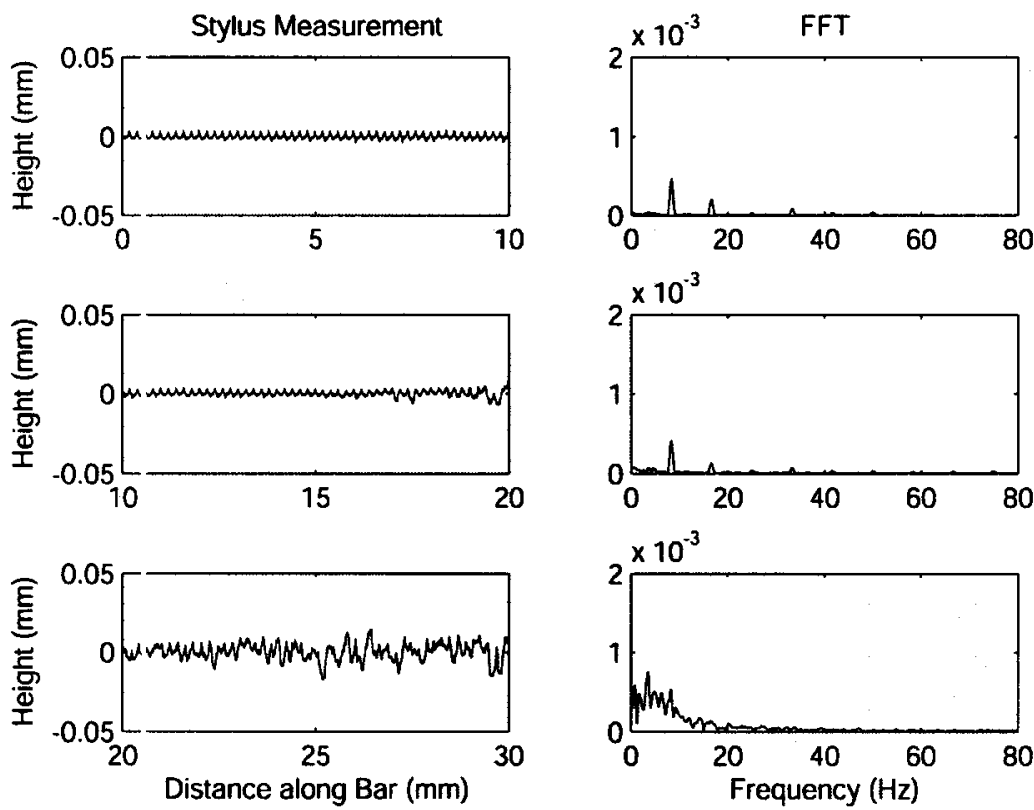

Figure 4.41: Stylus Measurements along Jominy Bar with FFT Corresponding to $F=100 \mathrm{~mm} / \mathrm{min}(0-30 \mathrm{~mm})$ 
M. A. Sc. Thesis McMaster University - Mechanical Engineering Drew A. Grandy
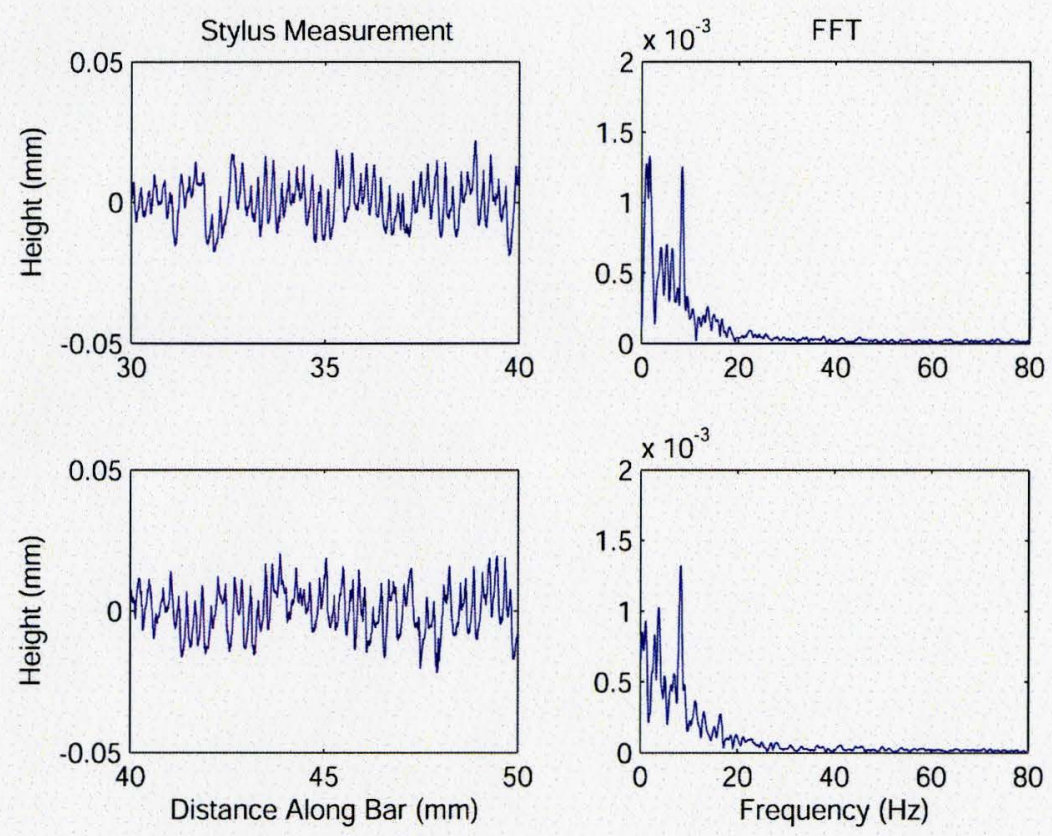

Figure 4.42: Stylus Measurements along Jominy Bar with FFT Corresponding to $F=100 \mathrm{~mm} / \mathrm{min}(30-50 \mathrm{~mm})$
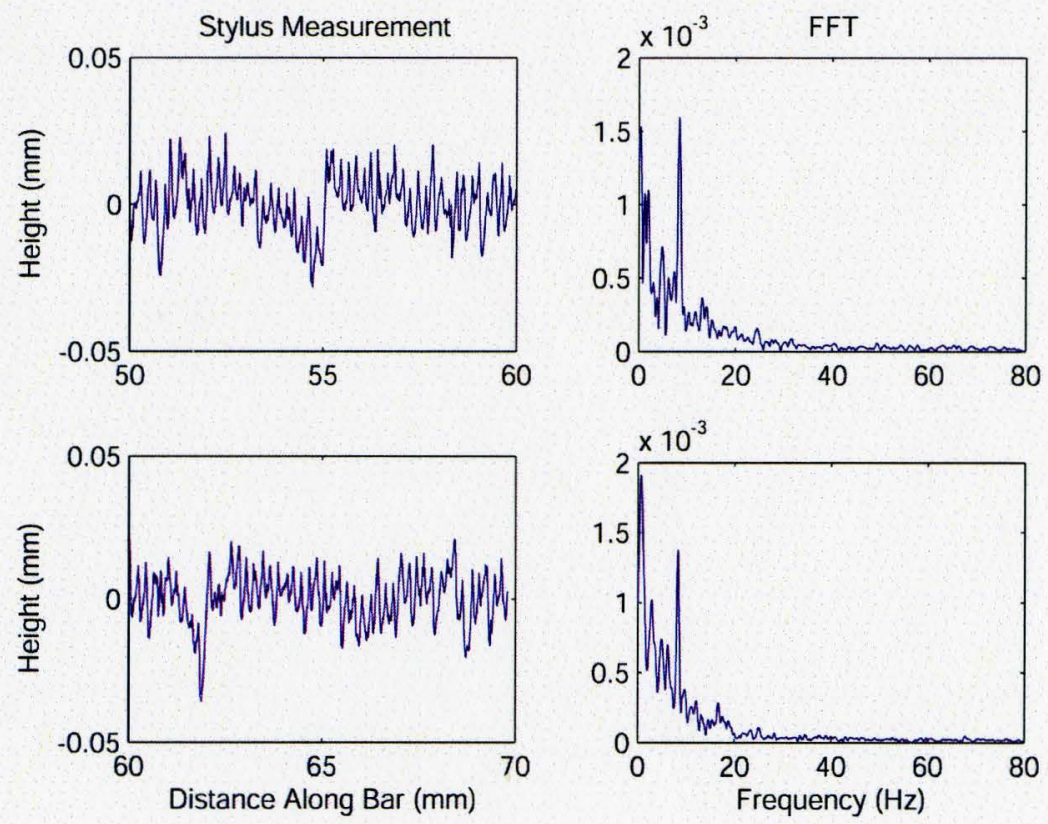

Figure 4.43: Stylus Measurements along Jominy Bar with FFT Corresponding to $F=100 \mathrm{~mm} / \mathrm{min}(50-70 \mathrm{~mm})$ 
M. A. Sc. Thesis McMaster University - Mechanical Engineering Drew A. Grandy

By observing; the trends in the figures presented above, it is clear that the roughness of the surface is increasing and that the frequency content of the surface is also increasing along the length of the bar. As expected, the dominant frequency that is present on the surface as a result of the feed rate used during the cutting process is clearly present in all of the samples. As the roughness is increasing, two important characteristics become evident in the frequency domain. With an increase in roughness, the amplitude at the dominant frequency is increasing and the presence of lower frequency content becomes much stronger. The increase in the lower frequency content can be attributed to the workpiece material being torn away instead of cut and due to the unstable nature of the built up edge that forms on the cutting tool in the softer workpiece material. These trends in the frequency domain will be used as an aid in verifying the results obtained from the pneumatic gauging system. Evidence of this can be clearly seen in Figure 4.44 at $\mathrm{z}=25 \mathrm{~mm}$ where $\varepsilon$. definite ledge has been formed due to the workpiece material being torn out. These characteristics in the surface of the Jominy sample will become much more prominent whe1 characterizing the sample when it is rotating. These locations on the sample will be represented as spikes in the backpressure signal as the nozzle passes over these locations. Further discussion will be provided during the characterization of a rotating workpiece in Section 4.4.3. 


\section{A. Sc. Thesis McMaster University-Mechanical Engineering Drew A. Grandy}

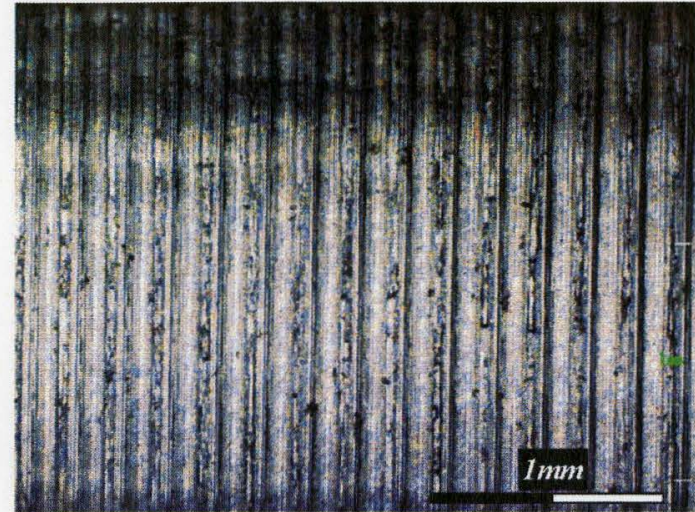

$z=5 \mathrm{~mm}$

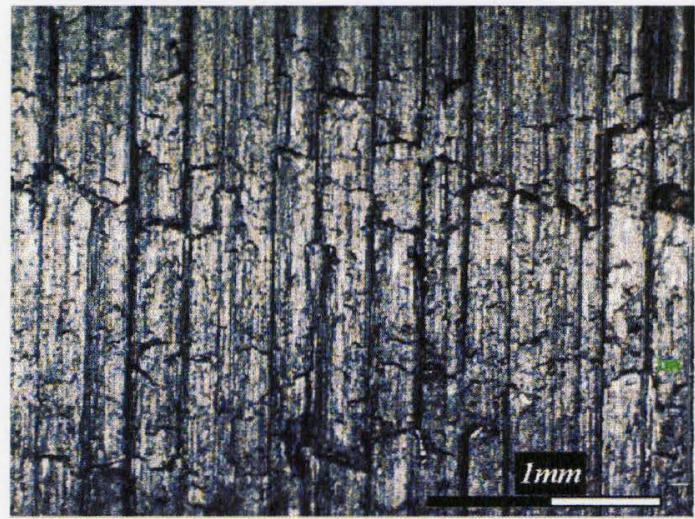

$z=55 \mathrm{~mm}$

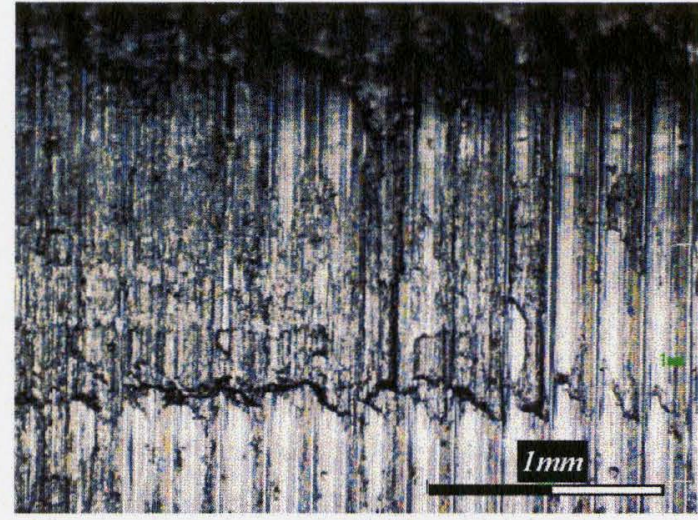

$z=25 \mathrm{~mm}$

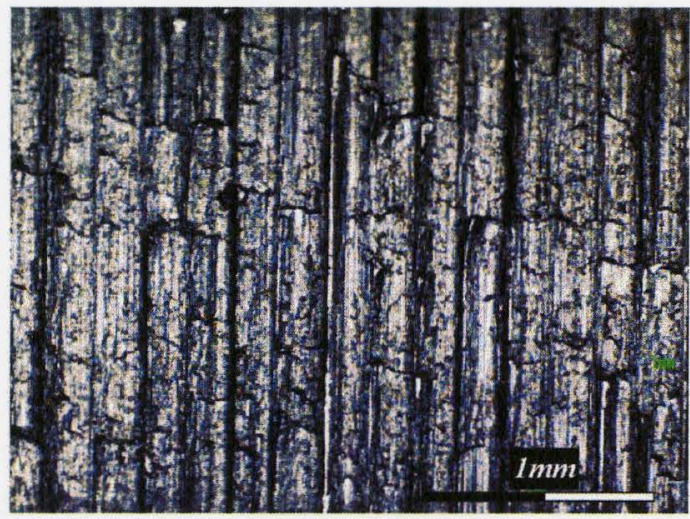

$z=65 \mathrm{~mm}$

Figure 4.44: Images of Select Locations on Jominy Sample

\subsubsection{Pneumatic Surface Assessment of a Stationary Jominy Sample}

For comparisons to the results obtained using the surface standards in Section 4.3, the pneumatic gauging system was fed across the stationary Jominy sample to collect the backpressure signal using the pneumatic device. The pneumatic gauge was adapted to be held in the tool holder so that the position, movement, and feed rate of the device were all controlled by the lathe's controller. Due to a slight taper in the Jominy sample, the standoff distance of the nozzle was adjusted as the nozzle traversed across the surface in order 
M. A. Sc. Thesis McMaster University - Mechanical Engineering Drew A. Grandy

to maintain a constant displacement between the nozzle tip and workpiece. This adjustment was done by the controller of the lathe and because the resolution of the drive controlling the motion of the tool was too large, a stepping motion was introduced into the system causing low frequency $(<1 \mathrm{~Hz})$ peaks within the back pressure signal as seen in Figure 4.46 .
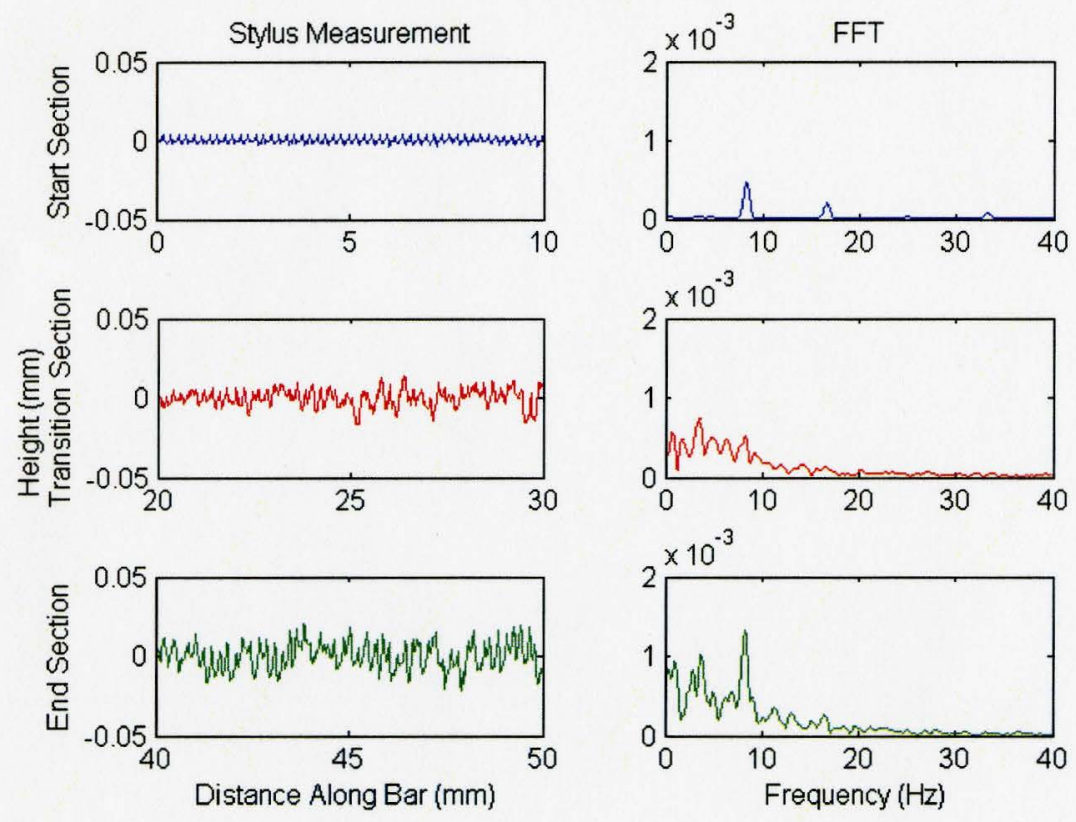

Figure 4.45: Stylus Measurements and FFT at Select Locations of Jominy Bar (F=100mm/min) 

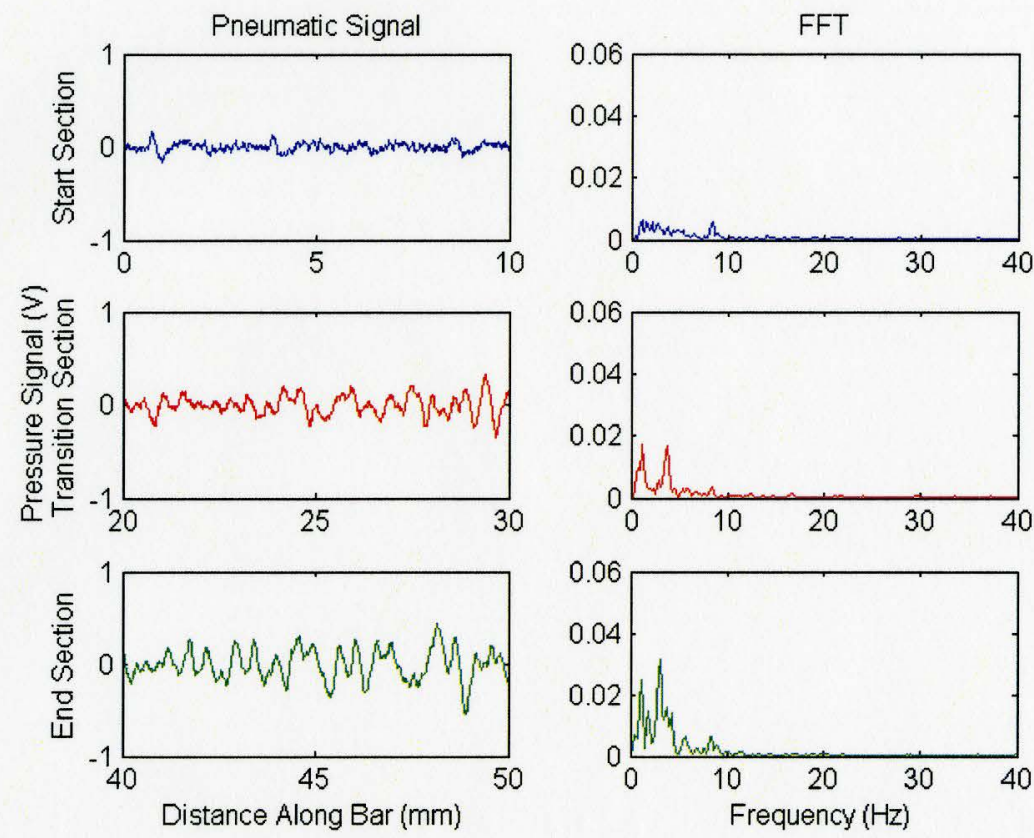

Figure 4.46: Backpressure Signal and FFT at Select Locations of Jominy Bar $(P s=138 \mathrm{kPa}, F=100 \mathrm{~mm} / \mathrm{min})$

Comparing Figure 4.45 and 4.46, it is clear that the pneumatic device is capable of detecting the changes in roughness over the length of the bar by the similar distinguishing characteristics in the signals of the different sections. In the raw pressure signals of Figure 4.46, the change in amplitude of the surface that occurs within the $20-30 \mathrm{~mm}$ and $40-50 \mathrm{~mm}$ sections are present in both the stylus measurement as well as the backpressure signal. This is the phenomenon that is occurring in the lower frequency range which is represented in the FFT plots at $3.8 \mathrm{~Hz}$ as an increase in amplitude. The frequency content occurring at $8.4 \mathrm{~Hz}$ is a result of the cusps created on the surface during the turning process corresponding to the feed rate of the cutting tool. In the stylus measurements of the Jominy sample, the amplitude in the frequency domain occurring at 


\section{A. Sc. Thesis McMaster University - Mechanical Engineering Drew A. Grandy}

this frequency is increasing as the roughness of the sample is increasing. In the backpressure signals however, there is very little increase in the amplitude occurring at the cutting frequency as would have been expected. This can be attributed to the nozzle of the pneumatic gauge and that the changes in backpressure are being measured as the mean variation in distance between the nozzle tip and workpiece over the circular area of the nozzle as opposed to a single point which is taken by a stylus. As a result, the larger peak to valley distances present in the rougher regions of the sample tend to dominate the change in escape area of the nozzle making the smaller peak to valley distances occurring at the cutting frequency less prominent in the backpressure fluctuations.

A study was also completed to determine the effect of increasing the feed rate of the nozzle across the surface and outline the limitations of the developed system when being used on a noll-rotating workpiece. In addition to the tests that were displayed previously with a feed rate of $100 \mathrm{~mm} / \mathrm{min}$, three higher feed rates of $200 \mathrm{~mm} / \mathrm{min}$, $300 \mathrm{~mm} / \mathrm{min}$, and $400 \mathrm{~mm} / \mathrm{min}$ were used with the results presented in Figures 4.47 through 4.49 . 

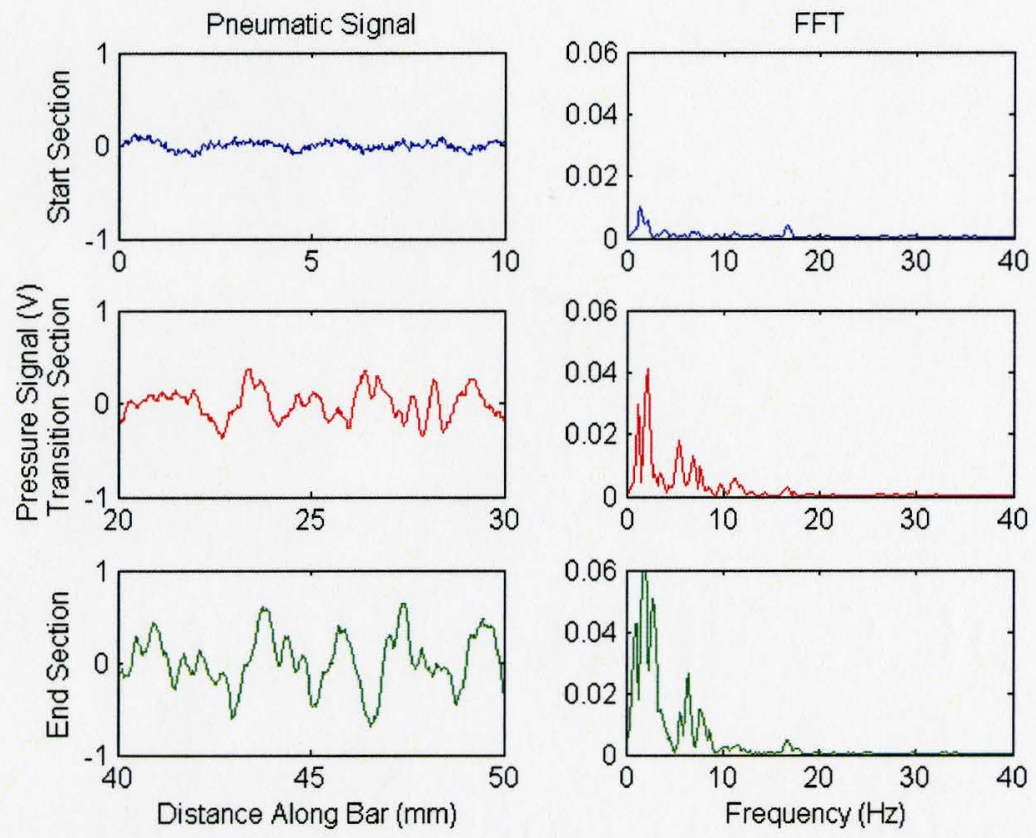

Figure 4.47: Backpressure Signal and FFT at Select Locations of Jominy Bar $(P s=138 \mathrm{kPa}, F=200 \mathrm{~mm} / \mathrm{min}$ )
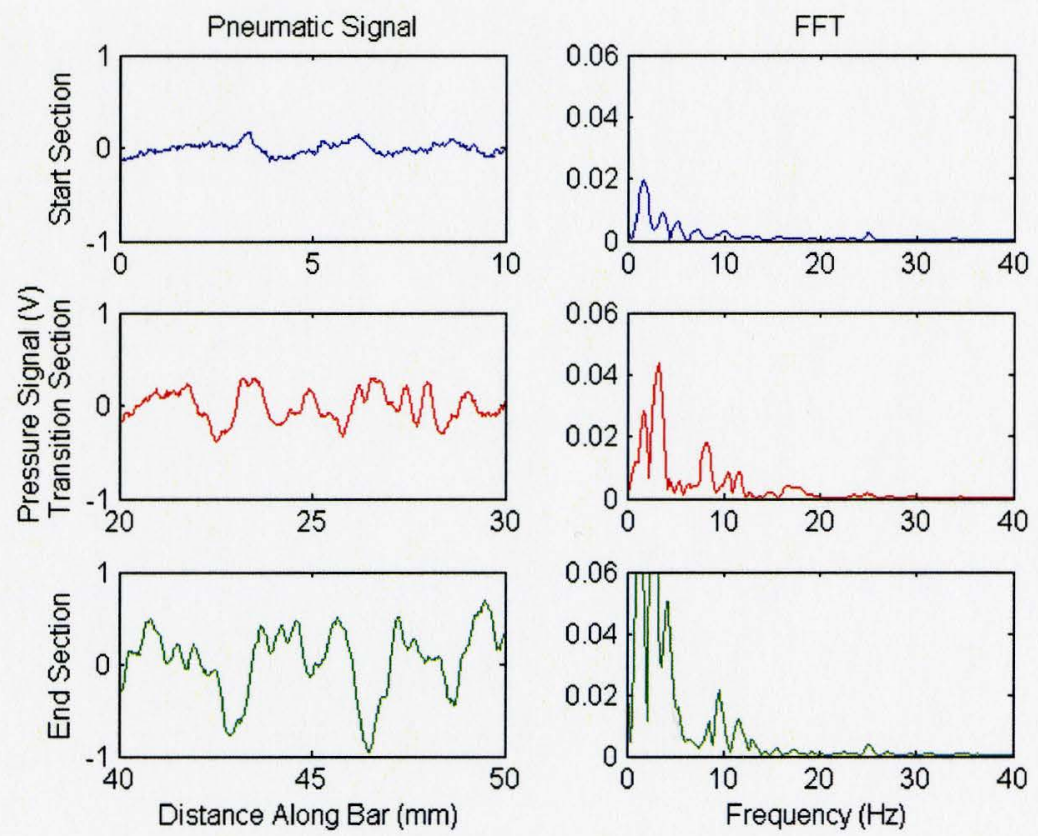

Figure 4.48: Backpressure Signal and FFT at Select Locations of Jominy Bar $(P s=138 \mathrm{kPa}, F=300 \mathrm{~mm} / \mathrm{min}$ ) 

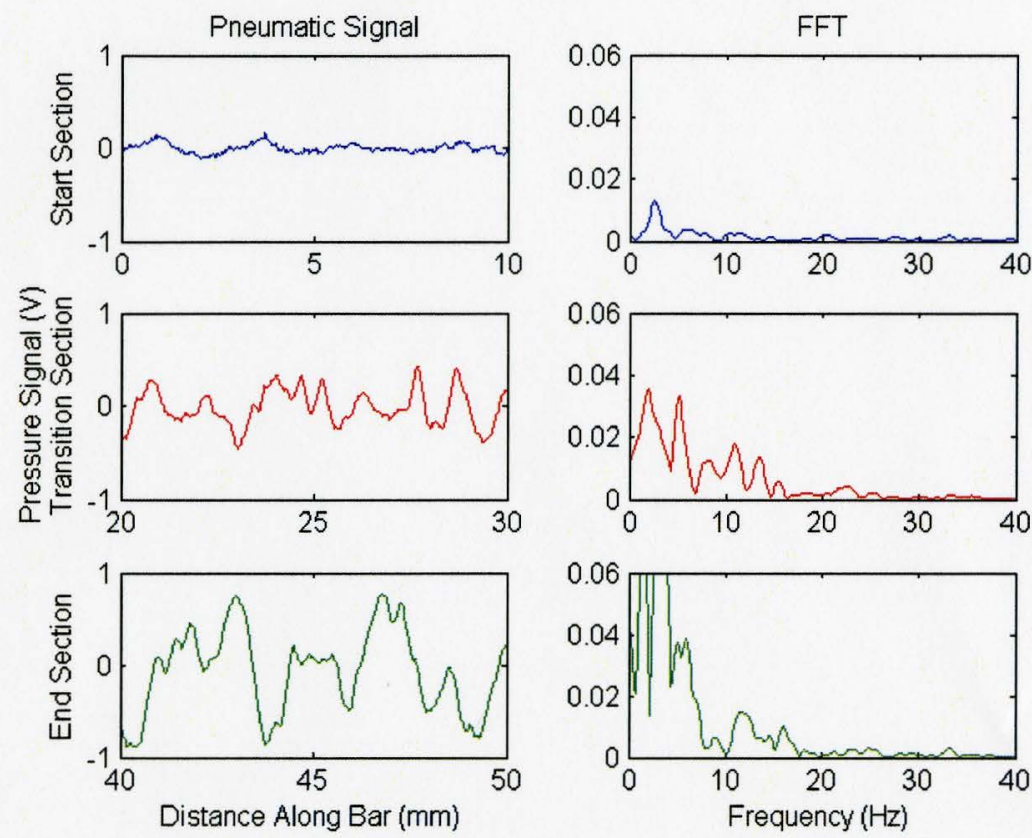

Figure 4.49: Backpressure Signal and FFT at Select Locations of Jominy Bar $(P s=138 \mathrm{kPa}, F=400 \mathrm{~mm} / \mathrm{min})$

By increasing the feed rate of the nozzle, it becomes clear that the details that were present in the backpressure signal from the slower speeds begin to disappear. Features such as the small pressure fluctuations caused by the passing cusps on the surface begin to diminish with increasing feed rates and the lower frequency content caused by the large peak to valley changes in the roughest section of the bar begin to dominate the entire signal. Within the frequency domain we can still detect the frequency content created by the passing cusps on the surface as the small peak that is moving into the higher frequency range as the feed rate is increased. It is evident that for the most accurate backpressure signal, using a slower nozzle feed rate is much more beneficial for reproducing a signal that is most representative of the surface being measured. For the 
M. A. Sc. Thesis McMaster University - Mechanical Engineering Drew A. Grandy non-rotating workpiese, using a feed rate of $100 \mathrm{~mm} / \mathrm{min}$ is the most appropriate for characterizing the changing surface across the Jominy sample.

\subsubsection{Pneumatic Surface Assessment of a Rotating Jominy Sample}

In the further development of the pneumatic gauging system for online measurements, the backpressure signal acquired from a rotating workpiece has been analyzed while defining the limitations of the device in an environment similar to that of a real world application. To achieve this, the Jominy sample was again mounted in the machining center alorg with the pneumatic gauge while acquiring signals to investigate the effects of changing many different parameters within the system. Two different methods to monitor the variation in the roughness across the bar were conducted. The first involved rotating the workpiece and feeding the nozzle across the sample similar to what was done in the non-rotating tests. The second method is to introduce the gauging system to different locations on the sample with the workpiece spinning while keeping the nozzle stationary and comparing the backpressure signals at each location. Method one would be similar to an application where the entire surface of the workpiece needs to be characterized in real time by either a pneumatic system implemented into the cutting tool or as a trailing unit, where as the second method is more representative of an application where only the roughness at a specific location on a workpiece must be assessed. 
M. A. Sc. Thesis McMaster University - Mechanical Engineering Drew A. Grandy

Since the wolkpiece is rotating, the backpressure signals being acquired no longer represent the variation of the profile along a single line but now reflect the surface characteristics around the entire bar. It is this feature of the pneumatic gauging system that gives insight into how the surface is changing around the entire sample in real time as opposed to stylus; methods where the measurements must be done post process and only reflect the surface along a single line.

It is also imprortant to note that the frequency domain of the backpressure signals will not reflect the dominant frequencies that would be expected from the cutting tool feed rates, but rather represent how much variation and the amplitudes of these variations occurring around the sample. It is expected that the major and minor frequencies within the backpressure signal should be located at the rotational frequency of the part and the subsequent harmonizs of that frequency.

Analysis of a Rotating Workpiece while Traversing the Nozzle

The same prirameters that were used to cut the workpiece have been used for the collection of the backpressure signals. Using the same parameters as the cutting operation mimics how the sensor would respond as a trailing unit to the cutting tool in a real world monitoring application. These parameters are presented in Table 4.11. 
M. A. Sc. Thesis McMaster University - Mechanical Engineering Drew A. Grandy

Table 4.11: Gauging Parameters for Rotating Workpiece with Nozzle Feed

\begin{tabular}{l|r}
\hline \hline Workpiece Diameter (D) & $25 \mathrm{~mm}$ \\
Cutting Speed (V) & $30 \mathrm{~m} / \mathrm{min}$ \\
Rotational Speed (v) & $477 \mathrm{RPM}$ \\
Rotational Frequency & $7.95 \mathrm{~Hz}$ \\
Nozzle Feed Rate (f) & $0.2 \mathrm{~mm} / \mathrm{rev}$ \\
Stand-off Distance (SOD) & $50 \mu \mathrm{m}$ \\
Supply Pressure (Ps) & $138 \mathrm{kPa}$ \\
Nozzle & $20 G D n 05 \mathrm{Dc}$ \\
\hline
\end{tabular}
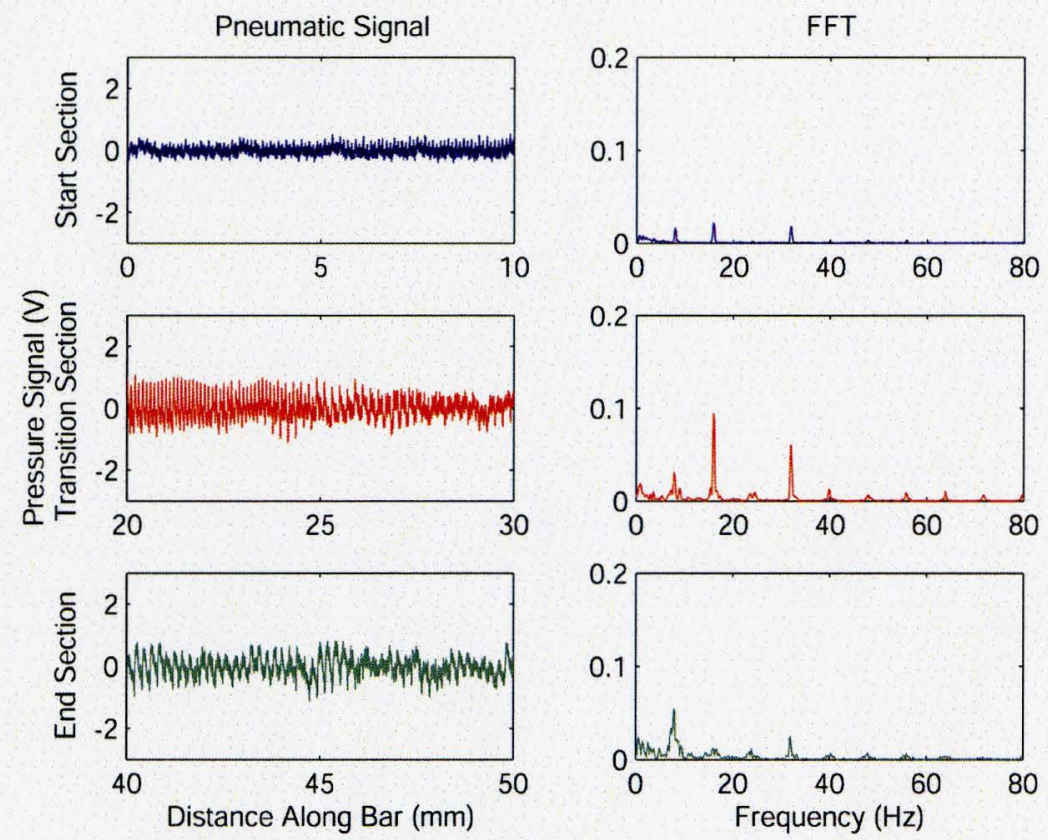

Figure 4.50: Backpressure Signal and FFT for Select Locations of Rotating Jominy Sample $(V=30 \mathrm{~m} / \mathrm{min}, S O D=50 \mu \mathrm{m}, F=0.2 \mathrm{~mm} / \mathrm{rev}, P s=138 \mathrm{kPa})$

Similar to the work done on the non-rotating workpiece, the standoff distance of the nozzle must be adjusted over the length of the bar to compensate for the slight taper in the sample. This is present in the backpressure signals of Figure 4.50 as the low frequency undulations that occur periodically, however this does not interfere with the 
M. A. Sc. Thesis McMaster University - Mechanical Engineering Drew A. Grandy important informatior that can be found in the frequency domain. From the FFT plots of the three samples in Jigure 4.50 , the rotational frequency and the subsequent harmonics are the dominating frequencies in the backpressure signals as expected.

Table 4.12: Amplitudes of FFT at Dominant Frequencies

\begin{tabular}{c|c|c|c|c}
\hline & \multicolumn{4}{|c}{ Amplitudes at Dominant } \\
Section & $R_{a}(\mu \mathrm{m})$ & $7.9 \mathrm{~Hz}$ & $15.8 \mathrm{~Hz}$ & $31.6 \mathrm{~Hz}$ \\
\hline \hline $0-10$ & 1.12 & 0.016 & 0.022 & 0.018 \\
$20-30$ & 3.89 & 0.031 & 0.092 & 0.060 \\
$40-50$ & 6.43 & 0.054 & 0.010 & 0.024 \\
\hline
\end{tabular}

The importart information within the frequency domain of the backpressure signals taken from the Jominy bar is how the amplitude of the signal is varying at each of these frequencies. The fluctuations occurring at $7.9 \mathrm{~Hz}$ is representative of the changes in the surface occurring within one rotation and since the nozzle is fed across the surface at the same feed rate as what the part was cut, one rotation of the part introduces a new cusp into the gauging area of the nozzle. As a result, the increase in amplitudes in this column of Table 4.12 is a result of the increase in peak to valley distance and an increase in $R_{a}$ at the cutting frequency on the surface. There was a concern that the fluctuations occurring at these frequencies were a result of run-out of the workpiece as it rotated, however on further investigation the run-out around the sample was less than the fluctuations in the surface as a result of the roughness.

The amplitudes of the signals occurring at $15.8 \mathrm{~Hz}$ and $31.6 \mathrm{~Hz}$ are a result of changes in the surface in half rotation intervals, and quarter rotation intervals 
M. A. Sc. Thesis McMaster University - Mechanical Engineering Drew A. Grandy

respectively. From these frequencies we can gauge how the surface is fluctuating around the entire sample. For example, the frequency content in the $20-30 \mathrm{~mm}$ range on the bar is dominated by the $5.8 \mathrm{~Hz}$ and $31.6 \mathrm{~Hz}$ frequencies which can be directly related to the region of built-up edge instability causing fluctuations in the surface topography around the bar. As the built-1up edge is formed and broken away from the cutting tool as the cut is being made around the cylindrical workpiece, steps in the surface will occur causing large backpressure fluctuations at these locations.

To verify that the low frequency impulses within the backpressure signal are a result of the machire tool controller stepping, and to investigate how well the system would operate without compensating for the taper of the sample, signals have been acquired at a set standoff distance of $50 \mu \mathrm{m}$ and not adjusted over the length of the sample. These signals are displayed in Figure 4.51 for comparisons to Figure 4.50. 
M. A. Sc. Thesis McMaster University - Mechanical Engineering Drew A. Grandy
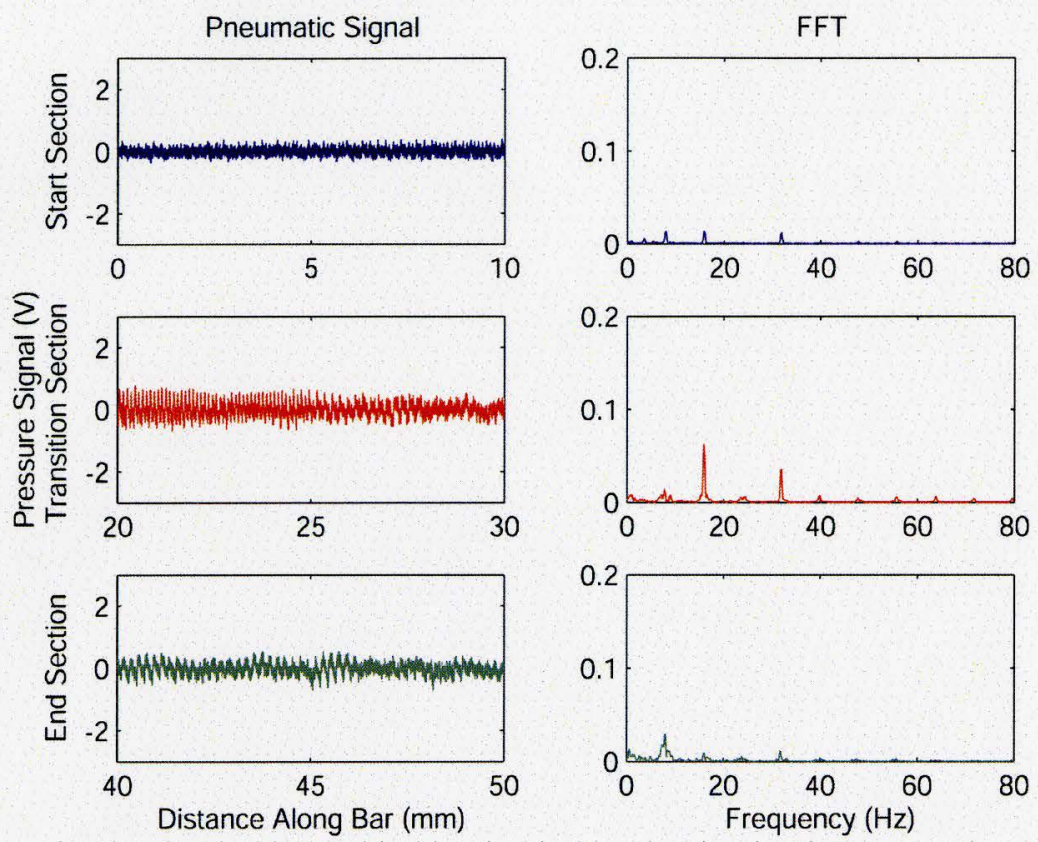

Figure 4.51: Backpressure Signal and FFT Without SOD Compensation for a Rotating Workpiece $\left(V=30 \mathrm{~m} / \mathrm{min}\right.$, Nominal $\left.S O D=50 \mu \mathrm{m}, F=0.2 \mathrm{~mm} / \mathrm{rev}, P_{S}=138 \mathrm{kPa}\right)$

Table 4.13: Amplitudes of FFT at Dominant Frequencies without SOD Compensation

\begin{tabular}{c|c|c|c|c}
\hline \multicolumn{2}{c|}{} & \multicolumn{3}{|c}{ Amplitudes at Dominant Frequencies } \\
\hline Section & $R_{a}(\mu \mathrm{m})$ & $7.9 \mathrm{~Hz}$ & $15.8 \mathrm{~Hz}$ & $31.6 \mathrm{~Hz}$ \\
\hline \hline $0-10$ & 1.12 & 0.014 & 0.013 & 0.011 \\
$20-30$ & 3.89 & 0.014 & 0.062 & 0.035 \\
$40-50$ & 6.43 & 0.030 & 0.007 & 0.011 \\
\hline \hline
\end{tabular}

As expected, the impulses in the backpressure signal are no longer present and can be accounted for by the stepping of the tooling controller. The similar results in an increase in amplitude at the dominant frequencies have been obtained, however the increase in amplitude over the length of the bar has decreased. The $20-30 \mathrm{~mm}$ section is again dominated by the $15.8 \mathrm{~Hz}$ and $31.6 \mathrm{~Hz}$ frequencies and thus proves that it is 
M. A. Sc. Thesis McMaster University - Mechanical Engineering Drew A. Grandy possible to assign the same distinguishing features of the signals to the different sections of the bar. The decrease in amplitude at $7.9 \mathrm{~Hz}$ as the nozzle is fed to the end section of the bar is a result of the stand-off distance between the nozzle tip and the surface increasing from the taper in the bar. To investigate the sensitivity of the pneumatic gauging system to the standoff distance, stand-off distances of $100 \mu \mathrm{m}$ and $150 \mu \mathrm{m}$ were also tested and presented in Figures 4.52 and 4.53.
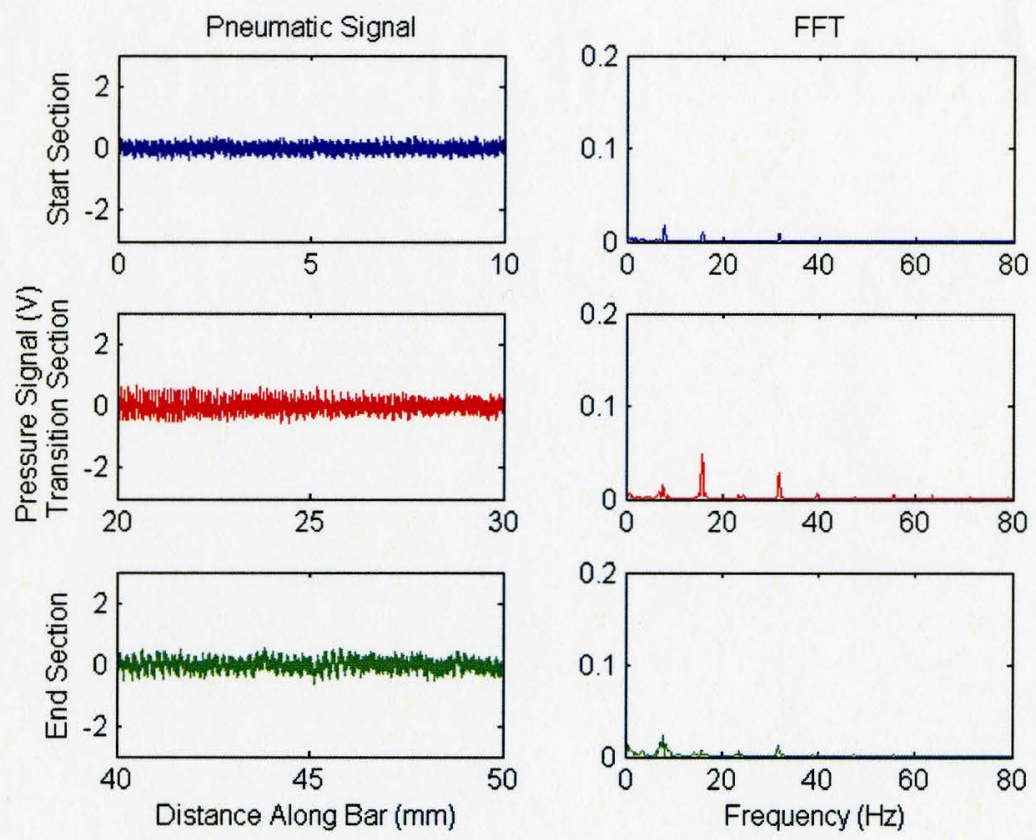

Figure 4.52: Backpressure Signal and FFT for $S O D=100 \mu \mathrm{m}$ $(V=30 \mathrm{~m} / \mathrm{min}, F=0.2 \mathrm{~mm} / \mathrm{rev}, P s=138 \mathrm{kPa}$ ) 


\section{A. Sc. Thesis McMaster University - Mechanical Engineering Drew A. Grandy}
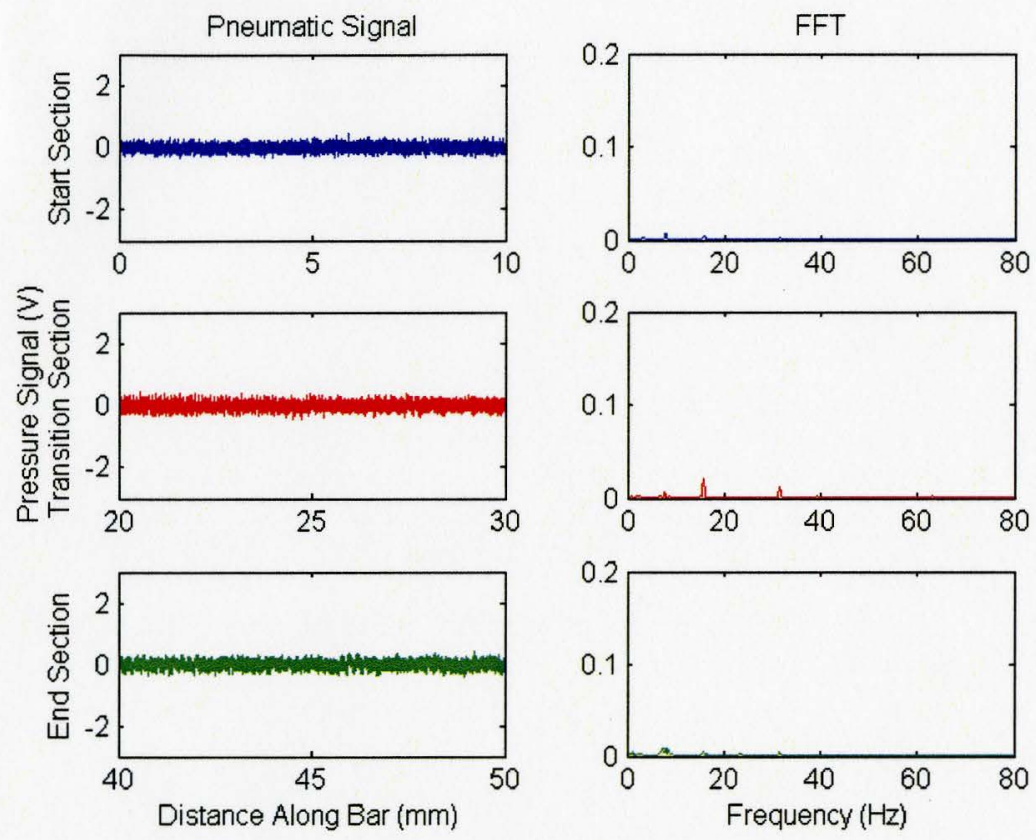

Figure 4.53: Backpressure Signal and FFT for $S O D=150 \mu \mathrm{m}$ $\left(V=30 \mathrm{~m} / \mathrm{min}, F=0.2 \mathrm{~mm} / \mathrm{rev}, P_{s}=138 \mathrm{kPa}\right.$ )

It is clear that the increase in standoff distance decreases the sensitivity of the pneumatic system dramatically as would be expected from the pneumatic gauging characteristics discussed in Section 1.2. From these observations, it is clear that the developed system has been optimized to operate at a standoff distance of $50 \mu \mathrm{m}$ as it results in a larger signal to noise ratio. At larger standoff distances the pressure fluctuations caused by the surface characteristics become lost in the noise of the air supply and are no longer recognizable in the backpressure signals.

Similar to the standoff distance, the supply pressure is theoretically linearly related to the sensitivity of the pneumatic gauge. Although it has been shown that a supply pressure of $138 \mathrm{kPa}(20 \mathrm{psi})$ is more than adequate to distinguish different surface 
M. A. Sc. Thesis McMaster University - Mechanical Engineering Drew A. Grandy characteristic during the surface standard experiments, supply pressures of $207 \mathrm{kPa}$ (30 psi), $276 \mathrm{kPa}(40 \mathrm{psi})$, and $345 \mathrm{kPa}(50 \mathrm{psi})$ have also been tested on the Jominy sample and presented in the following figures.
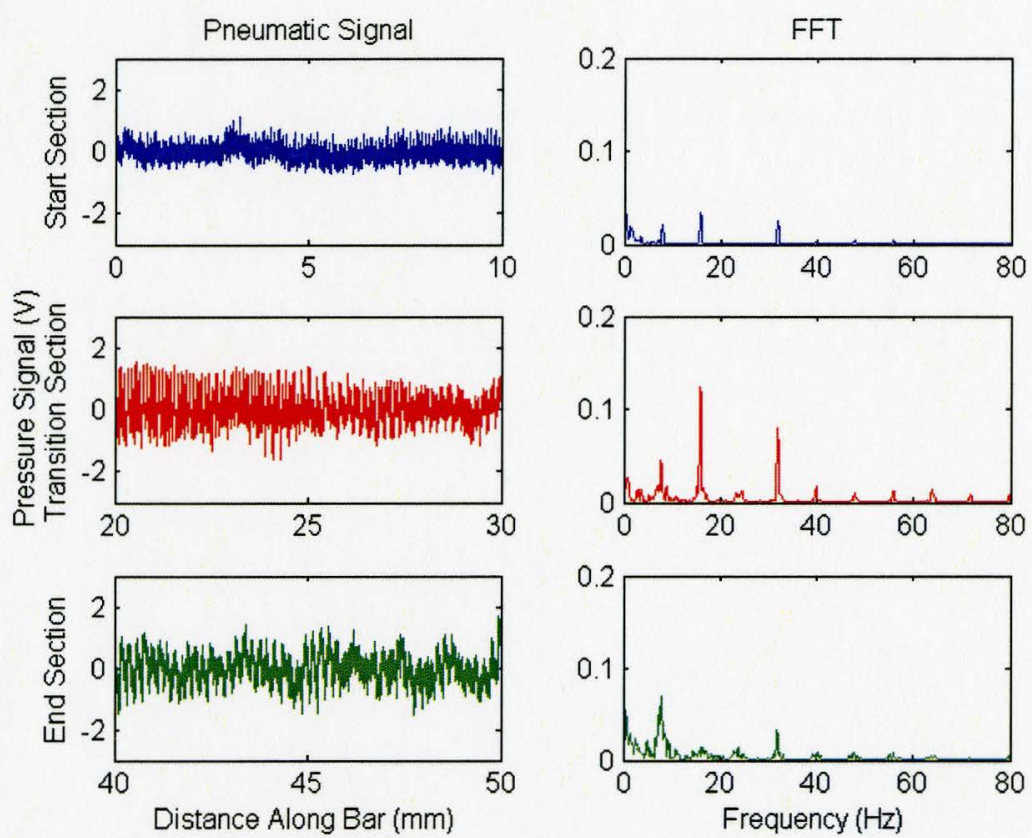

Figure 4.54: Backpressure Signal and FFT for $P s=207 \mathrm{kPa}$ $(V=30 \mathrm{~m} / \mathrm{min}, S O D=50 \mu \mathrm{m}, F=0.2 \mathrm{~mm} / \mathrm{rev})$ 


\section{A. Sc. Thesis McMaster University - Mechanical Engineering Drew A. Grandy}
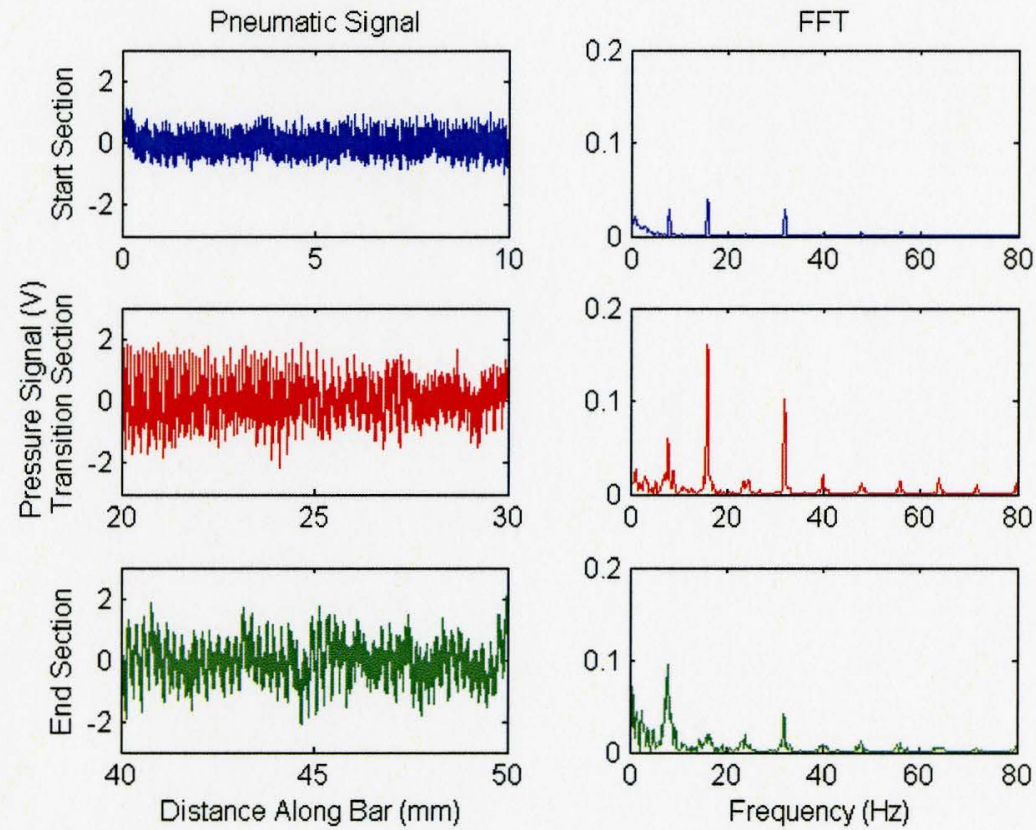

Figure 4.55: Backpressure Signal and FFT for $P s=276 \mathrm{kPa}$ $(V=30 \mathrm{~m} / \mathrm{min}, S O D=50 \mu \mathrm{m}, F=0.2 \mathrm{~mm} / \mathrm{rev})$
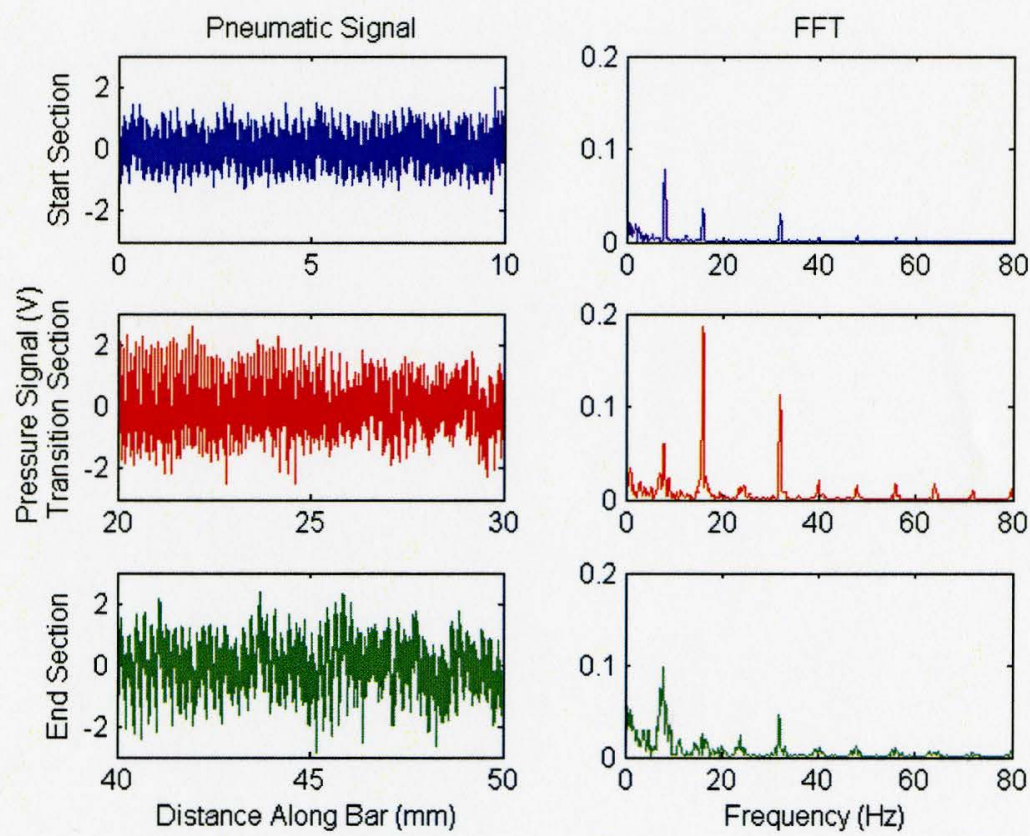

Figure 4.56: Backpressure Signal and FFT for $P s=345 \mathrm{kPa}$ $(V=30 \mathrm{~m} / \mathrm{min}, S O D=50 \mu \mathrm{m}, F=0.2 \mathrm{~mm} / \mathrm{rev})$ 
M. A. Sc. Thesis McMaster University - Mechanical Engineering Drew A. Grandy

As expected, the amplitude of the signal scales with the increase in supply pressure. Again the same trends in the signals are present when comparing the signals obtained from the di:ferent regions of the bar. Although the amplitudes of the dominant frequencies are increased with an increase in supply pressure, the noise within the signal also increases. It appears as though the amplitudes of the signals are not scaling linearly with the increase in supply pressure as would be expected from the theory. For example, when comparing the 3 sets of signals obtained using a supply pressure of $138 \mathrm{kPa}$ (20 psi), shown in Figure 4.50, to the 3 sets of signals obtained using a supply pressure $276 \mathrm{kPa}$ (40 psi), shown in Figure 4.55, we see that by doubling the supply pressure, the amplitudes of the dominant frequencies are not twice as large as the $138 \mathrm{kPa}$ (20 psi) signals. Quantitative results of these findings are presented in Table 4.14. Part of this could be a result of the compressibility of the air as suggested previously. The theory presented in Section 1.2 is created under the assumption that the air will remain uncompressible; however this is not necessarily true. With the increase in supply pressure, it should be expected that the compressibility of the air will increase acting as a damper to the fluctuations in the backpressure within the control volume. 
M. A. Sc. Thesis McMaster University - Mechanical Engineering Drew A. Grandy

Table 4.14: Comparison of Amplitudes of FFT at Dominant Frequencies for Larger Supply Pressure

\begin{tabular}{c|c|c|c|c|c}
\hline & & \multicolumn{4}{|c}{ Amplitudes at Dominant Frequencies } \\
\cline { 3 - 6 } Secti.jn & \multirow{2}{*}{$R_{a}(\mu \mathrm{m})$} & $P_{\mathrm{S}}(\mathrm{kPa})$ & $7.9 \mathrm{~Hz}$ & $15.8 \mathrm{~Hz}$ & $31.6 \mathrm{~Hz}$ \\
\hline \hline $0-10$ & \multirow{2}{*}{1.12} & 138 & 0.016 & 0.022 & 0.018 \\
& & 276 & 0.029 & 0.039 & 0.028 \\
\hline \multirow{2}{*}{$20-30$} & \multirow{2}{*}{3.89} & 138 & 0.031 & 0.092 & 0.06 \\
& & 276 & 0.059 & 0.161 & 0.101 \\
\hline \multirow{2}{*}{$40-50$} & \multirow{2}{*}{6.43} & 138 & 0.054 & 0.01 & 0.024 \\
& & 276 & 0.093 & 0.016 & 0.042 \\
\hline \hline
\end{tabular}

The last variable that has been tested while rotating the workpiece with a traversing nozzle wa; changing the feed rate of the nozzle away from the feed rate that was used to prepare the workpiece. For these tests one feed rate that was slower $(0.1 \mathrm{~mm} / \mathrm{rev})$ than the cutting feed rate and two that were faster $(0.3 \mathrm{~mm} / \mathrm{rev}$ and $0.4 \mathrm{~mm} / \mathrm{rev}$ ) than the cutting feed rate were used. By changing the feed rate of the nozzle away from the cutting feed rate, the nozzle will either capture more data around the circumference of the bar, as in the case of the $0.1 \mathrm{~mm} / \mathrm{rev}$ feed rate, or the nozzle will effectively be corkscrewing around the surface missing areas of the surface for assessment, as woulc be the case for the faster feed rates. 


\section{A. Sc. Thesis McMaster University - Mechanical Engineering Drew A. Grandy}
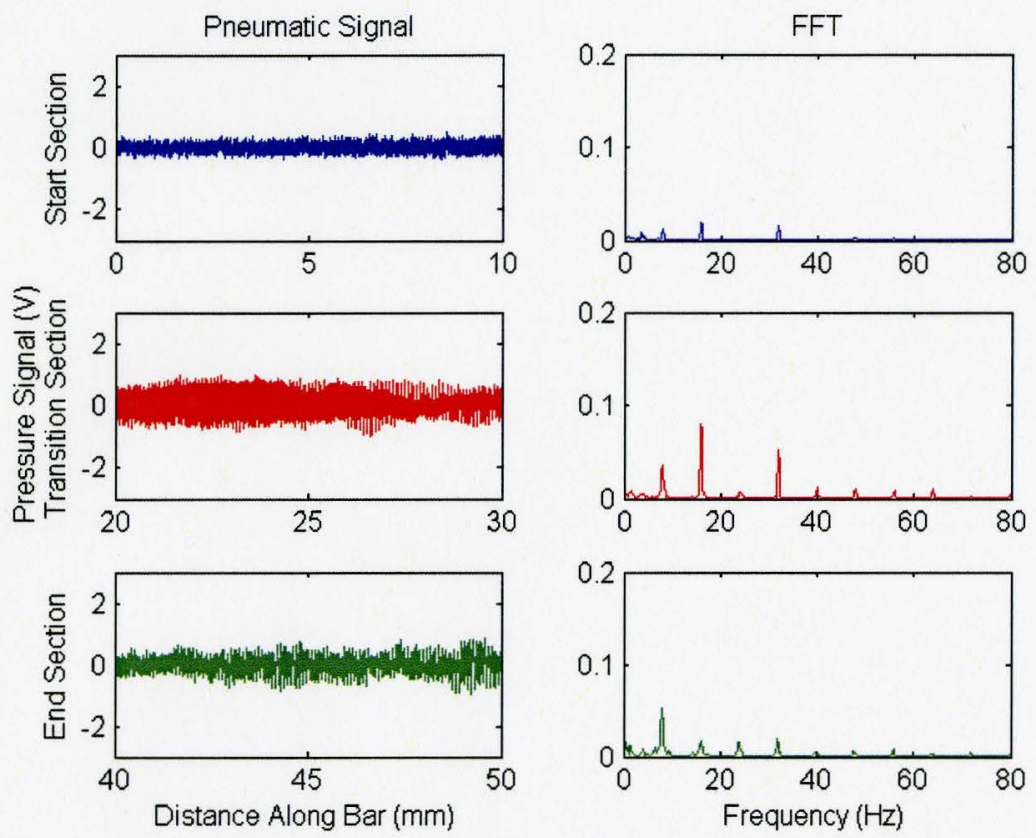

Figure 4.57: Backpressure Signal and FFT for $f=0.1 \mathrm{~mm} / \mathrm{rev}$ $(V=30 \mathrm{~m} / \mathrm{min}, S O D=50 \mu \mathrm{m}, P s=138 \mathrm{kPa})$
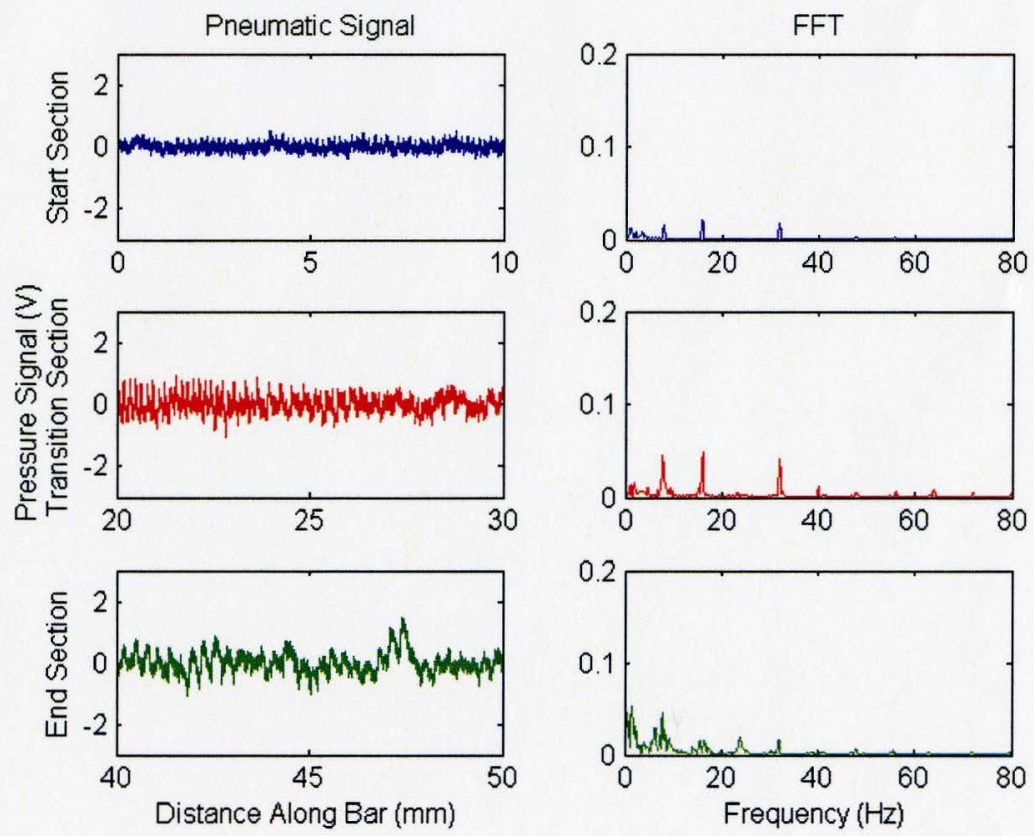

Figure 4.58: Backpressure Signal and FFT for $f=0.3 \mathrm{~mm} / \mathrm{rev}$ $(V=30 \mathrm{~m} / \mathrm{min}, S O D=50 \mu \mathrm{m}, P s=138 \mathrm{kPa})$ 


\section{A. Sc. Thesis McMaster University - Mechanical Engineering Drew A. Grandy}
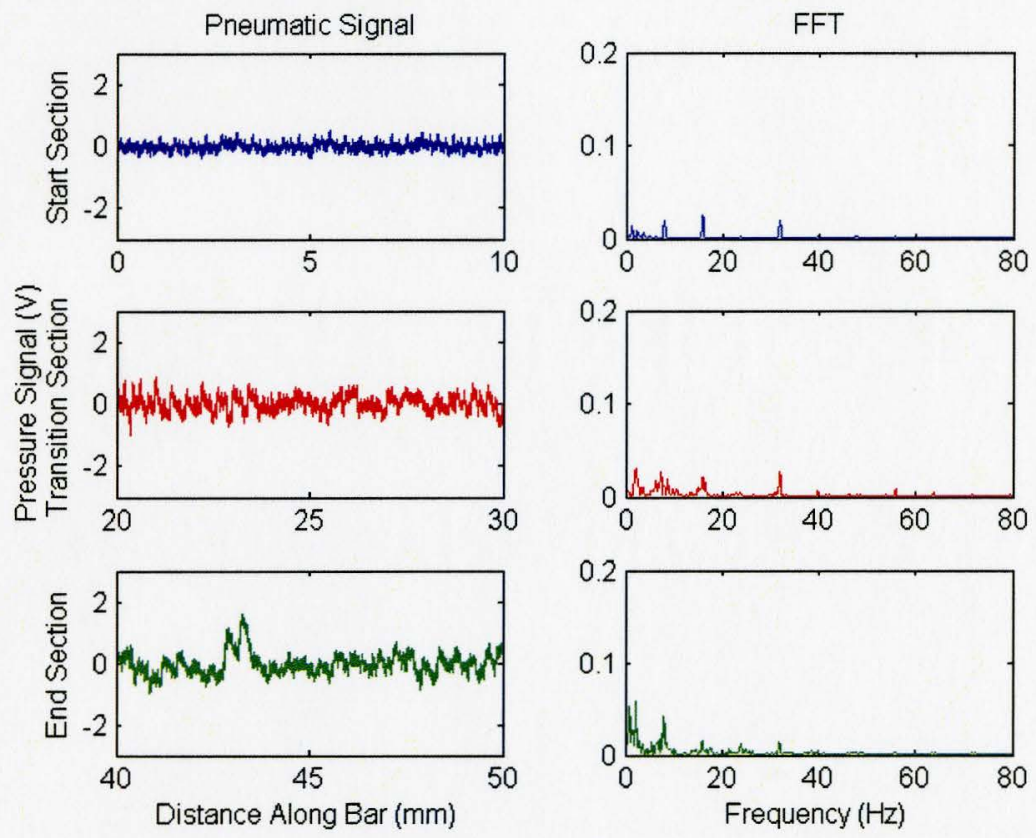

Figure 4.59: Backpressure Signal and FFT for $f=0.4 \mathrm{~mm} / \mathrm{rev}$ $(V=30 \mathrm{~m} / \mathrm{min}, S O D=50 \mu \mathrm{m}, P s=138 \mathrm{kPa})$

From the results shown in Figures 4.57 through 4.59, the amplitudes of the signals begin to decrease with an increase in feed rate. There is also an increase in the lower frequency content and other noise within the signal as the feed rate is increased. Using the slower $0.1 \mathrm{~mm} / \mathrm{rev}$ feed rate results in a very similar signal to what was obtained using the cutting feed rate of $0.2 \mathrm{~mm} / \mathrm{rev}$ however there was twice the amount of data collected over the $10 \mathrm{~mm}$ sample. In practice it would not be practical to use a feed rate slower than what the workpiece is being cut at. Therefore, the optimum results would be obtained by using the same parameters as what is used to generate the surface of the workpiece. 
M. A. Sc. Thesis McMaster University - Mechanical Engineering Drew A. Grandy

Now that it has been proven that the pneumatic gauging system is capable of characterizing the entire surface of a workpiece using the same parameters that would be used during the cutting operation, the robustness of the device was tested in an environment using cutting fluid. The presence of the cutting fluid being directed at the nozzle will test how well the nozzle is capable of evacuating the obstruction away from the surface and its ability to acquire accurate results for the characteristics of the surface through the means of in-situ, non-contact methods. Figure 4.60 is an example of the signals acquired during these tests and it is clear that even with an air supply pressure of $138 \mathrm{kPa}(20 \mathrm{psi})$, the pneumatic gauging system is unaffected by the presence of cutting fluid being directed at the tip of the pneumatic nozzle.
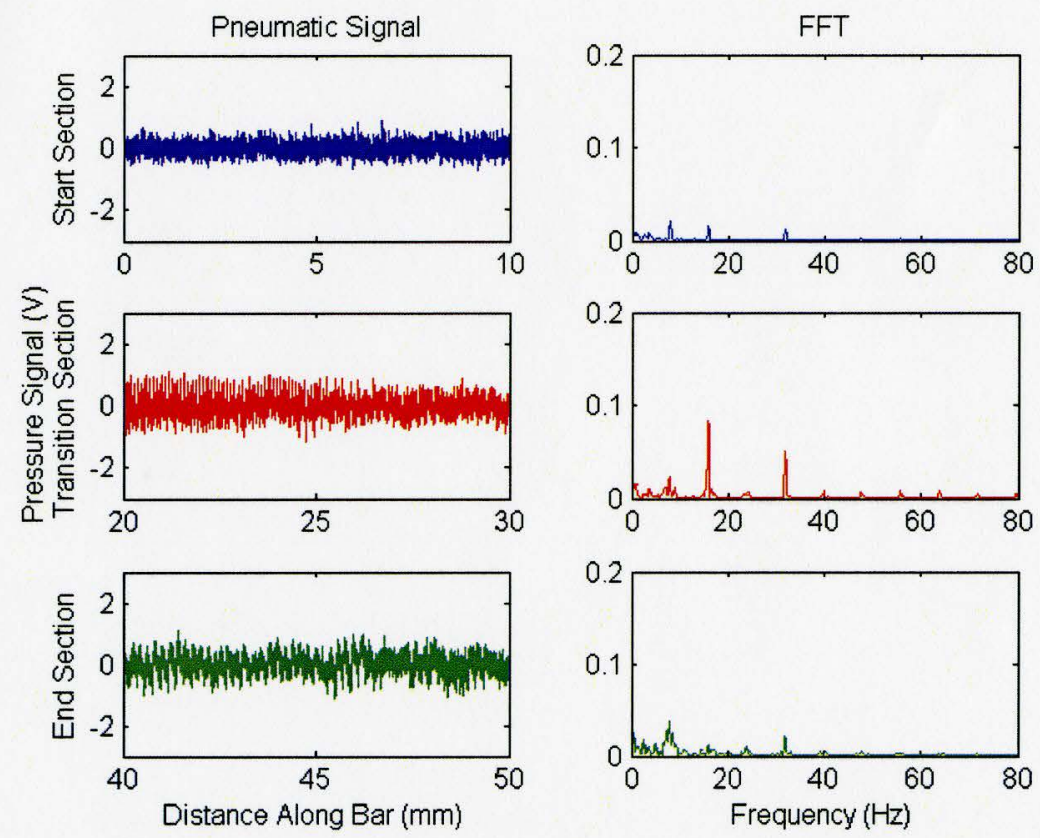

Figure 4.60: Backpressure Signal and FFT with the use of Cutting Fluid $(V=30 \mathrm{~m} / \mathrm{min}, S O D=50 \mu \mathrm{m}, F=0.2 \mathrm{~mm} / \mathrm{rev}, P s=138 \mathrm{kPa}$ ) 
M. A. Sc. Thesis McMaster University - Mechanical Engineering Drew A. Grandy

Comparing the results of Figure 4.50 to Figure 4.60, all of the distinguishing characteristics that have been discussed are still clearly present. Only a slight decrease in the amplitudes of the frequency domain and a slight increase in low frequency noise are a result of introducing cutting fluid into the monitoring environment. All of the same analysis techniques c.n be employed that have been presented earlier. This is an example of one of the advartages of using this device for in-process monitoring over other non-contact techniques, such as the use of lasers to characterize the surface, since surface obstructions are a non-issue when using pressurized air as the working medium.

Analysis of a Rotating Workpiece using a Stationary Nozzle

The final set of experiments was to determine whether the system is capable of detecting variations in the surface of a rotating workpiece using a stationary nozzle. These tests simulate an application where the user is only interested in monitoring the variations in roughness of a single location on the workpiece or performing spot checks. For these tests, the $\mathrm{J}$ ominy sample was rotated in the turning center to maintain a constant surface speed and the nozzle was introduced to different locations of the bar while signals were acquired for ?2 seconds allowing any variations over time to be captured. The locations along the bar and the corresponding $\mathrm{R}_{\mathrm{a}}$ values for these regions are presented in Table 4.15. 
M. A. Sc. Thesis McMaster University - Mechanical Engineering Drew A. Grandy

Table 4.15: Select Locations and $R_{a}$ Values Used for Stationary Nozzle Tests, Cutoff Length of $0.8 \mathrm{~mm}$

\begin{tabular}{c|c}
\hline \hline Distance $(\mathrm{mm})$ & $R_{a}(\mu \mathrm{m})$ \\
\hline \hline 5 & 1.12 \\
35 & 5.93 \\
55 & 6.81 \\
70 & 6.73
\end{tabular}

Pressure Signal
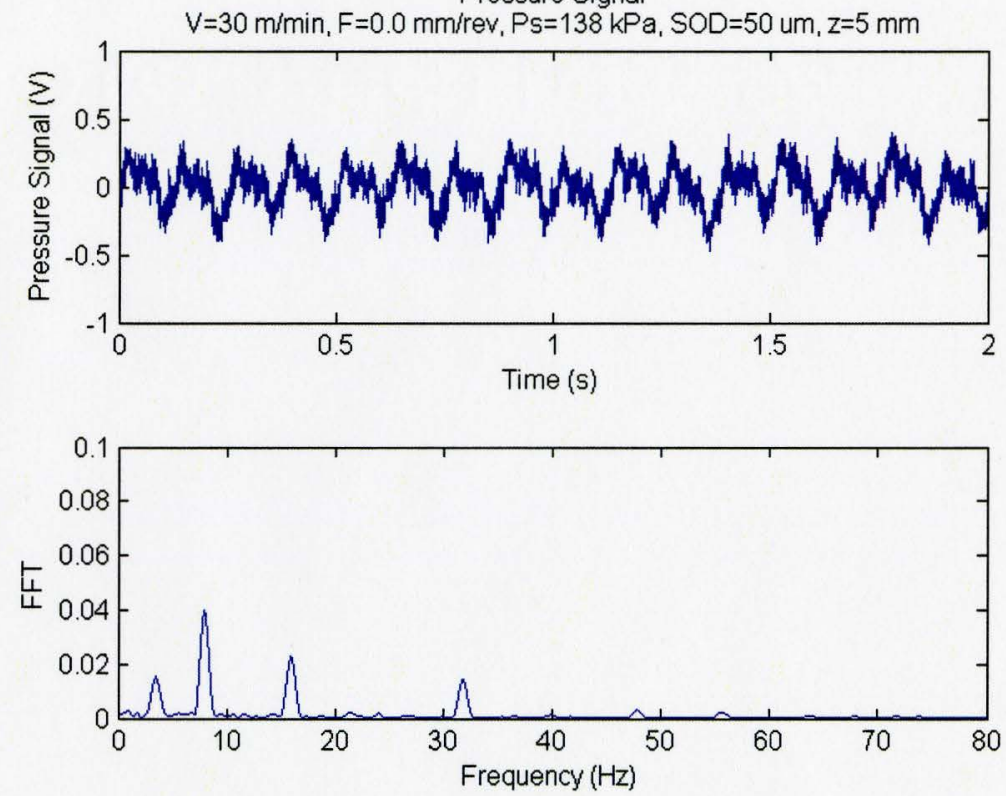

Figure 4.61: Backpressure Signal and FFT using a Stationary Nozzle at $z=5 \mathrm{~mm}$ 

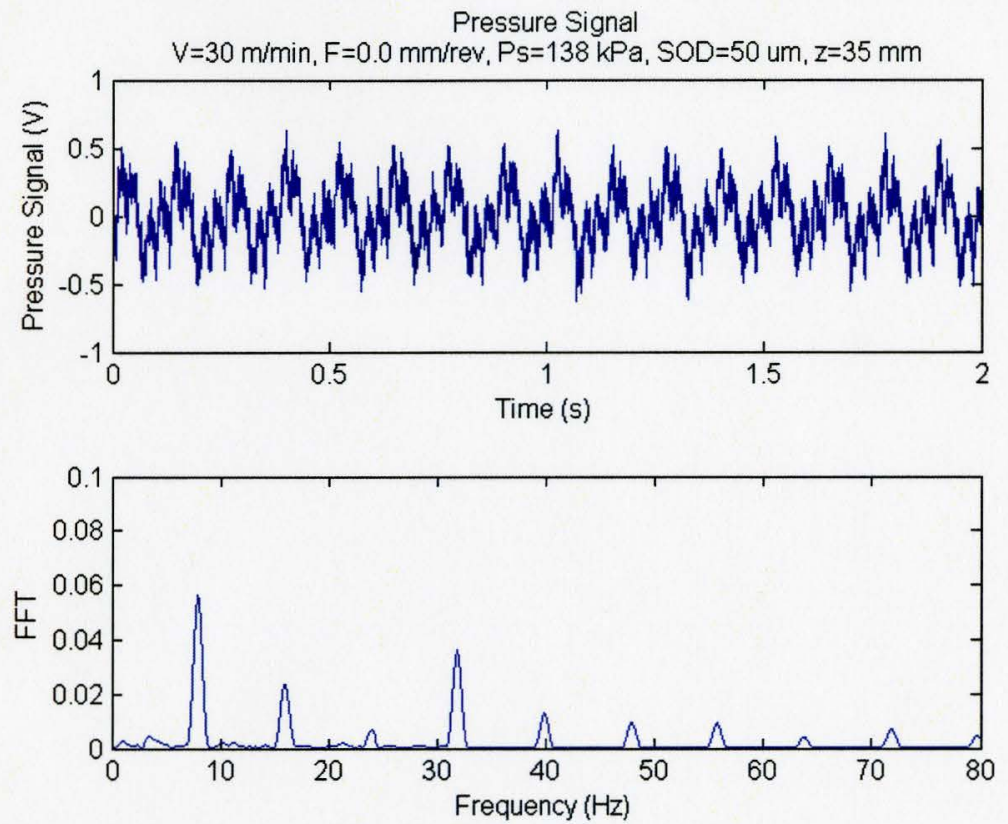

Figure 4.62: Backpressure Signal and FFT using a Stationary Nozzle at $z=35 \mathrm{~mm}$
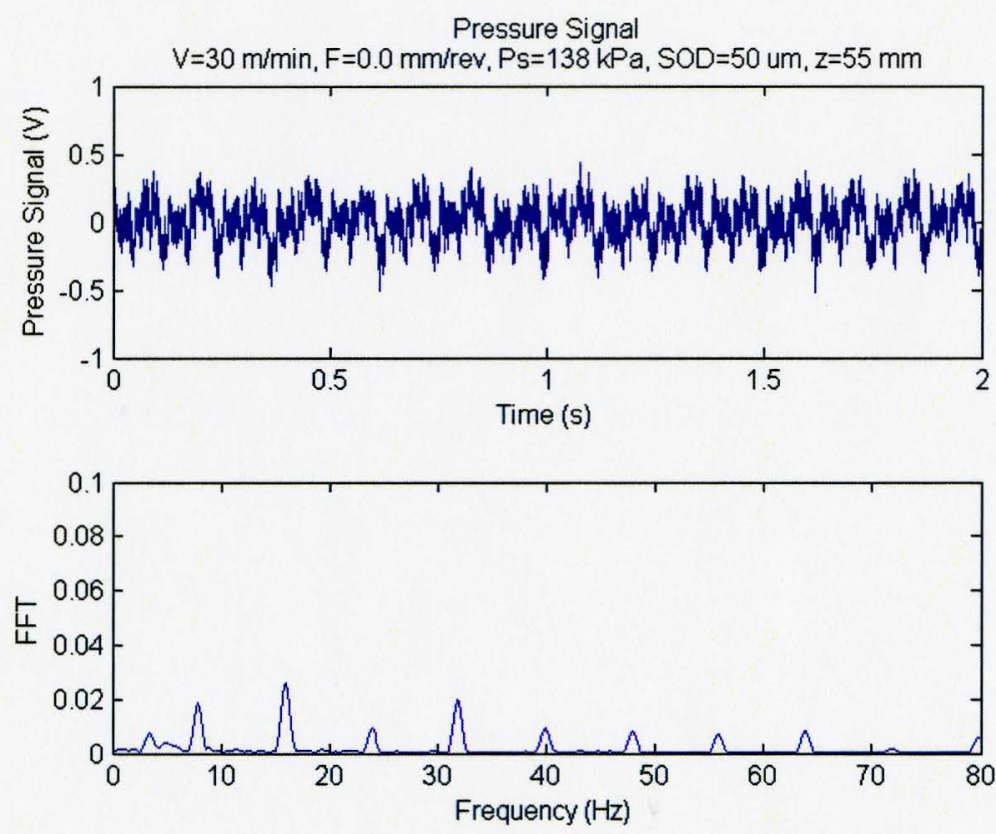

Figure 4.63: Backpressure Signal and FFT using a Stationary Nozzle at $z=55 \mathrm{~mm}$ 
M. A. Sc. Thesis McMaster University - Mechanical Engineering Drew A. Grandy
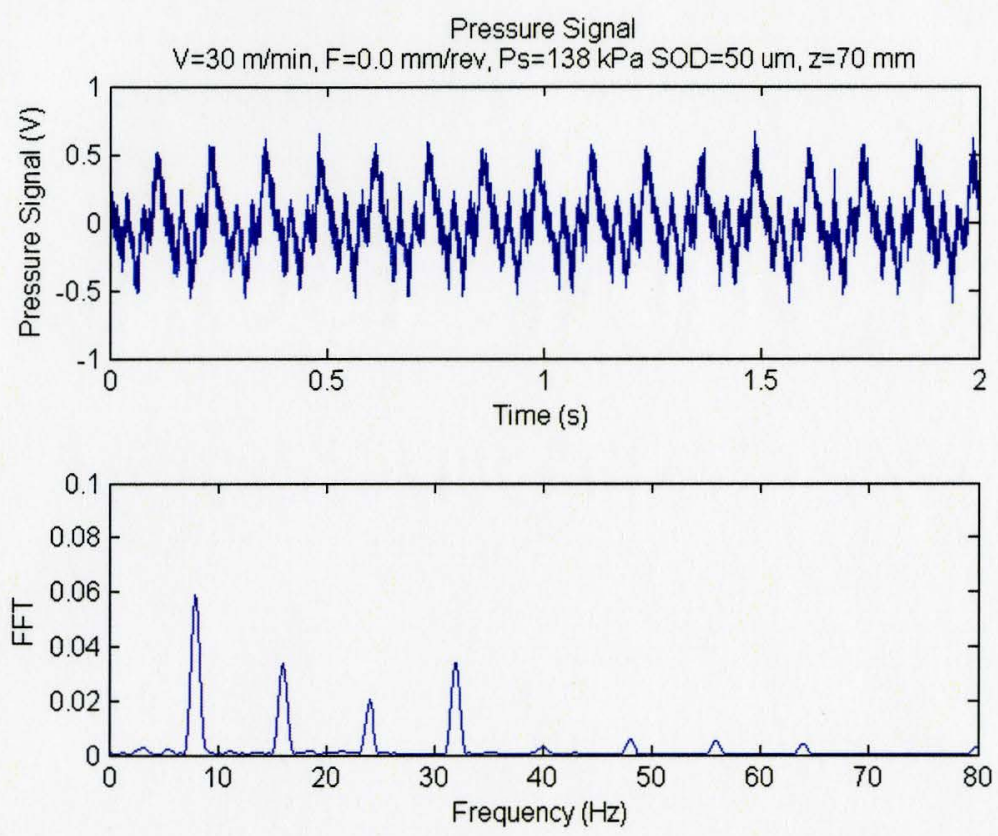

Figure 4.64: Backpressure Signal and FFT using a Stationary Nozzle at $z=70 \mathrm{~mm}$

As seen in the figures above, there is a definite variation between the signals for each of the different samples. Similar to the signals obtained when feeding the nozzle across the workpiece, the dominant frequencies are again the rotational frequency and the subsequent harmonics. An understanding of how the surface is changing around the entire surface is again achieved by comparing the amplitudes of the backpressure signal in the frequency domain and can also be seen visually in the raw pressure signals. Generally with an increase in roughness in terms of the measured $R_{a}$ value, the amplitude of the signal occurring at the rotational frequency of $7.9 \mathrm{~Hz}$ is increasing, which is verified by an increase in the peak to valley distance occurring as the lower frequency content caused by each rotation of the part in the raw backpressure signal. The variations occurring between the cycles of each rotation of the workpiece represent how the surface 
M. A. Sc. Thesis McMaster University - Mechanical Engineering Drew A. Grandy is changing around the bar. For example, the pressure signal taken at $z=5 \mathrm{~mm}$ in Figure 4.61 has very small fluctuations between each rotational period compared to the signal acquired at $\mathrm{z}=35 \mathrm{~mm}$ which has large pressure fluctuations caused by larger changes in the surface around the part.

The surface speed of the workpiece passing the nozzle maintained at $30 \mathrm{~m} / \mathrm{min}$ for the experiments using the stationary nozzle. If this device was implemented for use in an industrial setting, the effect of this surface speed on the signals must be tested to find the limit at which the device can perform accurately. Since the volume of the control chamber in the device has an effect on the time constant of the sensor, it is expected that while increasing the surface speed of the sample, a threshold will be found where the signal will not have enough time to reach the appropriate amplitude change caused by the backpressure. For these tests, surface speeds ranging from $30 \mathrm{~m} / \mathrm{min}$ to $200 \mathrm{~m} / \mathrm{min}$ were selected and signals were acquired at $\mathrm{z}=5 \mathrm{~mm}$ on the sample. 

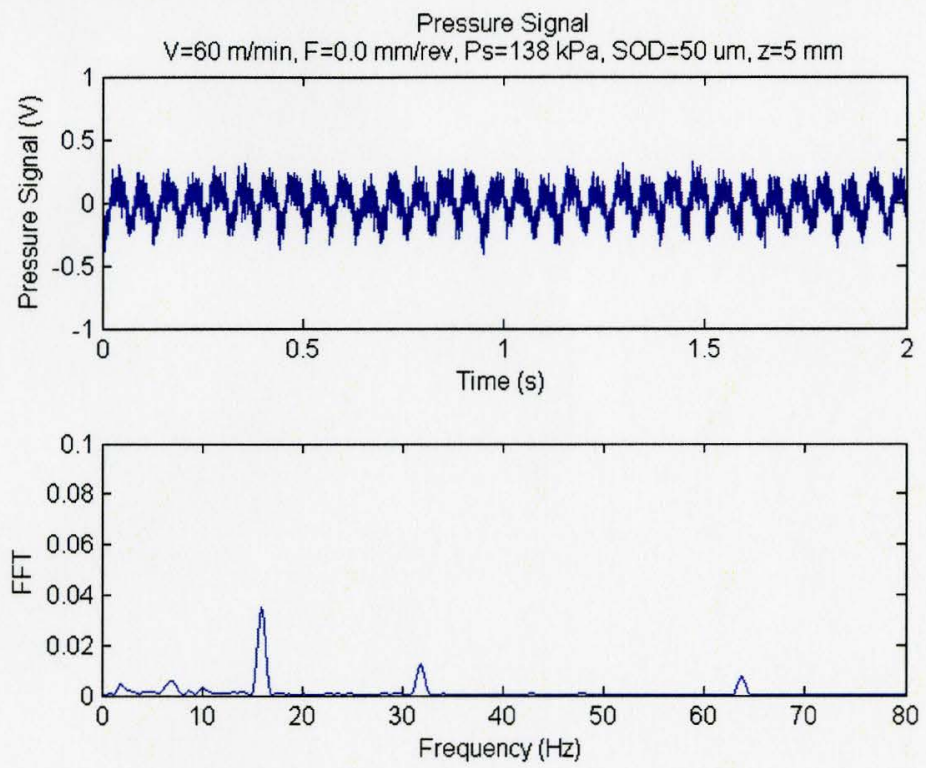

Figure 4.65: Backpressure Signal and FFT at $z=5 \mathrm{~mm}, V=60 \mathrm{~m} / \mathrm{min}$

Pressure Signal
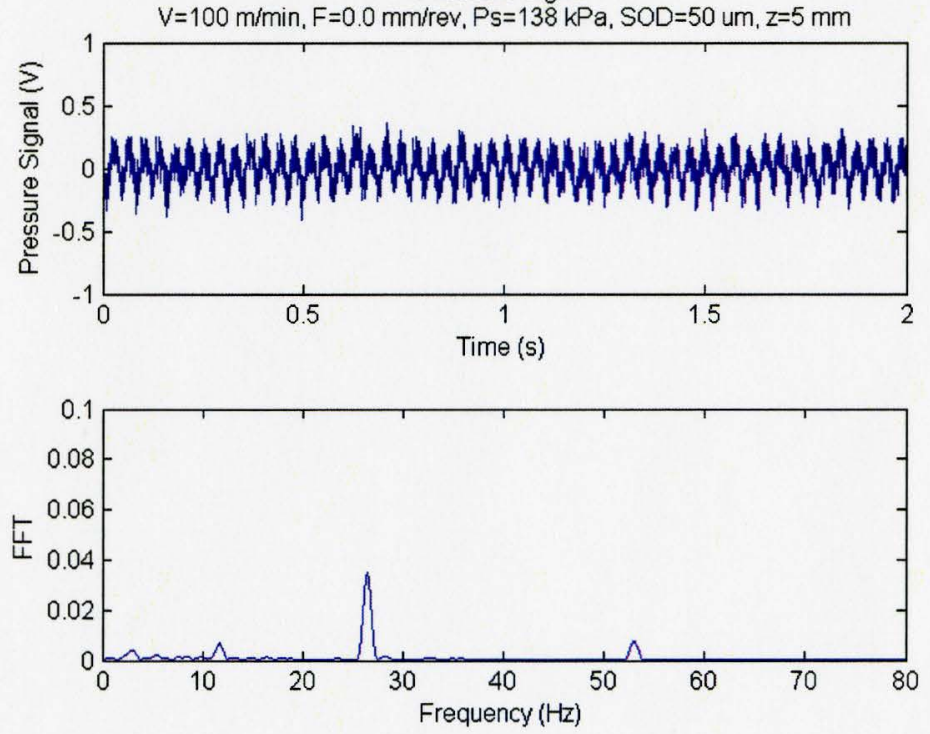

Figure 4.66: Backpressure Signal and FFT at $z=5 \mathrm{~mm}, V=100 \mathrm{~m} / \mathrm{min}$ 
M. A. Sc. Thesis McMaster University - Mechanical Engineering Drew A. Grandy
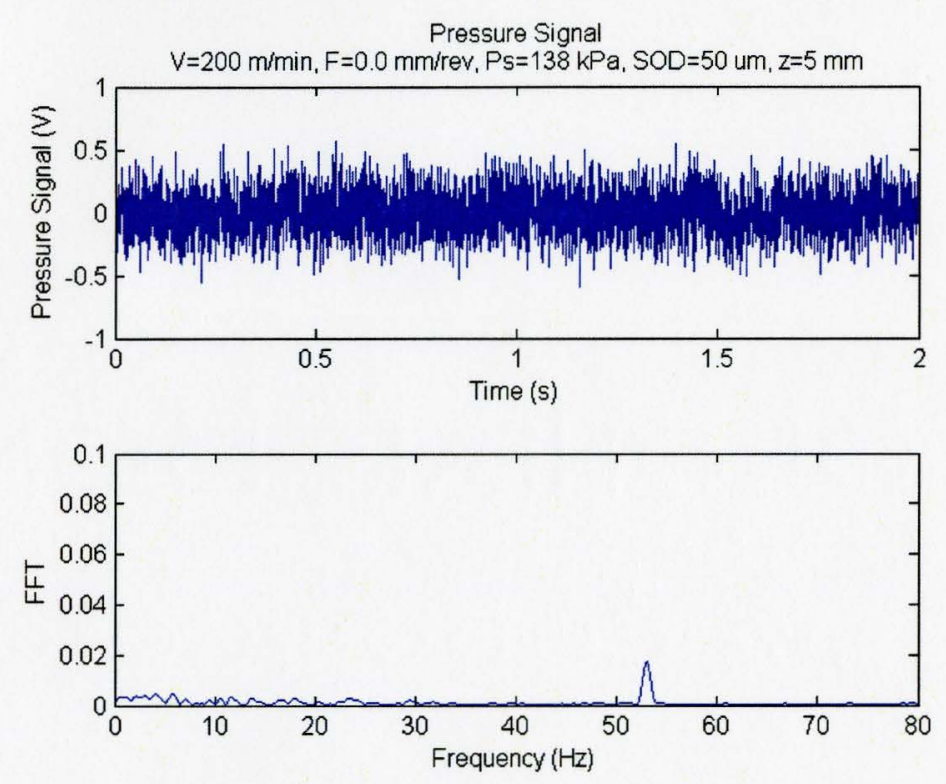

Figure 4.67: Backpressure Signal and FFT at $z=5 \mathrm{~mm}, V=200 \mathrm{~m} / \mathrm{min}$

Figures 4.65 through 4.67 illustrate the effects of the surface speed on the backpressure signal. An increase in speed causes the dominant frequency to shift in agreement to the rotation of the workpiece and the amplitude of the backpressure signal at the dominant frequency remains constant until a slight drop at $100 \mathrm{~m} / \mathrm{min}$. By $200 \mathrm{~m} / \mathrm{min}$ the amplitude at the rotational frequency has dropped significantly and the noise within the signal has increased dramatically. It can also be seen that the amplitudes of the harmonics within the signal begin to drop at much slower speeds. This is expected as the sensor will begin to have difficulties detecting the changes occurring around the bar because of the effects of the sensor time constant. From these tests it has been found that a surface speed of $100 \mathrm{~m} / \mathrm{min}$ is the maximum allowable speed for which the developed pneumatic gauging system can operate. 


\section{A. Sc. Thesis McMaster University - Mechanical Engineering Drew A. Grandy}

\section{Chapter 5}

\section{Conclusions and Future Work}

The developrnent of a non-contact surface roughness assessment tool which can be used for in-process monitoring applications has been presented. Related literature, development of the device, limitations of the device, and practical applications has all been presented. A biief summary of the developed pneumatic system and its advantages over existing technologies is presented in this Chapter as well as a description of future work which could be done to further develop its operational envelope.

\subsection{Conclusions}

The development of a pneumatic system for surface assessment provided a wide range of parameters to be investigated pertaining to increasing the sensitivity of the pneumatic gauge in order to detect the small fluctuation in a surface as a result of its roughness. During the development of the pneumatic system, many of these parameters have been tested to find the optimum set-up in order to produce clear and repeatable results to characterize surfaces. One of the major components of a pneumatic system to increase sensitivity is the pressure transducer. It has been found that a piezoelectric pressure transducer is ideal for characterizing a wider range of roughnesses when compared to a microphone for supply pressures which are representative of those required to evacuate debris from the measurement surface. In theory, the supply pressure is directly related to the overall sensitivity of a pneumatic system. An increase in supply pressure would thecretically result in a proportional increase in sensitivity, however it 
M. A. Sc. Thesis McMaster University - Mechanical Engineering Drew A. Grandy

was found that as the supply pressure was increased past $138 \mathrm{kPa}(20 \mathrm{psi})$ the increase gained in sensitivity would slightly decrease for higher pressures. This has been attributed to the compressibility of air at pressure higher than $138 \mathrm{kPa}$ since pneumatic gauging theory has been developed under the assumption that air will remain incompressible. The final set of parameters tested during the development of the pneumatic system was the nozzle and control orifice diameters. It is these parameters which effect the optinum stand-off distance required for the device to operate in a linear range as well as have an effect on the devices overall sensitivity. The focus of this research was to maintain a minimum stand-off distance of $50 \mu \mathrm{m}$ so the overall sensitivity of the device was fixed in terms of the control orifice and nozzle diameters, however it was found that a decrease in jet noise could be achieved by minimizing the nozzle diameter and control orifice diameter appropriately while maintaining the same sensitivity.

The developed pneumatic system has been demonstrated off-line and on-line to provide quick and accurate surface characterizations for surfaces created from vertical milling and turning operations for roughnesses ranging from $12.5 \mu \mathrm{m}$ to $0.8 \mu \mathrm{m} \mathrm{R}_{\mathrm{a}}$, however limited results have been obtained when trying to characterize ground surfaces where the mean height of the surface is quite small and created using cutting tools that do not have a defined cıtting edge. It has been shown that a non-contact pneumatic device is capable of producing surface characterizations similar to those obtained from stylus instruments, however pneumatic devices are capable of characterizing these surfaces at much higher surfact: speeds compared to stylus instruments. The ability to characterize 


\section{A. Sc. Thesis McMaster University - Mechanical Engineering Drew A. Grandy}

surfaces at surface speeds similar to those used during typical machining operations is ideal for in-process rronitoring applications. Comparing the developed pneumatic system to currently available optical methods used for in-process monitoring, it has been shown that the presence of $c$ atting fluid has little to no effect on the backpressure signals even at supply pressures as low as $138 \mathrm{kPa}(20 \mathrm{psi})$. The use of compressed air as the working medium in pneumatic devices also provides a much broader operating envelope compared to tactile and optical methods. Pneumatic systems are capable of characterizing soft, non-reflective surfaces in a machining environment where obstructions such as cutting fluid and other debris may be present. Further highlights of the developed system are provided as follows:

- The developed system provides a physical representation of the surface from the backpressure signal as well as a detailed view of the frequency domain which is used as an aid for detecting features such as the presence of built-up edge and ool wear during cutting.

- Capable of characterizing milled and turned surfaces with roughness values between $12.5 \mu \mathrm{m}$ and $0.8 \mu \mathrm{m} \mathrm{R}_{\mathrm{a}}$ while maintaining a stand-off distance of $50 \mu \mathrm{m}$.

- Impervious to surface obstructions such as cutting fluid and machining debris.

- Able to distinguish surface topographies created from different machining operations for the same $R_{a}$ values.

- In a turning environment, during on-line applications the pneumatic system characterizes the entire circumferential surface of the sample instead of along a single line. This is further emphasized by analyzing the frequency domain of the signal to determine how the surface is changing around the circumference of the part. 
- It has been shown that optimum results are obtained when the pneumatic system is operating at the same parameters used when cutting the sample. This is ideal for collecting data in-process.

- In-processi, the developed system can be used to monitor the entire surface or be used as a spot check for features of interest.

- Capable of detecting surface features at surface speeds up to $100 \mathrm{~m} / \mathrm{min}$.

Many of the highlights presented for the developed system demonstrate the capabilities of incorporating a pneumatic system in-process for non-contact surface roughness assessmert. Further research could prove beneficial in order to broaden the operational envelope of the developed device and overcome some of the problems that have been presented.

\subsection{Future Work}

In its current state, the pneumatic system is limited to characterizing surfaces with roughesses greater than $0.8 \mu \mathrm{m} \mathrm{R}_{\mathrm{a}}$. A possible solution to detect surface characteristics with mean characteristics below $0.8 \mu \mathrm{m}$ would be to manipulate the sensitivity of the pneumatic gauging clevice by making the control orifice diameter smaller and using a pressure transducer with a higher sensitivity such as a microphone. The focus of the research presented when adjusting the nozzle dimensions was to maintain the same sensitivity and optimum stand-off distance of the pneumatic gauge while eliminating the jet noise. The increased sensitivity would create larger fluctuations in backpressure for the small surface undulations however controlling the noise might become an issue. 
M. A. Sc. Thesis McMaster University - Mechanical Engineering Drew A. Grandy

Furthermore, characterization of surfaces generated by grinding where the cutting tool does not have a defined cutting edge to produce surface features at regular intervals have shown limited success when trying to characterize these surfaces using the presented pneumatic techniques. The main contributing factor to this lies in the use of the frequency domain to aid in distinguishing surface characteristics. For surfaces created during milling and turning where a dominant frequency is introduced to the surface from the feed rate and tosl nose radius the variations between surfaces became clear in the frequency domain. This is not the case for a ground surface where the surface is created with a wide spectrurn of frequencies so that visually distinguishing these changes in the frequency domain becomes nearly impossible. For this reason, a multivariate analysis method could be incorporated to compare the frequency spectra from different surfaces. Principal Component Analysis (PCA) or Projection to Latent Structures (PLS) analysis would take the frequency domain of the backpressure signals acquired from different surfaces and detect slight variations that might not be visible to the human eye. PCA and PLS methods are capable of manipulating a multi-dimensional set of data and project it down into a viewable two dimension plot where the variations between different sets of data can potentially secome quite clear. These techniques seem as though they would be ideal for distinguishing the slight variations in the frequency domain of ground surfaces.

Lastly, an ideal design of the pneumatic gauge would be incorporated directly within the machine tool for use in-process. The nozzle tip could be located behind the cutting edge of the tzol where the standoff distance would be controlled from the nozzle tip to the tip of the tool. By incorporating the pneumatic system into the machine tool 
M. A. Sc. Thesis McMaster University - Mechanical Engineering Drew A. Grandy itself, the requirement of using a unit trailing the cutting tool would greatly reduce the bulk of the system within the machining center. Some potential issues that would have to be addressed include machine tool vibration during cutting and tool wear. The inclusion of vibration from culting into the frequency domain would have to be dealt with through an isolation technique or perhaps advanced filtering systems. Tool wear would perhaps have a larger effect on the pneumatic system because the increase of tool wear would cause a decrease in stand-off distance. As shown from the characteristic curves for pneumatic gauging, 1 decrease in stand-off distance would shift the operational range of the device to the edges of its linear range. However an increase of tool wear would result in a change of surfece roughness, typically introducing more frequency content to the generated surface either through chatter or ploughing. It would be these characteristics in the frequency domain that would indicate the change of roughness during a machining process combined with a variation in the backpressure amplitude that would indicate the changing surface characteristics. 
M. A. Sc. Thesis McMaster University - Mechanical Engineering Drew A. Grandy

\section{References}

[1] D. Whitehouse, Surfaces and their Measurement, $1^{\text {st }}$ ed. Taylor and Francis Books, Inc., New York, NY (2002)

[2] H.K. Tönshojf, I. Inasaki, Sensors in Manufacturing, $1^{\text {st }}$ ed., Wiley-VCH, Weinheim; New York, (2001)

[3] E. O. Doebclin, Measurement Systems Application and Design, International $3^{\text {rd }}$ ed., McGraw-Hill Inc., Singapore (1982)

[4] S. Wang, K B. Hsu, The Study of Pneumatic Gauge to Surface Roughness Measuremeni. Journal of the Chinese Society of Mechanical Engineers 8(5) (1987) $347-363$

[5] T. R. Thoma:; Rough Surfaces, $2^{\text {nd }}$ ed. Imperial College Press, London (1999)

[6] C. B. Rao, B. Raj, Study of Engineering Surfaces Using Laser-Scattering Techniques., Sadhana - Academy Proceedings in Engineering Sciences 28(3-4) (2003) $739-736$

[7] B. Nowicki, Surface Roughness and Measurement with new Contact Methods. International Journal of Machine Tool Design and Research 26(1) (1986) 61-68

[8] P. Lehmann, Optical versus Tactile Geometry Measurement - Alternatives or Counterparts, SPIE 5144 (2003) 183-196

[9] S. I. Deutshke, S. M. Wu, C. M. Strolkowsski, A New Irregular Surface Measuring System, International Journal of Machine Tool Design and Research $13(1973) 2 \circlearrowleft-42$

[10] R. J. Hocken, Optical Metrology of Surfaces, CIRP Annals 54(2) (2005) 705-719

[11] C. J. Tay, \$. H. Wang, C. Quan, H. M. Shang, In Situ Surface Roughness Measurement Using a Laser Scattering Method, Optics Communications 218(1-3) (2003) $1-10$

[12] G. Y. Tian, R. Lu, Hybrid Vision System for Online Measurement of Surface Roughness, Journal of the Optical Society of America A: Optics and Image Science, and Vision 23(12) (2006) 3072-3079

[13] P. Beckmanı, A. Spizzichino, The Scattering of Electro-Magnetic Waves from Rough Surfaises, Artech House, Nirwood, MA, (1987)

[14] U. Minoni, F. Cavalli, Surface Quality Control Device for On-Line Applications, Measurement 41 (2008) 774-782 
M. A. Sc. Thesis McMaster University - Mechanical Engineering Drew A. Grandy

[15] K. Lee, S. F[. Ho, S. Y. Ho, Accurate Estimation of Surface Roughness from Texture Features of the Surface Image Using an Adaptive Neuro-Fuzzy Inference System, Precision Engineering 29 (2005) 95-100

[16] C. Brady, Y. Wong, Surface Texture Indicators of Tool Wear-A Machine Vision Approach, Journal of Advanced Manufacturing Technology 17 (2001) 435-443

[17] R. Kumar, P. Kulashekar, B. Dhanasekar, B. Ramamoorthy, Application of Digital Image Magnification for Surface Roughness Evaluation using Machine Vision, International Journal of Machine Tools and Manufacture 45 (2005) 228-234

[18] G. A. Al-Kindi, B. Shirinzadeh, An Evaluation of Surface Roughness Parameters Measuremen: using Vision-Based Data, International Journal of Machine Tools and Manufacture 47 (2007) 697-708

[19] J. C. Evans, I. G. Morgan, Principles of Pneumatic Gauging, Notes on Applied Science No. 34, National Physical Laboratory (1964)

[20] L. H. Tanner, A Pneumatic Wheatstone Bridge for Surface Roughness Measuremen:, Journal of Physics E: Scientific Instruments 12 (1979) 957-960

[21] L. H. Tannir, A Self-Balancing Pneumatic Wheatstone Bridge for Surface Roughness L'easurement, Wear 83 (1982) 37-47

[22] A. P. Kuroclkin, F. V. Tsidulko, Ways for Speeding Up Pneumatic Testing of Dimensions, Zzmeritel'naya Tekhnika 10 (1966) 12-15

[23] M. Rucki, Air Gauge Adjustment Uncertainty Reduction, Advanced Methods for Uncertainty Estimation in Measurements (2007) 16-18

[24] M. Rucki, St:pp Response of the Air Gauge, Metrology and Measurement Systems 14(3) (2007) 429-436

[25] M. Rucki, et. al., Analysis of Air Gage Inaccuracy Caused by Flow Instability, Measurement 41 (2008) 655-661

[26] H. Zhang, S. X. Deng, H. Q. Wang, S. Chen, An Ultra-Precision Air-Pin Sensor and its Dynamic Characteristics, Key Engineering Materials 295-296 (2005) 557-562

[27] J. G. Wager, Surface Effects in Pneumatic Gauging, International Journal of Machine Tocl Design and Research 7 (1967) 1-14

[28] J. Y. M. Chs:w, S. S. S. Cardoso, W. R. Paterson, D. I. Wilson, CFD Studies of Dynamic Gairging, Chemical Engineering Science 59 (2004) 3381-3398 
M. A. Sc. Thesis McMaster University - Mechanical Engineering Drew A. Grandy

[29] A. M. Hamouda, A Precise Pneumatic Co-Axial Jet Gauging System for Surface Roughness Measurements, Precision Engineering 1 (1979) 95-100

[30] R. W. Woolley, Pneumatic Method for Making Fast, High Resolution Non-Contacting Measurement of Surface Topography, SPIE 1573 (1991) 205-215

[31] T. M. A. Naksoud, A. A. Mokbel, J. E. Morgan, In-Process Detection of Grinding Wheel Truing and Dressing Conditions Using a Flapper Nozzle Arrangement. Journal of Engineering Manufacture 211 (1997) 335-343

[32] K. Furutani, N. Ohguro, N. T. Hieu, T. Nakamura, In-Process Measurement of Topography Change of Grinding Wheel by Using Hydrodynamic Pressure, International Journal of Machine Tools and Manufacture 42 (2002) 1447-1453 
Appendix A - Pressure Transducer Specifications 


\section{Microphone capsules}

Omni-directional electret microphone capsule

\section{Features}

- High max. sound preasure level

- Exceptionally compact desiga (TO 18 transiscor size)

- Excellent frequency response

- Back electret desiga ensures cxcellent attenuation of handling noise

- Low operating voltage

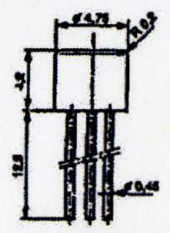

KE 4-211-8

Cat. no. 03369

Technical Data

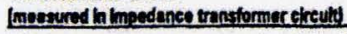

Frequency response

$20 \cdot 20,000 \mathrm{~Hz}$

Sensitivity

(free field, no load) (1 kHz) $6.3 \mathrm{mVRR} \pm 2.5 \mathrm{~dB}$

Electrical impodance (1 kHza) approx. $1 \mathrm{k \Omega}$

Min terminating impedance $4.7 \mathrm{k} \Omega$

Equivalent cound level $38 \mathrm{~dB}$ (CCAR weightoed)

Supply volange

$+4.5 \ldots 15 \mathrm{~V}$

Current consumption approx. 200 , $400 \mathrm{pH}$

Max. SPL CWOSBY

Temperature range

tortage: $200 \mathrm{C} 10+70^{\circ} \mathrm{C}$

opention: $-100 \mathrm{C}$ wo $+50^{\circ} \mathrm{C}$

Climatic factors

up $\infty+40^{\circ} \mathrm{C}$ and $20 \%$

relative humicing (torage) 


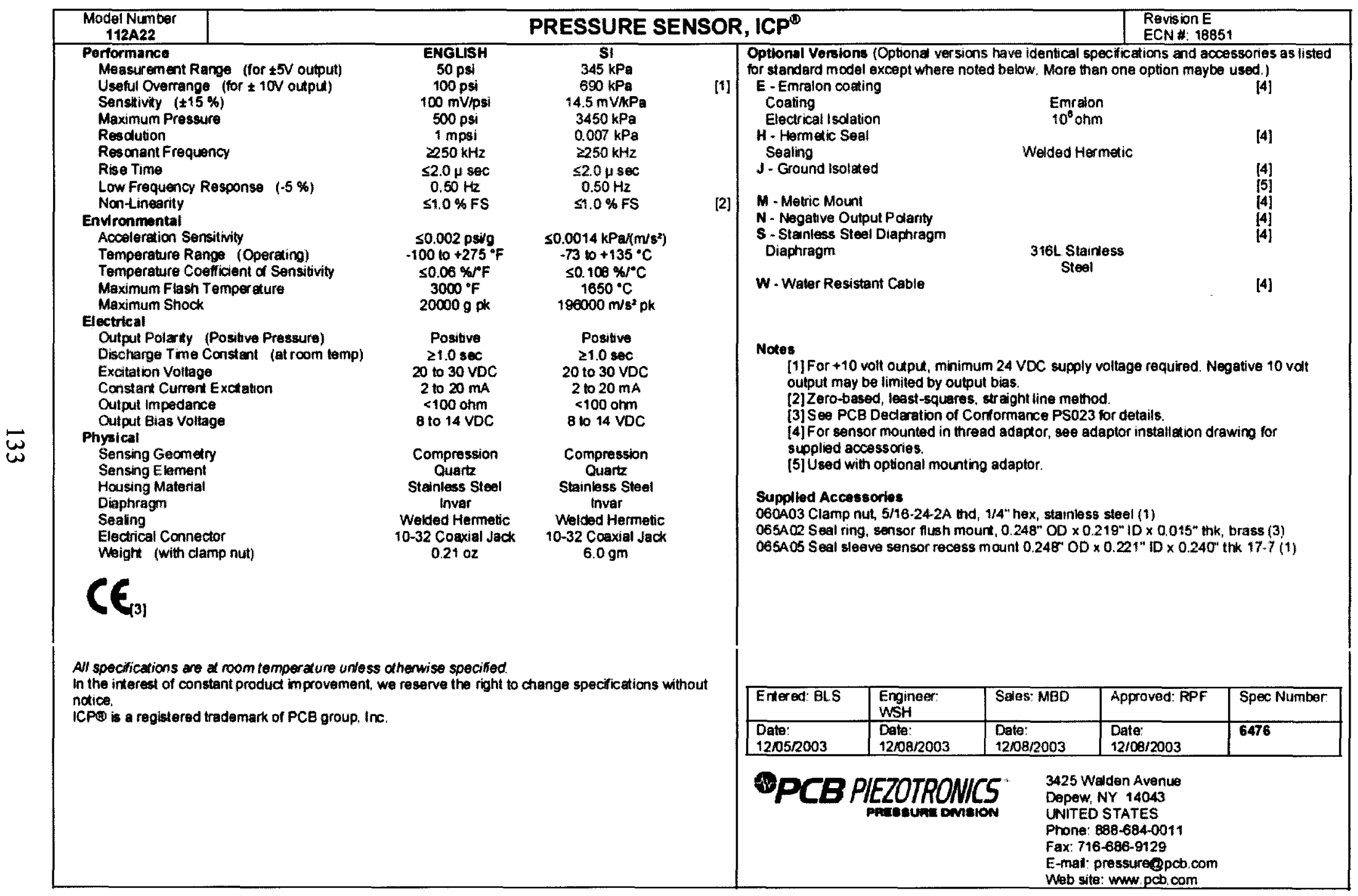

